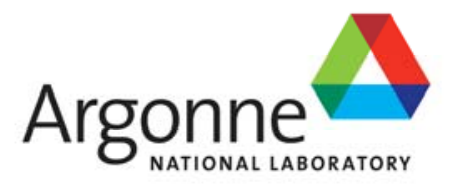

ANL/ESD-16/1 Rev1

\title{
Survey of U.S. Ancillary Services Markets
}

\section{Energy Systems Division}


About Argonne National Laboratory

Argonne is a U.S. Department of Energy laboratory managed by UChicago

Argonne, LLC under contract DE-AC02-06CH11357. The Laboratory's main

facility is outside Chicago, at 9700 South Cass Avenue, Argonne, Illinois 60439.

For information about Argonne and its pioneering science and technology

programs, see www.anl.gov.

\section{DOCUMENT AVAILABILITY}

Online Access: U.S. Department of Energy (DOE) reports produced after 1991 and a

growing number of pre-1991 documents are available free via DOE's SciTech Connect

(http://www.osti.gov/scitech/)

Reports not in digital format may be purchased by the public from the

National Technical Information Service (NTIS):

U.S. Department of Commerce

National Technical Information Service

5301 Shawnee Rd

Alexandria, VA 22312

www.ntis.gov

Phone: (800) 553-NTIS (6847) or (703) 605-6000

Fax: (703) 605-6900

Email: orders@ntis.gov

Reports not in digital format are available to DOE and DOE contractors from the

Office of Scientific and Technical Information (OSTI):

U.S. Department of Energy

Office of Scientific and Technical Information

P.O. Box 62

Oak Ridge, TN 37831-0062

www.osti.gov

Phone: (865) 576-8401

Fax: (865) 576-5728

Email: reports@osti.gov

Disclaimer

This report was prepared as an account of work sponsored by an agency of the United States Government. Neither the United States Government nor any agency thereof, nor UChicago Argonne, LLC, nor any of their employees or officers, makes any warranty, express or implied, or assumes any legal liability or responsibility for the accuracy, completeness, or usefulness of any information, apparatus, product, or process disclosed, or represents that its use would not infringe privately owned rights. Reference herein to any specific commercial product, process, or service by trade name, trademark, manufacturer, or otherwise, does not necessarily constitute or imply its endorsement, recommendation, or favoring by the United States Government or any agency thereof. The views and opinions of document authors expressed herein do not necessarily state or reflect those of the United States Government or any agency thereof, Argonne National Laboratory, or UChicago Argonne, LLC. 


\section{Survey of U.S. Ancillary Services Markets}

prepared by

Zhi Zhou, Todd Levin, and Guenter Conzelmann

Center for Energy, Environmental, and Economic Systems Analysis, Energy Systems Division, Argonne National Laboratory

June 2016 
This page intentionally left blank. 


\section{Contents}

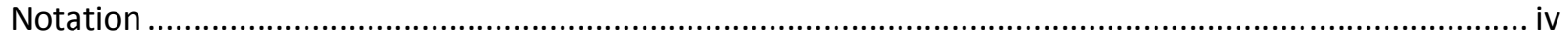

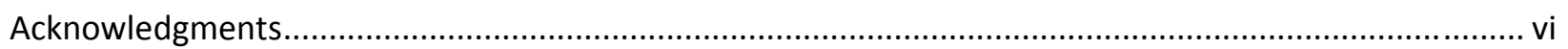

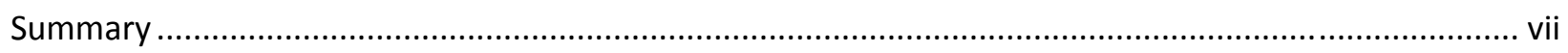

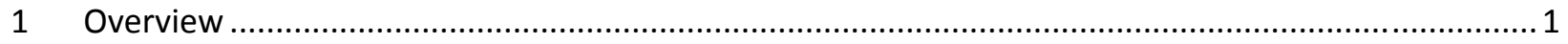

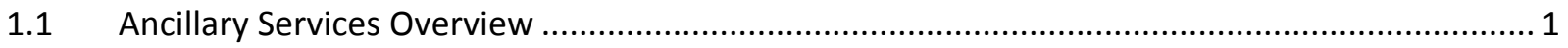

1.1.1 Regulation and Frequency Response ..................................................................... 1

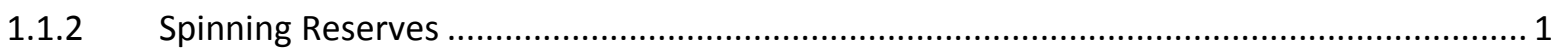

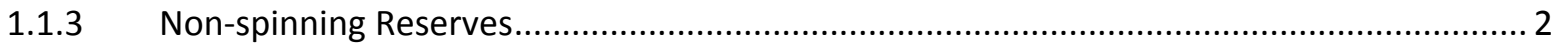

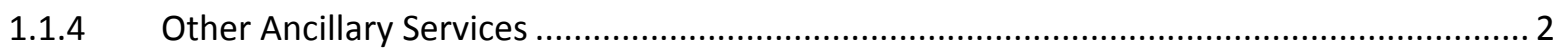

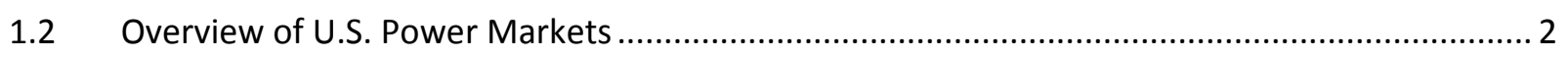

2 CAISO

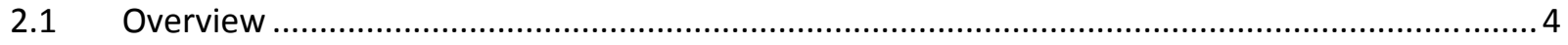

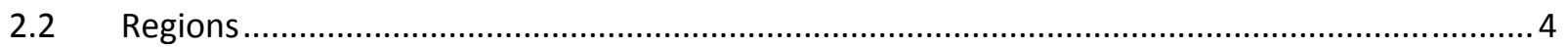

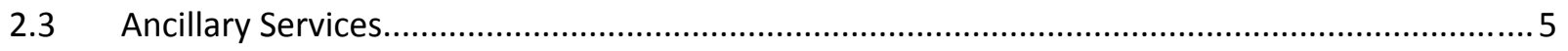

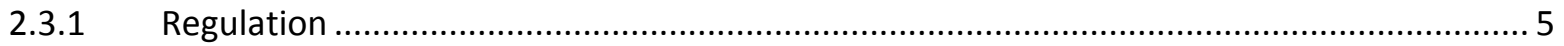

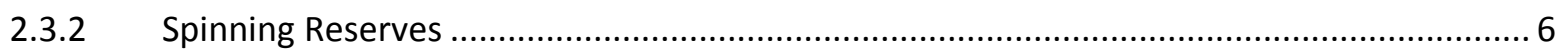

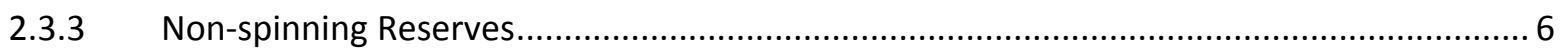

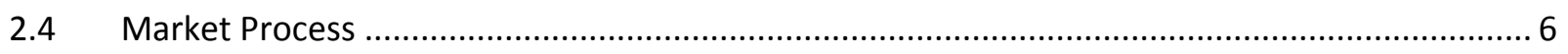

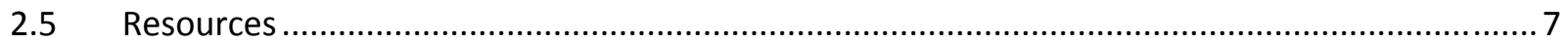

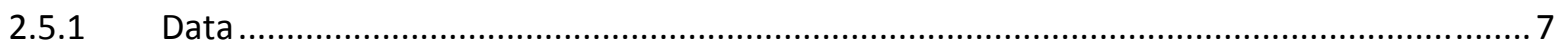

2.5.2 Ancillary Services Definition and Market Process......................................................... 7

$3 \quad$ ERCOT

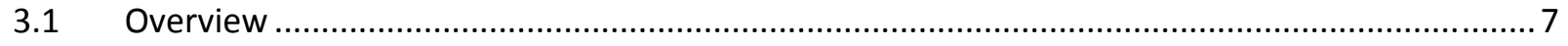

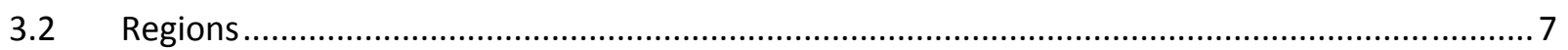

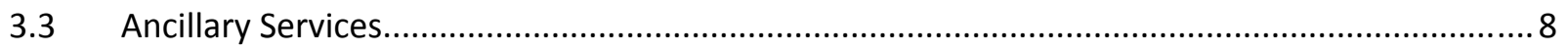

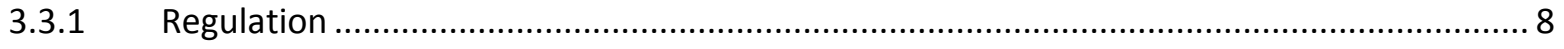

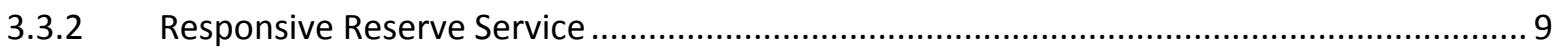

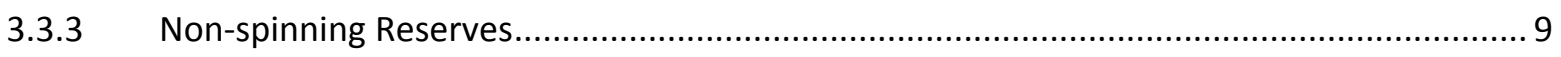

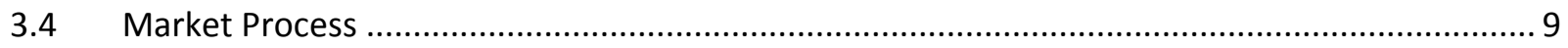

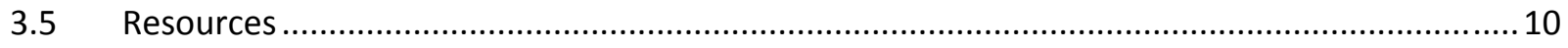


3.5.1 Methodologies for Determining Ancillary Service Requirements .................................. 10

3.5.2 Methodology for Implementing ORDC to Calculate Real-Time Reserve Price Adder.........10

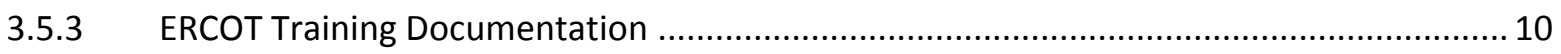

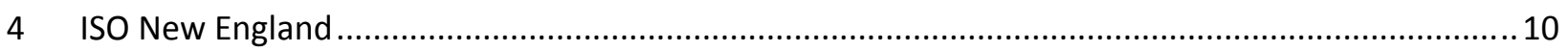

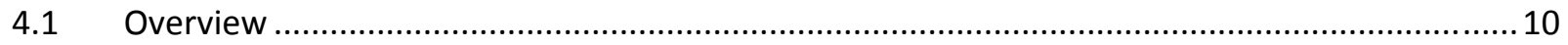

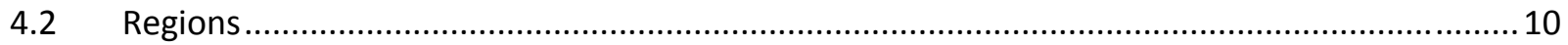

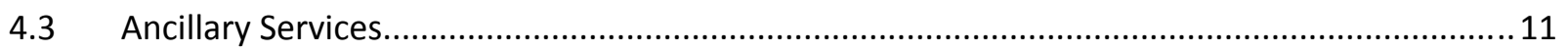

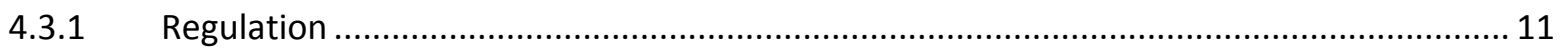

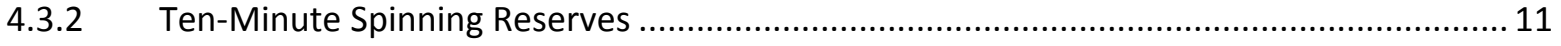

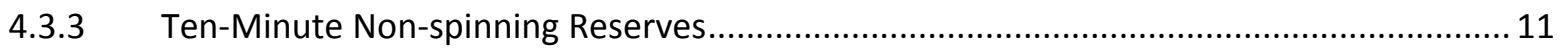

4.3.4 Thirty-Minute Operating Reserves.......................................................................... 12

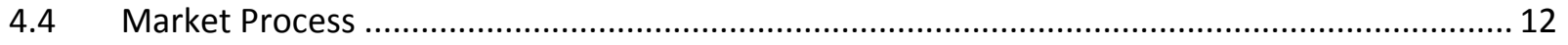

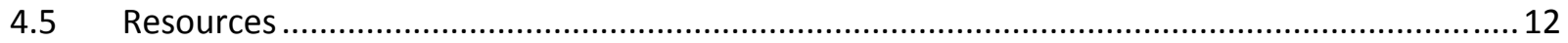

4.5.1 Overview of ISO New England's Wholesale Electricity Markets and Market Oversight..... 12

4.5.2 ISO New England Operating Procedure No. 8: Operating Reserve and Regulation ............ 12

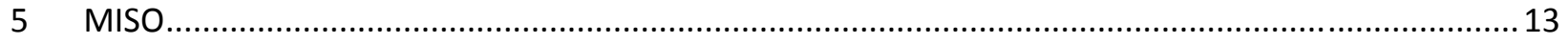

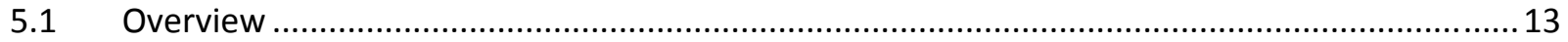

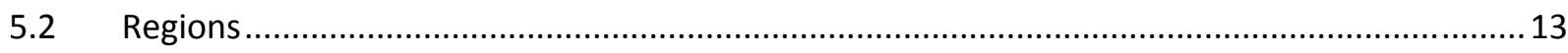

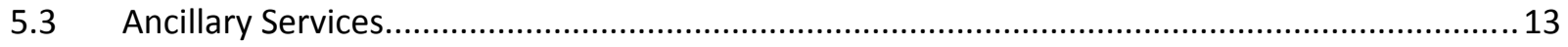

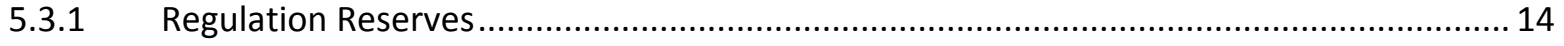

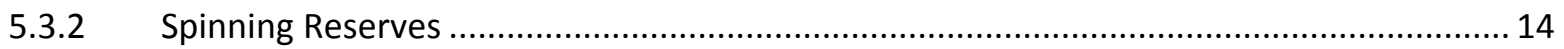

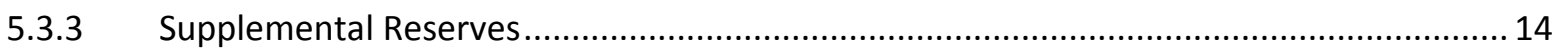

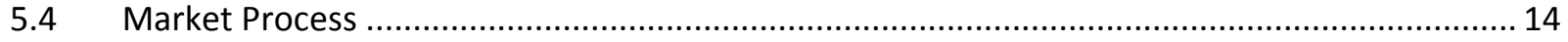

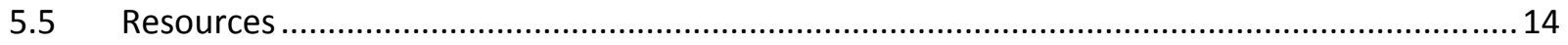

5.5.1 Ancillary Services Definition and Market Process....................................................... 14

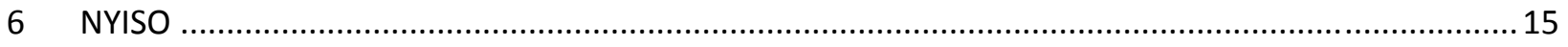

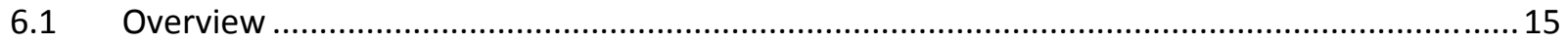

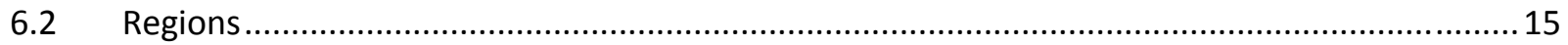

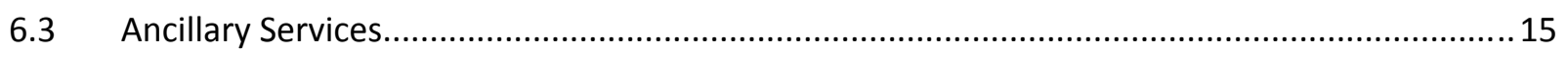

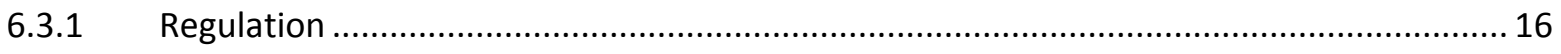

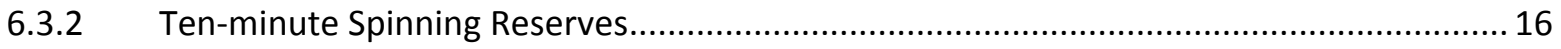

6.3.3 Ten-minute Non-synchronized Reserves .............................................................. 16 


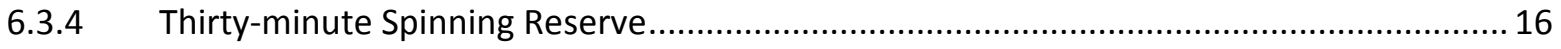

6.3.5 Thirty-minute Non-synchronized Reserves................................................................ 16

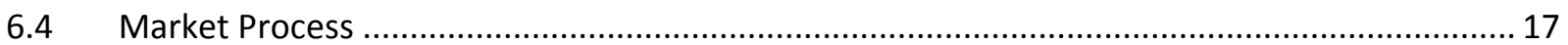

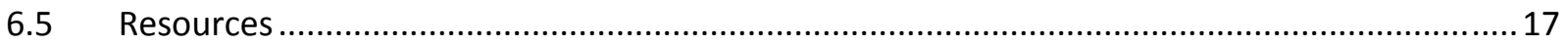

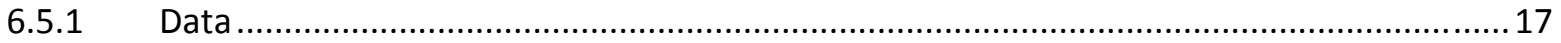

6.5.2 Ancillary Services Definition and Market Process.......................................................... 17

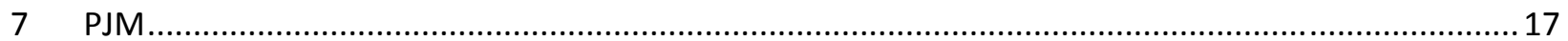

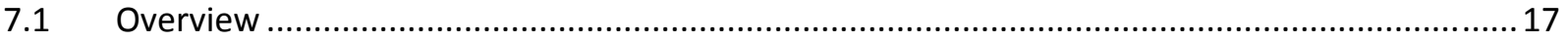

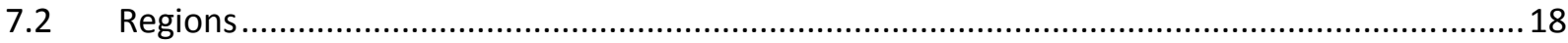

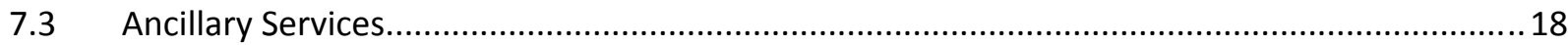

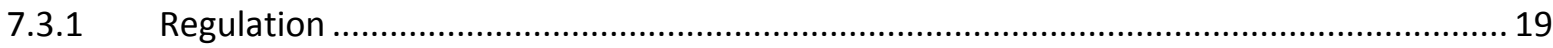

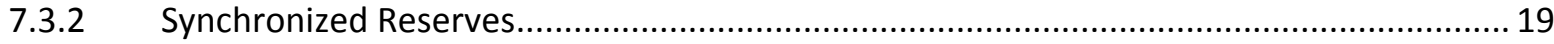

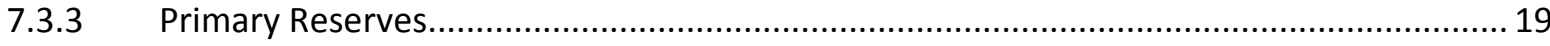

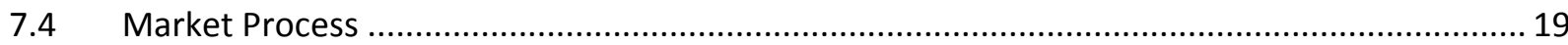

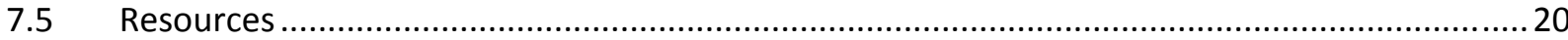

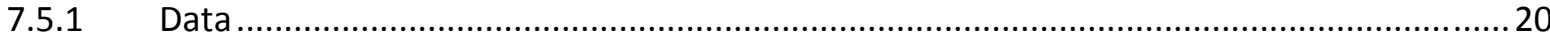

7.5.2 Ancillary Services Definition and Market Process........................................................ 20

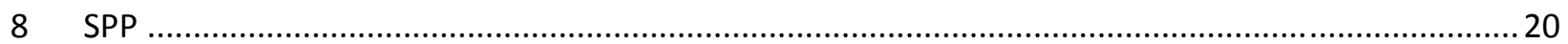

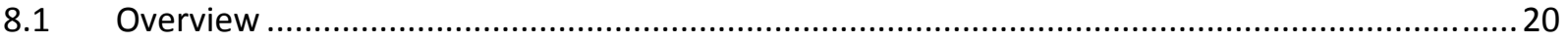

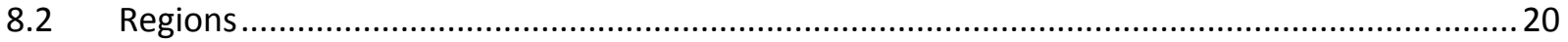

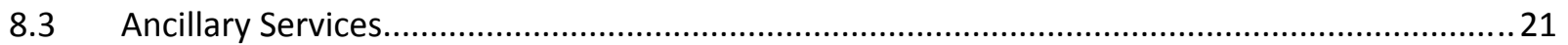

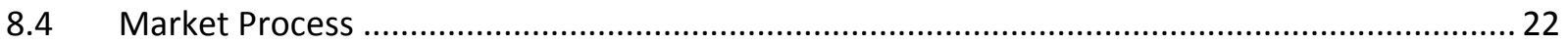

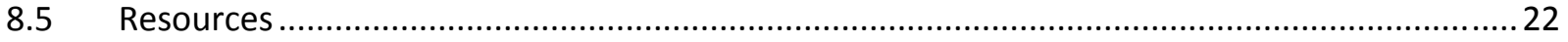

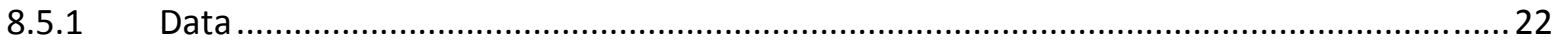

8.5.2 Ancillary Services Definition and Market Process............................................................ 22

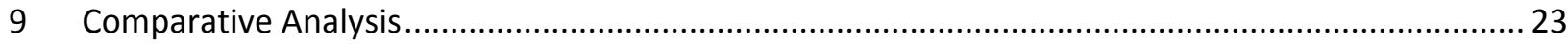

9.1 Regulation Reserves Market Data......................................................................................... 23

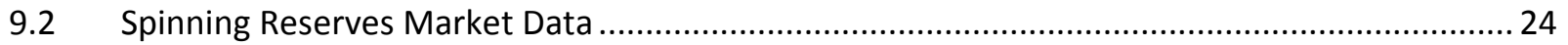

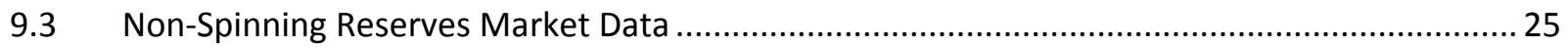

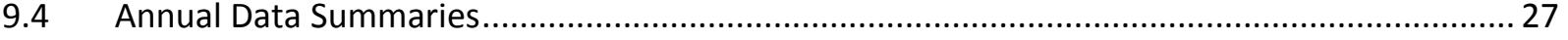




\section{Notation}

ACE

AGC

ASMP

BAAL

CAISO

CPS

DAM

EMS

ERCOT

FERC

HAM

ISO

ISO-NE

LMP

MAD

MCP

MISO

NERC

NRR

NYISO

ORDC

QSE

RIPS

RMCP

RMCCP

RMPCP
Area Control Error

automatic generation control

ancillary service marginal price

Balance Authority ACE Limit

California Independent System Operator

Control Performance Standard

Day Ahead Market

Energy Management System

Electric Reliability Council of Texas

Federal Energy Regulatory Commission

Hour Ahead Market

Independent System Operator

ISO New England

Locational Marginal Price

Mid-Atlantic Dominion

Market Clearing Price

Midcontinent ISO

North American Electric Reliability Council

Normal Response Rate

New York ISO

Operating Reserve Demand Curve

Qualified Scheduling Entity

regulation interval performance score

regulation market clearing price

regulation market capability clearing price

regulation market performance clearing price 


$\begin{array}{ll}\text { RTC } & \text { Real-time Commitment } \\ \text { RTM } & \text { Real-time Market } \\ \text { RTO } & \text { Regional Transmission Organization } \\ \text { SCED } & \text { Security-Constrained Economic Dispatch } \\ \text { SERC } & \text { SERC Reliability Corporation } \\ \text { SPP } & \text { Southwest Power Pool } \\ \text { Texas RE } & \text { Texas Reliability Entity, Inc. } \\ \text { TMNSR } & \text { Ten-minute Non-synchronized Reserves } \\ \text { TMOR } & \text { Thirty-minute Operating Reserves } \\ \text { TMSR } & \text { Ten-minute Synchronized Reserves } \\ & \end{array}$




\section{Acknowledgments}

The authors are grateful for extremely helpful technical reviews and other contributions provided by several individuals. Within the Department of Energy, input was provided by Rima Oueid, Karen Wayland, Alex Breckel, and Eric Hsieh. An external review was also provided by Erik Ela at The Electric Power Research Institute. Special thanks are due to Audun Botterud at Argonne National Laboratory for providing technical support. These reviewers helped to make this report as technically sound as possible; however, any remaining errors or omissions are those of the authors. 


\section{Summary}

In addition to providing energy to end-consumers, power system operators are also responsible for ensuring system reliability. To this end, power markets maintain an array of ancillary services to ensure that it is always possible to balance the supply and demand for energy in real-time. A subset of these ancillary services are commonly procured through market-based mechanisms: namely, Regulation, Spinning, and Non-spinning Reserves.

Regulation Reserves are maintained to respond to supply/demand imbalances over short time frames, typically on the order of several seconds to one minute. Resources that provide Regulation Reserves adjust their generation or load levels in response to automatic generation control (AGC) signals provided by the system operator.

Contingency reserves are maintained to provide additional generation capacity in the event that load increases substantially or supply side resources reduce their output or are taken offline. The reserves are typically segmented into two categories, 1) Spinning or Synchronized Reserves that are provided by generation units that are actively generating and have the ability to increase or decrease their output, 2) Non-spinning or Non-synchronized Reserves that are provided by generation resources that are not actively generating, but are able to start up and provide generation within a specified timeframe. Contingency reserves typically have response times on the order of ten to 30 minutes and can also be provided by demand-side resources that are capable of reducing their load.

There are seven distinct power markets in the United States, each operated by a Regional Transmission Operator (RTO) or Independent System Operator (ISO) that operates the transmission system in its territory, operates markets for energy and ancillary services, and maintains system reliability. Each power market offers its own set of ancillary services, and precise definitions, requirements, and market mechanisms differ between markets.

Despite the differences between markets, both in terms of services offered and system requirements, some broad trends generally apply. Regulation Reserves typically have the highest market prices, followed by Spinning Reserves and Non-spinning Reserves. Prices for Regulation Reserves have been the highest in the PJM market, since it opened in October 2012. This is partially because PJM experienced large price spikes during the period of extreme weather conditions in early 2014. ERCOT has traditionally had the highest prices for Spinning Reserves (called Responsive Reserves in ERCOT), including several periods of sustained high prices between 2010 and 2012. This can be explained in part by the relatively high penetration of variable wind resources and a similarly high requirement relative to peak load. ERCOT has also traditionally had the highest price for Non-spinning Reserves, followed by the NYISO East region. Both have experienced several periods of prolonged high prices since their inception, an occurrence that has not been regularly seen in other markets. In ISO-NE and PJM for example, the market clearing price for Non-spinning Reserves is typically $\$ 0 / \mathrm{MWh}$ more than $95 \%$ of the time.

Market volume (in terms of the average amount of capacity of each service that is provided to a system) typically follows the reverse order of prices, as systems maintain the most Non-spinning Reserves capacity followed by Spinning Reserves and Regulation Reserves. PJM generally has the largest market 
for Regulation Reserves both in terms of capacity. The size of most Regulation Reserves markets in terms of capacity stay relatively constant year-to-year, as this is dictated largely by system requirements. PJM also generally has the largest Spinning Reserves market in terms of capacity. SPP, MISO, ISO-NE and SPP (beginning in 2014) all have Spinning Reserve markets with similar average capacity levels. When combined, the markets for Non-spinning and Operating reserves in ISO-NE have a comparable capacity to the market for Primary Reserves ${ }^{1}$ in PJM. SPP, MISO, and CAISO all have smaller markets for their respective Non-spinning Reserves products that are roughly the same size as each other in terms of capacity.

${ }^{1}$ The Primary Reserve product in PJM is discussed in more detail in Section 7 


\section{Overview}

\subsection{Ancillary Services Overview}

In addition to generating energy to serve demand, generation units in a power system are also major providers of an array of ancillary services that support system reliability. Energy storage and demand response resources can also provide ancillary services, but currently do so to a lesser extent than supplyside resources in most power systems. The specific services offered and exact definitions of each service vary from market to market. In general, market operators procure ancillary services from market participants according to reliability standards established by the North American Electric Reliability Corporation (NERC) and/or regional Coordinating Councils, such as the Western Electricity Coordinating Council (WECC). Winning bids for energy and ancillary services are mutually exclusive, but a generator can be compensated for both generation and ancillary service provision in the same period.

\subsubsection{Regulation and Frequency Response}

Regulation service is used to constantly and automatically balance small fluctuations in supply and demand in real time. Generation units that provide regulation service must be available to respond to an initial signal within a target timeframe, five minutes in most markets. Such resources then must respond to automatic generation control (AGC) signals from the system operator and change their output accordingly on very short time scales, typically on the order of several seconds to one minute. Some markets offer only a single regulation product, while others offer separate products for Regulation-up (capacity that is available to increase output) and Regulation-down (capacity that is available to decrease output). Some markets have also created a separate signal for Fast-frequency Regulation, which is typically provided by storage and demand response resources that can change output faster than traditional generators. Demand-side resources that are able to respond to AGC signals are also able to provide regulation services.

A separate component referred to as Regulation Mileage is also available in select markets. This measures the total absolute change in service set points, as measured over short intervals (several seconds). The market for Regulation Mileage compensates units for their performance in response to regulation signals, in addition to making their capacity available. Therefore a resource that constantly changes its output level will receive greater compensation than a resource that generates at a more consistent level. This product is currently offered in the all markets except for ERCOT. However, we do not include any analysis of these products here as they are relatively new and data are sparsely available.

\subsubsection{Spinning Reserves}

Spinning reserves are intended to help the system respond quickly to forced outages or other contingency events. Spinning reserves are provided by generation units that are online but are not generating at full capacity and can therefore increase their output to provide additional capacity to the system within a target timeframe. In all markets except for ERCOT, generation units that provide spinning reserves must be able to fully ramp up their generation within ten minutes of receiving instructions to do so while market rules in ERCOT require that units are able to respond with "within the 
first few minutes of an event." NYISO also has a second-tier spinning reserve product that must be able to respond within 30 minutes. Demand-side resources can also provide spinning reserves if they are able to similarly reduce their load within the required timeframe. Naming conventions for spinning reserves differ between markets, as detailed in Table 1-1.

\subsubsection{Non-spinning Reserves}

Non-spinning reserves are also intended to help the system recover from unplanned contingencies. However, non-spinning reserves can also be provided by generation units that are offline, as long as they are able to start up and increase their output to the target level within a predefined period of time. In all markets except for ERCOT this response time is ten minutes, similar to spinning reserves. In ERCOT the required response time for non-spinning reserves is 30 minutes. Both NYISO and ISO-NE maintain an additional non-spinning reserve product with a 30 minute response time. Online units with available capacity can also provide non-spinning reserves. In PJM units that provide Synchronized Reserves are also considered to simultaneously provide Primary Reserves. Therefore the Primary Reserves product represents the total available reserve capacity of all spinning and non-spinning units. Naming conventions for non-spinning reserves differ between markets, as detailed in Table 1-1.

\subsubsection{Other Ancillary Services}

There are several other ancillary services that supply- and demand-side resources can provide to a power system, including black start capabilities, reactive supply and voltage control, inertial response, ramp capability, and energy imbalance services. As many generation units require input energy in order to start up and begin operation, power systems must maintain a black start capability so that they are able to restore operations in the event of a system-wide power outage. Such black start generators typically rely on small diesel generators or hydroelectric resources to provide the initial energy needed for startup. Reactive power supply and voltage control are achieved by managing the amount of reactive power in an alternating-current power system. The provision of this service ensures that system voltages are maintained within a desired range and also seeks to minimize the congestion caused by reactive power in a transmission network, so as to maximize the transmission of real power. Energy imbalance service may be provided by either supply- or demand-side resources in the event that there is a difference between scheduled and delivered energy over the course of an operating period. Most U.S. power systems do not operate markets for these products but do maintain adequate resources through internal requirements and other procurement mechanisms. They are therefore not covered further in this report.

\subsection{Overview of U.S. Power Markets}

There are seven distinct power markets in the United States (see Figure 1-1). In addition, there are two similar markets located within Canada. These markets are each operated by an Independent System Operator (ISO) or Regional Transmission Organization (RTO), hereafter jointly referred to as an ISO/RTO, which operates the transmission infrastructure in its service territory, administers markets for energy and ancillary services, and is responsible for ensuring that system reliability requirements that are established by NERC are met. With the exception of the Electric Reliability Council of Texas (ERCOT) system in Texas, each U.S. ISO/RTO is subject to the jurisdiction of the Federal Energy Regulatory Commission (FERC). As the ERCOT system is wholly contained within a single state and does not have 
any transmission ties to other states, it does not participate in interstate commerce and is therefore not subject to FERC jurisdiction. Roughly two-thirds of all energy demand in the United States falls in territory served by an ISO/RTO; however, large portions of the Western and Southeastern United States are not served by an ISO/RTO. Generators and utilities in these regions do not participate in wholesale power markets, but rather fulfill service obligations through power purchase agreements, bilateral trades, and as vertically integrated utilities.

Each ISO/RTO operates markets for ancillary services. While these services typically fall into the three general categories outlined previously, Regulation, Spinning Reserves, and Non-spinning Reserves, the names and details of each service can differ from market to market. Table 1-1 summarizes the services offered in each ISO/RTO, and a more detailed discussion of each market is presented in the following sections.

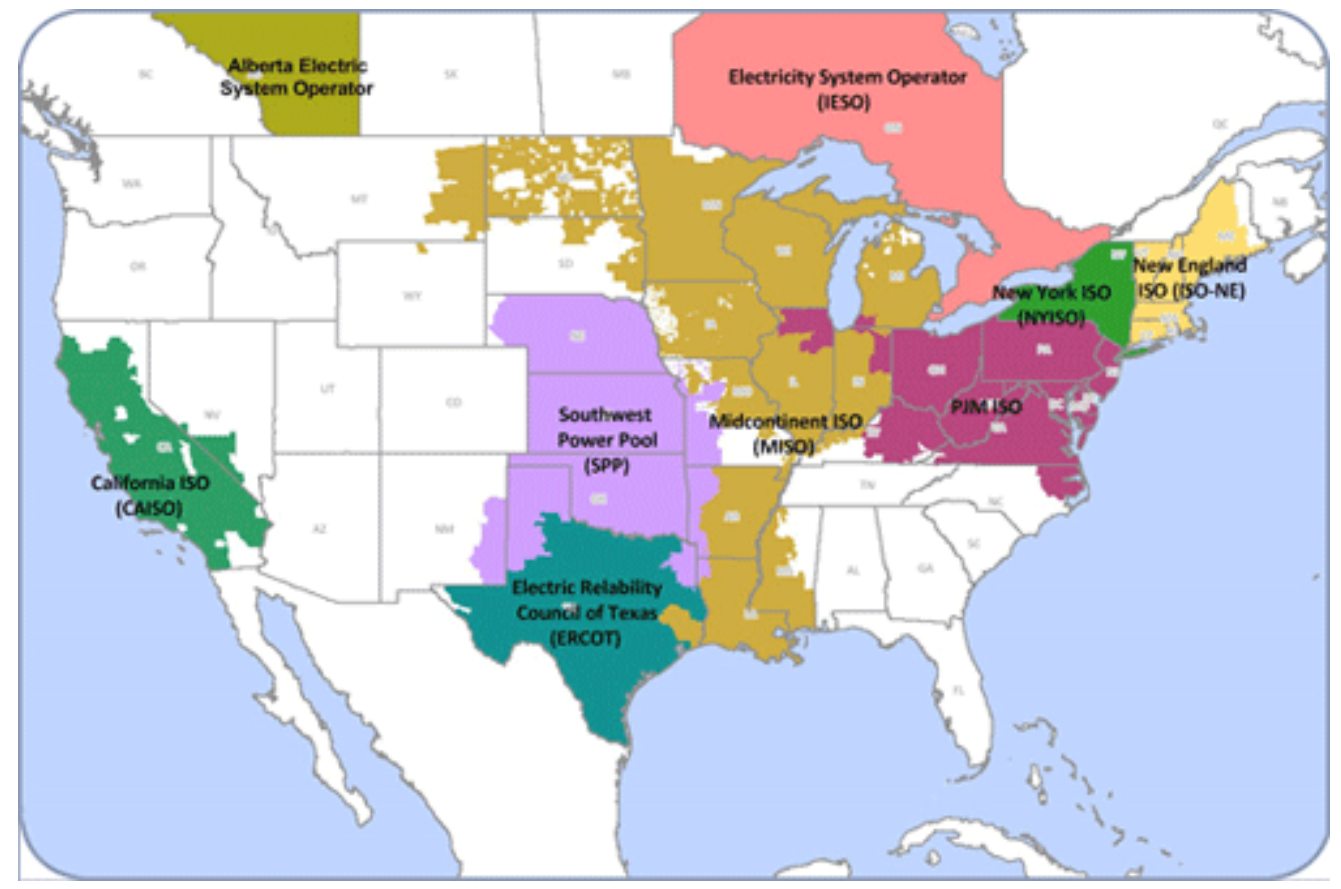

Figure 1-1 Map of the transmission operators that serve the United States

\begin{tabular}{|llll|}
\hline CAISO & Spinning Reserves & Non-spinning Reserves & Regulation \\
& Spinning (10) & Non-spinning (10) & $\begin{array}{l}\text { Regulation-up } \\
\text { Regulation-down }\end{array}$ \\
\hline ERCOT & Responsive ("a few") & Non-spinning (30) & $\begin{array}{l}\text { Regulation-up } \\
\text { Regulation-down }\end{array}$ \\
\hline ISO-NE & Ten-minute Synchronized (10) & $\begin{array}{l}\text { Ten-minute Non-synchronized (10) } \\
\text { Thirty-minute Operating (30) }\end{array}$ & Regulation (5) \\
\hline MISO & Spinning (10) & Supplemental (10) & Regulation (5) \\
\hline NYISO & Ten-minute Spinning (10) & Ten-minute Non-synchronized (10) & Regulation (5) \\
& Thirty-minute Spinning (30) & Thirty-minute Non-synchronized (30) & \\
\hline
\end{tabular}




\begin{tabular}{|llll|}
\hline PJM & Synchronized (10) & Primary (10) & Regulation (5) \\
\hline SPP & Spinning (10) & Supplemental (10) & Regulation-up (5) \\
& & Regulation-down (5) \\
\hline
\end{tabular}

Table 1-1 Overview of the ancillary services offered by each ISO/RTO, the required response time in minutes for each product is indicated in parentheses when available.

\section{CAISO}

\subsection{Overview}

The California Independent System Operator (CAISO) was established in 1996 to operate the region's power grid and wholesale electric markets, which include an energy market, an ancillary service market, and a financial transmission rights market. CAISO procures Regulation-up, Regulation-down, Spinning Reserves, and Non-spinning Reserves in the Day Ahead Market (DAM) and 15-minute Market. Spinning and Non-spinning Reserves are jointly referred to as Contingency Reserves.

\subsection{Regions}

CAISO maintains two Ancillary Service Regions and eight Ancillary Service Sub-Regions. The two Ancillary Service Regions are the CAISO System Region and the CAISO Expanded System Region. The CAISO Expanded System Region is defined as the entire CAISO balancing authority area plus all system resources at scheduling points outside of the CAISO balancing authority area. The CAISO System Region is defined as the subset of certified resources defined in the CAISO Expanded System Region that are located internal to the CAISO balancing authority area.

There are eight sub-regions, each of which may have its own minimum ancillary service requirements based on system reliability conditions. Figure 2-1 illustrates the territory of the CAISO, and its subregions. Zone ZP26 in Figure 2-1 is divided into SP26 (South of Path 26) and NP26 (North of Path 26). There is an expanded region ${ }^{2}$ for each of the four regions, with a total of eight sub-regions.

The minimum ancillary service constraints for the CAISO System Region are defined to be a percentage of the ancillary service requirements for the Expanded System Region, currently at 50\%, to limit ancillary services procurement from System Resources for reliability purposes.

\footnotetext{
${ }^{2}$ The expanded ancillary service sub-region is defined to include all generators in the original sub-region, and specific intertie resources.
} 


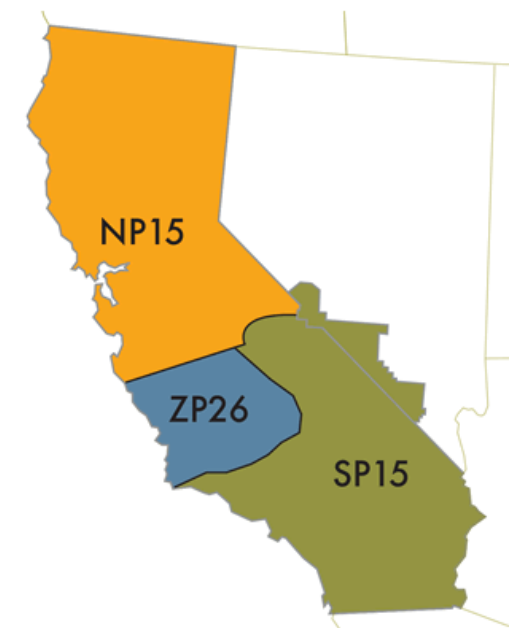

Figure 2-1 Map of the CAISO territory

\subsection{Ancillary Services}

CAISO currently has markets for Regulation-up, Regulation-down, Spinning Reserves, and Non-spinning Reserves. Table 2-1 summarizes the requirements and regions for each of the products.

\begin{tabular}{|c|c|}
\hline Product & Description \\
\hline Regulation-up & $\begin{array}{l}\text { - Must immediately increase output in response to } \\
\text { automated signals. }\end{array}$ \\
\hline Regulation-down & $\begin{array}{l}\text { - Must immediately decrease output in response to } \\
\text { automated signals. }\end{array}$ \\
\hline Spinning Reserves & $\begin{array}{l}\text { - } \quad \text { Synchronized to the grid. } \\
\text { - } \quad \text { Must respond within } 10 \text { minutes. } \\
\text { - } \quad \text { Must run for at least two hours. }\end{array}$ \\
\hline Non-Spinning Reserves & $\begin{array}{l}\text { - Must respond within } 10 \text { minutes. } \\
\text { - } \quad \text { Must run for at least two hours. }\end{array}$ \\
\hline
\end{tabular}

Table 2-1 Summary of ancillary services offered by CAISO

\subsubsection{Regulation}

In CAISO, there are separate ancillary services for both Regulation-up and Regulation-down; the system requirement for Regulation is a target between 300 and $400 \mathrm{MW}$ for each. This target is typically set as either a percentage of peak load or a fixed number so as to satisfy NERC reliability requirements. CAISO measures the accuracy of a resource's response to CAISO Energy Management System (EMS) signals. It will sum a resource's AGC set points for each four-second regulation interval every 15 minutes and then sum the total deviations from the AGC set point for each four-second regulation interval during that 15 minute period. CAISO then applies the resulting percentage to a resource's instructed mileage to calculate the resource's regulation performance payment. 


\subsubsection{Spinning Reserves}

Spinning Reserves must be synchronized with the grid, able to respond within ten minutes, and able to run for at least two hours. Spinning Reserves must account for at least $50 \%$ of the total Contingency Reserves requirements.

\subsubsection{Non-spinning Reserves}

Non-spinning Reserves must be able to respond within ten minutes and able to run for at least two hours. The combined requirement for Contingency Reserves (defined to be the sum of Spinning and Non-spinning Reserves) is equal to the greater of the largest credible contingency or five percent of the load served by hydro generation and seven percent of the load served by thermal generation.

\subsection{Market Process}

In the CAISO market, all ancillary service bids may be accompanied by an energy bid in the DAM, and must be accompanied by an energy bid in the Real-time Market (RTM). CAISO determines its ancillary service needs on the basis of an internal demand forecast, and obtains these ancillary services either through self-scheduling resources in its territory or through participation by resources in the CAISO Ancillary Services Market. Ancillary service bids are evaluated simultaneously with energy bids in the Integrated Forward Market to clear bid-in supply and demand. The Integrated Forward Market cooptimizes energy and ancillary services. The capacity of a resource with energy and ancillary service bids is optimally used to provide energy, and/or it is reserved for ancillary service provision in the form of ancillary service awards.

Contingency Reserves (Spinning Reserves and Non-Spinning Reserves) are procured in the DAM to meet $100 \%$ of the contingency reserve ancillary service requirement associated with the California Forecast of California Demand to satisfy current NERC Standards. If additional Contingency Reserves are necessary after the DAM, then they are purchased through the RTM.

Load serving entities in CAISO are required to procure ancillary services either through self-provision or through purchase on the CAISO market. They can also bid excess ancillary services into the market. Scheduling Coordinators simultaneously submit bids to supply any or all of the above products to the CAISO in conjunction with their preferred day-ahead and hour-ahead schedules. CAISO selects resources to provide ancillary service capacity based only on their capacity bid prices and deliverability.

Ancillary service marginal prices (ASMPs) are produced as a result of the co-optimization of energy and ancillary services for each ancillary region. They represent the marginal cost of providing an additional unit of that service. In supply shortage conditions, when co-optimization fails to clear the market and there is not a well-defined ASMP, CAISO will use scarcity reserve demand curves to set the administrative values for ASMPs. These are based upon a stepwise demand curve corresponding to the shortage of three upward reserve products (i.e. Spinning Reserves, Non-spinning Reserves, and Regulation-up) and a stepwise demand curve corresponding to shortage of Regulation-down service. 


\subsection{Resources}

\subsubsection{Data}

http://oasis.caiso.com/

\subsubsection{Ancillary Services Definition and Market Process}

http://www.caiso.com/Documents/Section8 AncillaryServices Jul1 2013.pdf

http://bpmcm.caiso.com/BPM\%20Document\%20Library/Market\%200perations/BPM for Market\%200 perations V44 clean.doc

\section{ERCOT}

\subsection{Overview}

The Electricity Reliability Council of Texas (ERCOT) was established in its current form as a power market operator in 2001. ERCOT currently serves approximately $85 \%$ of the electrical load in Texas and, as the EROCT system does not participate in interstate commerce, is the only ISO/RTO in the United States that is not regulated by FERC. ERCOT operates a DAM for four ancillary services, Responsive Reserves, Regulation-up, Regulation-down, and Non-spinning Reserves. These services are co-optimized along with energy provisions in the DAM. In addition, ERCOT implemented a real-time Operating Reserve Demand Curve (ORDC) methodology in 2014. Through this process, price adders are generated to reflect the value of available reserves in the market in real time. These price adders are based on the administratively determined value of lost load in the system and the probability that load would have to be shed, given the realized reserve levels. Price adders are calculated for both online (synchronized) and offline (unsynchronized) reserves and are added to the real-time locational marginal price (LMP) to determine settlement price points. This process is intended to approximate the co-optimization of energy and reserves in real-time. ERCOT is subject to reliability standards that are developed by the Texas Reliability Entity, Inc. (Texas RE) through FERC approved processes. According to Texas RE, its standards "go beyond, add detail to, or implement NERC Reliability Standards." ERCOT also updated their procedure for determining reserve requirements on June 1,2015 . The following discussion reflects these updated procedures.

\subsection{Regions}

There is only a single ERCOT region related to ancillary services, which spans the entire ERCOT service territory (see Figure 3-1). The real-time ORDC price adders for Spinning and Non-spinning Reserves are added to the real-time energy LMPs that are calculated for each energy settlement point. A single system-wide price adder is calculated for both Spinning and Non-spinning Reserves. These are then each added to energy prices at each node throughout the ERCOT system. 


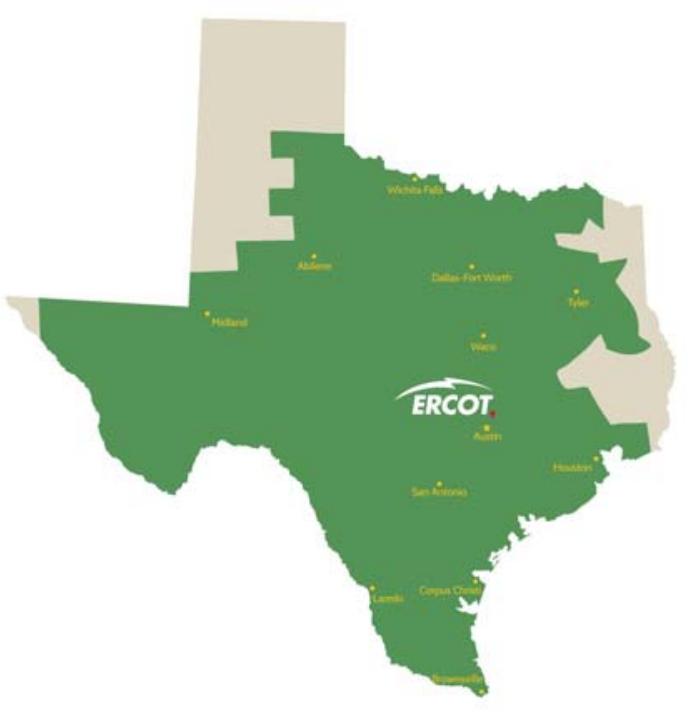

Figure 3-1 Map of the ERCOT service territory

\subsection{Ancillary Services}

As shown in Table 3-1, ERCOT operates markets for Regulation-up, Regulation-down, Responsive Reserves and Non-spinning Reserves.

\begin{tabular}{|c|l|l|}
\hline \multicolumn{1}{|c|}{ Product } & \multicolumn{1}{c|}{ Description } \\
\hline Regulation-up & - $\begin{array}{l}\text { Must immediately increase output in response to } \\
\text { automated signals. }\end{array}$ \\
\hline Regulation-down & - $\begin{array}{l}\text { Must immediately decrease output in response to } \\
\text { automated signals. }\end{array}$ \\
\hline Responsive Reserves & - $\begin{array}{l}\text { Must respond within "the first few minutes of an event } \\
\text { that causes a significant deviation from the standard }\end{array}$ \\
\hline frequency"
\end{tabular}

Table 3-1 Summary of ancillary services offered by ERCOT

\subsubsection{Regulation}

Regulation Reserves are deployed by ERCOT in response to changes in the system frequency and are used to maintain system frequency within a predetermined range. The system requirements for Regulation-up and Regulation-down are determined as follows for Regulation-up/down respectively:

The largest of:

1. The 98.8th percentile of Regulation-up/down deployments over the last 30 days;

2. The 98.8th percentile of Regulation-up/down deployments in the same month of the previous year;

3. The 98.8th percentile of the positive/negative net load changes over the last 30 days; or 
4. The 98.8th percentile of positive/negative net load deployments in the same month of the previous year.

This base value may be further adjusted as necessary in the event that the system's 30 day rolling average NERC Control Performance Standard 1 (CPS1) score was less than 100\%, or because of increased wind penetration and other circumstances. Resources with the technical ability to provide Regulation Reserves may bid their supply into the market. Resources with winning bids after the market clears are paid the market clearing price (MCP) for each unit of capacity that they are selected to provide.

\subsubsection{Responsive Reserve Service}

Responsive Reserves must be able to respond quickly to changes in system frequency. Requirements for Responsive Reserves are calculated in four-hour blocks on the basis of forecasted load and wind patterns as well as the largest system contingency. Interruptible load resources can provide Responsive Reserves, but their contribution is limited to $50 \%$ of the total requirement in each hour.

\subsubsection{Non-spinning Reserves}

Non-spinning Reserves must be able to become synchronized with the grid, ramp to a specified output level within $\mathbf{3 0}$ minutes, and generate at that level for at least one hour. Reserve capacity that is already synchronized with the grid can also provide this service, as can demand-side resources that can reduce their load.

The system requirement for Non-spinning Reserves is determined by first calculating the 95th percentile of net load uncertainty from both the previous 30 days and the same month of the previous year. Net load is defined as total load minus wind generation, and net load uncertainty is defined as the difference between the realized net load and forecast net load. ERCOT then subtracts the Regulation-up requirement from this $95^{\text {th }}$ percentile to obtain the Non-spinning Reserves requirement. During on-peak hours (hours 0700 through 2200 Central time, ERCOT also maintains a minimum Non-spinning requirement that is equal to the largest single unit in the system. The Non-spinning requirement is also never permitted to exceed $2000 \mathrm{MW}$ during all hours of operation.

\subsection{Market Process}

In the DAM, ERCOT establishes an Ancillary Services Plan and publishes relevant system information each day by 0600 hours Central time. This Ancillary Services Plan identifies the ancillary service obligations of all Qualified Scheduling Entities ${ }^{3}$ (QSEs) during each hour of the following day. QSEs can meet their obligations either through self-supply, bilateral trades with other QSEs, or purchases from ERCOT through the DAM. QSEs must submit their bids and offers for ancillary services by 1000 hours Central time. The day-ahead market is executed between 1000 and 1330 hours Central time, at which point results are posted. QSEs then have the opportunity to make bilateral trades with other QSEs based upon the results of the day-ahead market; any such trades must be reported to ERCOT by 1430 hours Central time.

\footnotetext{
${ }^{3}$ QSEs submit bids and offers on behalf of generating resource entities or load-serving entities.
} 
In real-time operations security constrained economic dispatch (SCED) is conducted every five minutes and two price-adders are calculated on the basis of the reserve levels that are realized during each settlement period-currently every 15-minute interval. One adder is calculated on the basis of the realized level of online reserves and the other is calculated on the basis of the sum of the realized levels of online and offline reserves. These adders are then added to the LMP-based energy price that is paid to generating entities and charged to load-serving entities in each settlement period. If the Responsive Reserve level falls below a $2000 \mathrm{MW}$ minimum contingency in any period, ERCOT will set the price adder to the administratively determined value of lost load (VOLL) in the system, which is currently $\$ 9000 / \mathrm{MWh}$.

\subsection{Resources}

\subsubsection{Methodologies for Determining Ancillary Service Requirements} http://www.ercot.com/content/mktinfo/dam/kd/ERCOT\%20Methodologies\%20for\%20Determining\%20 Ancillary\%20Service.zip

\subsubsection{Methodology for Implementing ORDC to Calculate Real-Time Reserve Price Adder} http://www.ercot.com/content/mktinfo/rtm/kd/Methodology\%20for\%20lmplementing\%200RDC\%20to \%20Calculate\%20Real-Time\%20Res.zip

\subsubsection{ERCOT Training Documentation}

http://www.ercot.com/content/wcm/training courses/107/ordc workshop.pdf

http://www.ercot.com/content/wcm/training courses/58/GEN101 M2 Jan2010.pdf

\section{ISO New England}

\subsection{Overview}

ISO New England (ISO-NE) was established in 1997 and began operating a wholesale power market in 1999. It currently operates a forward reserve market and a real-time reserve pricing market, as well as a regulation market.

The forward reserve market secures commitments for Ten-minute Non-synchronized Reserves (TMNSR) and Thirty-minute Operating Reserves (TMOR) in the system during peak hours. A real-time reserve pricing market is also conducted throughout the operating day for both TMNSR and TMOR, as well as for an additional product, Ten-minute Synchronized Reserves (TMSR). This market is designed to offset the opportunity cost a resource faces when it is selected to provide reserves instead of energy in real-time. It also provides additional revenues that are consistent with the increased value of reserves and energy when the system is short.

\subsection{Regions}

ISO-NE consists of four zones for reserve products:

1. Southwest Connecticut 


\section{Connecticut}

3. Northeast Massachusetts and Boston

4. Rest of System (all territory not included in the other zones)

There are system-wide requirements for TMSR, TMNSR and TMOR. In addition, there are individual requirements for TMOR in each of the first three zones (Table 4-1).

\begin{tabular}{|c|ll|}
\hline \multicolumn{1}{|c|}{ Product } & \multicolumn{1}{c|}{ Description } \\
\hline Regulation & - $\begin{array}{l}\text { Must immediately increase or decrease output in } \\
\text { response to automated signals. }\end{array}$ \\
\hline $\begin{array}{c}\text { Ten-minute Synchronized } \\
\text { Reserves (TMSR) }\end{array}$ & - $\begin{array}{l}\text { Synchronized to the grid. } \\
\text { Ten-minute Non-synchronized } \\
\text { Reserves (TMNSR) }\end{array}$ & - Must respond within 10 minutes. \\
\hline $\begin{array}{c}\text { Thirty-minute Operating } \\
\text { Reserves (TMOR) }\end{array}$ & - Must respond within 10 minutes. \\
\hline
\end{tabular}

Table 4-1 Summary of ancillary services offered by ISO-NE

\subsection{Ancillary Services}

\subsubsection{Regulation}

The system requirements for Regulation Reserves are calculated in accordance with NERC Control Performance Criteria and vary hourly, daily and seasonally. Historical requirements are available on the ISO-NE website ${ }^{4}$. For every four-second interval, if observed performance closely matches AGC set points, the regulation interval performance score (RIPS) will be $100 \%$. The compensation for each Regulation Reserves supplier is then adjusted in proportion to the RIPS performance score in each interval.

\subsubsection{Ten-Minute Spinning Reserves}

Ten-minute Spinning Reserves must be synchronized with the grid and able to convert their capacity into generation within ten minutes of receiving a signal from the system operator.

\subsubsection{Ten-Minute Non-spinning Reserves}

Ten-minute Non-spinning Reserves must be able to convert their capacity into generation within ten minutes of receiving a signal from the system operator, but do not necessarily have to be synchronized with the grid.

During normal conditions, the combined quantity of TMSR and TMNSR must be at least as great as the capacity of the largest single system contingency multiplied by a Contingency Reserve Adjustment Factor for the most recent operating quarter. Regulation Reserves that are available within ten minutes

\footnotetext{
${ }^{4}$ http://www.iso-ne.com/isoexpress/web/reports/operations/-/tree/daily-regulation-requirement
} 
can also contribute to this requirement. As a baseline, $100 \%$ of the total ten-minute reserve capacity must be spinning reserve However, at the discretion of the ISO this requirement may be relaxed so that as little as $25 \%$ of the total ten-minute reserve requirement is made up of spinning capacity. The process for adjusting the required TMSR percentage is outlined in detail in NE-ISO Operating Procedure No. $8^{5}$.

\subsubsection{Thirty-Minute Operating Reserves}

Thirty-minute Operating Reserves must be able to convert their capacity into generation within thirty minutes of receiving a signal from the system operator, but do not necessarily have to be synchronized with the grid. The TMOR requirement is equal to $50 \%$ of the second-largest system contingency. Excess TMSR and TMNSR may also contribute to meeting this requirement.

\subsection{Market Process}

A forward market auction for reserve (non-energy) capacity occurs twice per year, prior to the beginning of each seasonal capability period. These periods run from June through September (summer) and October through May (winter). Forward reserve resources are assigned hourly schedules one day in advance of the operating day. The market is designed to set threshold prices at approximately the marginal cost of a peaking plant with a $2-3 \%$ capacity factor.

In real-time operations, ISO-NE co-optimizes energy and reserves, finding the least-cost means of serving energy demand and meeting reserve requirements for TMSR (whole-system), TMNSR (wholesystem) and TMOR (whole-system and the three specified zones). If necessary, the system will redispatch resources to increase the amount of reserves that are available. This typically involves reducing the output of fast-response resources, which may increase the real-time energy LMP. There are administratively defined limits on the re-dispatch costs that the system will incur to meet reserve constraints, known as Reserve Constraint Penalty Factors. In addition to these real-time reserve prices, a regulation clearing price is also calculated on the basis of the offer of the highest marginal cost resource providing regulation capacity in each 5 -minute settlement period. ISO-NE does not co-optimize ancillary services in the day-ahead timeframe and does not maintain a day-ahead ancillary services market.

\subsection{Resources}

\subsubsection{Overview of ISO New England's Wholesale Electricity Markets and Market Oversight http://www.iso-ne.com/pubs/spcl rpts/2013/markets overview 051513 final.pdf}

\subsubsection{ISO New England Operating Procedure No. 8: Operating Reserve and Regulation} http://www.iso-ne.com/static-assets/documents/rules proceds/operating/isone/op8/op8 rto final.pdf

\footnotetext{
${ }^{5}$ http://www.iso-ne.com/static-assets/documents/rules_proceds/operating/isone/op8/op8_rto_final.pdf
} 


\section{MISO}

\subsection{Overview}

The Midcontinent Independent System Operator (MISO) operates an Ancillary Services Market for Regulation and Contingency Reserves, which began operation in 2009. Currently, MISO operates both a DAM and RTM for ancillary services, which are simultaneously co-optimized with its Day-ahead and Real-time energy market. MISO's contingency reserve consists of two separate products for Spinning Reserves and Supplemental (Non-spinning) Reserves.

\subsection{Regions}

MISO manages the transmission network and energy markets throughout a geographic area from Montana to Michigan, and Manitoba, Canada. In late 2013, MISO expanded to include the new MISO South sub-region, which spans portions of Texas, Louisiana, Mississippi, and Arkansas.

MISO determines the ancillary service requirements on both a system-wide level and a zonal level. Figure 5-1 illustrates the MISO reserve zones, also known as MCP zones. Separate MCPs are calculated for Regulating, Spinning and Supplemental Reserves in each zone. There are seven such zones in MISO related to ancillary services provision.

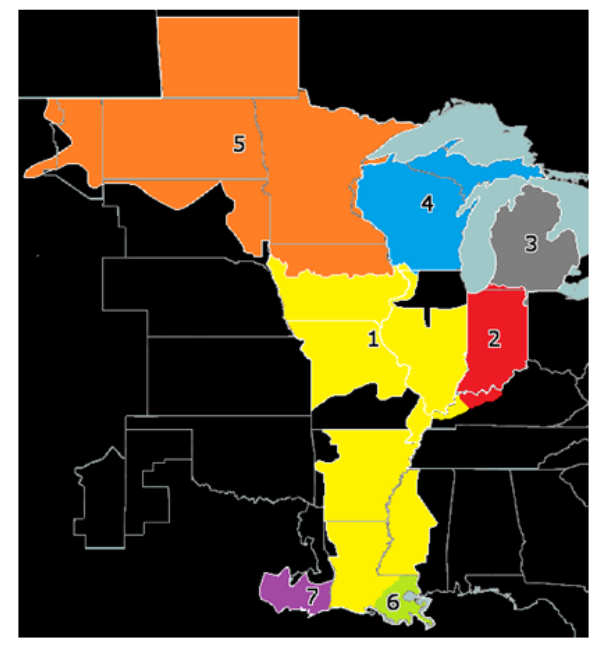

Figure 5-1 Map of MISO ancillary market

\subsection{Ancillary Services}

MISO currently has markets for Regulation, Spinning Reserves, and Supplemental Reserves in both the Day-ahead and Real-time Energy and Operating Reserve Market. Table 5-1 summarizes the ancillary services offered by MISO.

\begin{tabular}{|l|l|l}
\hline \multicolumn{2}{|c|}{ Product } & \multicolumn{1}{c}{ Description } \\
\hline Regulation & - Must respond fully within five minutes. \\
& - Online and synchronized with the grid. \\
\hline
\end{tabular}




\section{Spinning Reserve \\ Supplemental Reserve}

- Synchronized to the grid.

- Must respond within 10 minutes.

- Not necessarily synchronized to the grid.

- Must respond within 10 minutes.

Table 5-1 Summary of ancillary services offered by MISO.

\subsubsection{Regulation Reserves}

Regulation Reserves are comprised of two components: generation-based resources and stored energy resources. These resources must be able to adjust their output in response to automatic signals within five minutes of receiving a signal to do so. MISO has only a single product for Regulation Reserves. The system requirement for total Regulation Reserves across all zones varies between $300 \mathrm{MW}$ and 500 MW, depending on system conditions.

\subsubsection{Spinning Reserves}

Spinning Reserves can be provided by either generation resources or demand-side resources at MISO. This capacity must be synchronized to the grid and able to adjust output within ten minutes of receiving an instruction to do so. There is a fixed requirement of $1000 \mathrm{MW}$ for Spinning Reserves.

\subsubsection{Supplemental Reserves}

Supplemental Reserves can be provided by either generation resources or demand-side resources at MISO. This capacity does not necessarily need to be synchronized to the grid, but must be able to start up and adjust output within ten minutes of receiving an instruction to do so. There is a fixed requirement of $1000 \mathrm{MW}$ for Supplemental Reserves.

\subsection{Market Process}

In the MISO market, resource owners who wish to participate in the DAM must submit offers no later than 1100 hours EST on the day prior to the operating day for use in clearing the market. At 1500 hours EST, the results for the DAM are posted. From 1500 to 1600 hours EST, participants can revise offers for RAC Post Day-Ahead (with knowledge of DAM results).

When the market is short of one or more of its ancillary service products, MISO uses an administratively defined demand curve to set prices. This price of each ancillary service is also included in the price of all higher-valued reserves and the energy price as a consequence of co-optimized market clearing. Separate demand curves are applied both to the entire market (Market-Wide Operating Reserve, etc.) and to each Reserve Zone (Zonal Operating Reserve, etc.).

\subsection{Resources}

\subsubsection{Ancillary Services Definition and Market Process}

https://www.misoenergy.org/Library/Repository/Report/IMM/2014\%20State\%20of\%20the\%20Market \%20Report.pdf

https://www.misoenergy.org/MarketsOperations/RealTimeMarketData/Pages/AncillaryMarketMCP.asp $\underline{x}$ 
https://www.misoenergy.org/Library/BusinessPracticesManuals/Pages/BusinessPracticesManuals.aspx

https://www.misoenergy.org/Library/Repository/Meeting\%20Material/Stakeholder/Training\%20Materi als/200\%20Level\%20Training/Level\%20200\%20-

\%20Energy\%20and\%200perating\%20Reserves\%20Markets.pdf

\section{NYISO}

\subsection{Overview}

In December 1999, New York ISO (NYISO) took over responsibility for the electric grid in New York. NYISO operates DAMs for both ancillary services and energy, which are co-optimized. In February 2005, a number of enhancements to the RTM systems were implemented, and a two-settlement system was designed for the Reserve and Regulation Markets. NYISO operates markets for Regulation Reserves and four Operating Reserve products: Ten-minute Spinning Reserves, Ten-minute Non-synchronized Reserves, Thirty-minute Spinning Reserves, and Thirty-minute Non-synchronized Reserves.

\subsection{Regions}

NYSIO consists of three nested zones for reserve products:

1. West of Central-East (West or Western), a system-wide zone that includes the East and Long Island zones

2. East of Central-East, including Long Island (East or Eastern)

3. Long Island

NYISO determines separate DAM and RTM prices for each of the three Operating Reserve products in the East and West regions. NYISO also calculates separate reserve prices in the Long Island Region, but does not post them or use them for settlement purposes. There is only a single Regulation Reserves price for the whole ISO. The regions are illustrated in Figure 6-1.

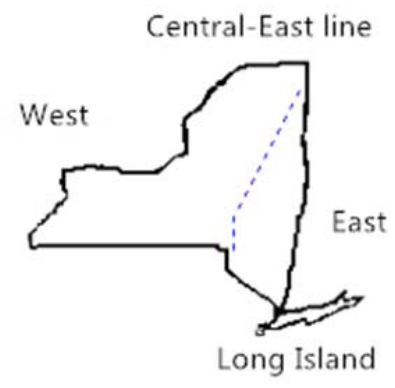

Figure 6-1 Map of NYISO East, West, and Long Island regions

\subsection{Ancillary Services}

NYISO has markets for Regulation Reserves and Ten-minute and Thirty-minute products for both Spinning and Non-synchronized Reserves (Table 6-1). 


\begin{tabular}{|c|c|}
\hline Product & Description \\
\hline Regulation & $\begin{array}{l}\text { - Must immediately increase or decrease output in } \\
\text { response to automated signals. }\end{array}$ \\
\hline Ten-minute Spinning Reserves & $\begin{array}{l}\text { - } \quad \text { Synchronized to the grid. } \\
\text { - } \quad \text { Must respond within } 10 \text { minutes. }\end{array}$ \\
\hline $\begin{array}{c}\text { Ten-minute Non- synchronized } \\
\text { Reserves }\end{array}$ & - Must respond within 10 minutes. \\
\hline Thirty-minute Spinning Reserves & $\begin{array}{l}\text { - } \quad \text { Synchronized to the grid. } \\
\text { - } \quad \text { Must respond within } 30 \text { minutes. }\end{array}$ \\
\hline $\begin{array}{l}\text { Thirty-minute Non-synchronized } \\
\text { Reserves }\end{array}$ & - $\quad$ Must respond within 30 minutes. \\
\hline
\end{tabular}

Table 6-1 Summary of operating reserve services offered by NYISO

\subsubsection{Regulation}

The system requirements for Regulation Reserves are determined by the NYISO, consistent with industry standards set by NERC, and may vary by hour or season. Each potential supplier includes several different response rates (in MW per minute) that can be achieved by its resource under various system conditions as part of each bid. Generators and demand-side resources are not permitted to provide regulation capacity in excess of their normal response rate (NRR) times five minutes. NYISO has only a single Regulation Reserves product for the entire ISO, whereas there are separate Spinning and Synchronized Reserves products for the East and West regions.

\subsubsection{Ten-minute Spinning Reserves}

Ten-minute Spinning Reserves must be synchronized with the grid and able to convert their capacity into generation within ten minutes of receiving a signal from the system operator. The system-wide requirement for Ten-minute Spinning Reserves is equal to $50 \%$ of the largest single system contingency (655 MW). There is also an additional specific requirement for the East region (330 MW).

\subsubsection{Ten-minute Non-synchronized Reserves}

Ten-minute Non-synchronized Reserves must be able to convert their capacity into generation within ten minutes of receiving a signal from the system operator, but do not necessarily have to be synchronized with the grid. The combined quantity of Ten-minute Reserves (Spinning and Nonsynchronized) must be greater than or equal to the single largest system contingency (1310 MW). There are also additional specific requirements for the East region (1200 MW) and for Long Island (120 MW).

\subsubsection{Thirty-minute Spinning Reserve}

Thirty-minute Spinning Reserves must be synchronized with the grid and able to convert their capacity into generation within thirty minutes of receiving a signal from the system operator. There is no specific system requirement for Thirty-minute Spinning Reserves alone.

\subsubsection{Thirty-minute Non-synchronized Reserves}

Thirty-minute Non-synchronized Reserves must be able to convert their capacity into generation within thirty minutes of receiving a signal from the system operator, but do not necessarily have to be synchronized with the grid. The combined quantity of Thirty-minute Reserves (Spinning and Nonsynchronized) must be greater than or equal to $150 \%$ of the single largest system contingency (1965 
$\mathrm{MW})$. There are also additional specific requirements for the East region (1200 MW) and for Long Island (270-540 MW).

\subsection{Market Process}

Ancillary services are procured through a DAM, $\mathrm{HAM}^{6}$, and RTM. The DAM ancillary service prices are posted at approximately 1100 hours Eastern Time for the East and West regions. In the DAM, resources may submit availability bids for each hour of the upcoming day. NYISO selects operating reserve suppliers for each hour of the upcoming day through a co-optimized day-ahead commitment process that minimizes the total cost of energy, operating reserves, and regulation service, according to the bids submitted by market participants.

The RTM ancillary service prices for the selected date are posted every five minutes for the East and West regions. Resources may submit bids for Regulation Reserves until the RTM closes, 75 minutes prior to the operating hour. NYISO will automatically select operating reserve suppliers in the RTM from eligible resources. All suppliers will automatically be assigned a real-time operating reserves availability bid of $\$ 0 / \mathrm{MW}$. Suppliers will thus be selected on the basis of their response rates, their applicable upper operating limit, and their energy bid (which will reflect their opportunity costs). This selection takes place through a co-optimized dispatch process that minimizes the total cost of energy, regulation, and operating reserves.

\subsection{Resources}

\subsubsection{Data}

http://www.nyiso.com/public/markets operations/market data/pricing data/index.jsp

\subsubsection{Ancillary Services Definition and Market Process}

http://www.nyiso.com/public/webdocs/markets operations/documents/Manuals and Guides/Manual s/Operations/ancserv.pdf

http://www.nyiso.com/public/webdocs/markets operations/documents/Manuals and Guides/Guides/ User Guides/mpug.pdf

http://www.nyiso.com/public/webdocs/markets operations/committees/bic miwg/meeting materials 2014-11-04/Comprehensive\%20Shortage\%20Pricing\%20November\%20MIWG\%20FINAL.pdfPJM

\section{PJM}

\subsection{Overview}

PJM implemented several coordinated ancillary service markets in 2001 to co-optimize the provision of energy, regulation and operating reserves. These include a Day-Ahead Energy Market, Real-Time Energy Market, Regulation Market, Synchronized Reserve Market, and Day-Ahead Scheduling Reserve Market.

\footnotetext{
${ }^{6}$ HAM was part of the legacy NYISO system (pre-2005)
} 
Both generation and demand resources are allowed to participate in each ancillary service market with eligibility validation. Load-serving entities are obliged to acquire a share of the PJM ancillary services requirement in any of three ways: self-scheduling the entity's own resources; bilateral contracts to purchase services from other participants; and purchasing services from the ancillary service markets. The share of obligation is determined on the basis of the entity's total load in the PJM RTO.

\subsection{Regions}

PJM consists of two zones for reserve products:

1. PJM RTO

2. PJM Mid-Atlantic Dominion (PJM MAD)

The PJM RTO zone spans the entire PJM territory (including PJM MAD), while PJM MAD is a sub-zone covering the eastern portion of the PJM territory. PJM applies a unified regulation requirement for the whole PJM RTO region. Owing to potential deliverability issues, PJM also established the MAD sub-zone for synchronized reserve and primary reserve services, as illustrated in Figure 7-1.

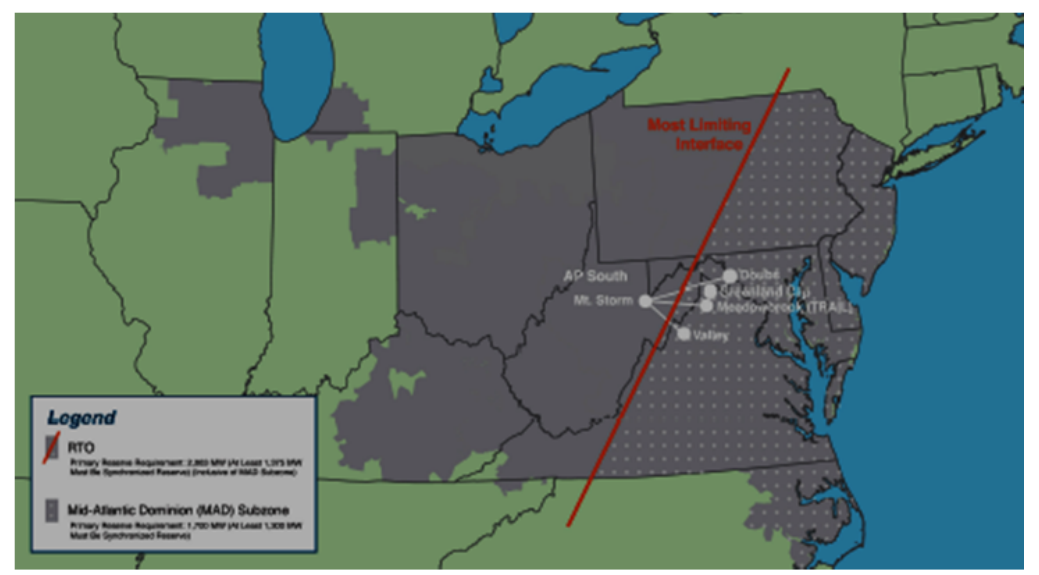

Figure 7-1 Map of PJM RTO territory and MAD Sub-Zone

\subsection{Ancillary Services}

PJM currently has markets for Regulation, Synchronized Reserves, and Primary Reserves. PJM determines the hourly zonal demands for Regulation and Synchronized Reserves in accordance with NERC reliability requirements. PJM monitors and adjusts reserves to ensure compliance with NERC, SERC Reliability Corporation (SERC), and ReliabilityFirst Corporation (RFC) Balance standards for the PJM Balancing Area. Table 7-1 summarizes the requirements and regions for each of the products.

\begin{tabular}{|c|c|}
\hline Product & Description \\
\hline Regulation & $\begin{array}{l}\text { - Must immediately increase or decrease output in response } \\
\text { to automated signals. }\end{array}$ \\
\hline Synchronized Reserves & $\begin{array}{l}\text { - } \quad \text { Synchronized to the grid. } \\
\text { - } \quad \text { Must respond within } 10 \text { minutes. }\end{array}$ \\
\hline Primary Reserves & - $\quad$ Must respond within 10 minutes. \\
\hline
\end{tabular}


- Includes Synchronized Reserves.

Table 7-1 Summary of ancillary services offered by PJM

\subsubsection{Regulation}

Regulation Reserves must be able to increase or decrease their output in response to automated control signals within five minutes in order to maintain target system frequency. There are two important regulation signals: regulation signal $A$ and $D$. Regulation signal $A$ is a function of total ACE. Signal $D$ was specifically developed for energy storage devices with limited storage capabilities. It is designed so that storage can provide more signal-correcting output in the short-term with less storage needs. The resource is monitored for accuracy at a ten-second scan rate; payments are reduced for poor accuracy. Resources must be able to sustain full output for 40 minutes. There is no separate Regulation product for the PJM MAD sub-zone, only a single product for the entire PJM RTO. The Regulation requirement is equal to $700 \mathrm{MW}$ during peak periods (0500-2359 hours) and $525 \mathrm{MW}$ during off-peak periods (00000459 hours).

\subsubsection{Synchronized Reserves}

Synchronized Reserves must be synchronized with the grid and able to convert their capacity into generation within ten minutes of receiving a signal from the system operator. There are two separate Synchronized Reserve products for the whole PJM RTO and for the PJM MAD sub-zone. The requirement for the whole PJM system is equal to the greater of (i) the RFC-imposed minimum requirement and (ii) the largest contingency on the system. The requirement for the PJM MAD sub-zone is equal to the largest contingency in PJM MAD.

\subsubsection{Primary Reserves}

The Primary Reserves product in PJM represents the combined quantity of available Synchronized Reserves and Non-synchronized Reserves (also available within ten minutes). There are two separate Primary Reserve products for the whole PJM RTO and for the PJM MAD sub-zone. The requirement for the whole PJM system is equal to $150 \%$ of the largest contingency on the system. The requirement for the PJM MAD sub-zone is set to a predefined value, usually $1700 \mathrm{MW}$.

\subsection{Market Process}

Ancillary service prices and cost-related data must be supplied by 1800 hours Eastern time one day ahead of operation and are applicable for the entire 24-hour period. All data can be revised until 60 minutes before the operating hour. Sixty minutes prior to the operating hour, PJM executes the Ancillary Services Optimizer to jointly optimize energy, Synchronized Reserves, Primary Reserves, and Regulation on the basis of forecasted system conditions to determine an economical set of inflexible reserve resources to commit for the operating hour.

In the PJM regulation market, resource owners also submit specific offers for regulation capability and regulation performance. PJM optimizes the RTO dispatch profile and forecasts LMPs to calculate an hourly regulation market clearing price (RMCP), regulation market performance clearing price (RMPCP), and regulation market capability clearing price (RMCCP). For each hour, RMCP is the total of RMPCP and RMCCP. 
PJM calculates real-time prices for Synchronized Reserves and Primary Reserves simultaneously with the LMP every five minutes in real time. When there is no Synchronized Reserve shortage, the prices will be determined by the cost of the marginal Synchronized Reserve resource, which is defined as the Synchronized Reserve offer plus any opportunity cost for this resource relative to forgone energy or other ancillary service payments. When there is no Primary Reserve shortage, the prices will be determined by the cost of the marginal Primary Reserve resource, which is defined as the opportunity cost for this resource relative to forgone energy or other ancillary service payments. When there is a shortage in Synchronized Reserves, then the price will be the sum of the Primary Reserve and Synchronized Reserve penalty factors. When there is a shortage in Primary Reserves, the Primary Reserves price will be equal to the penalty factor of the location where the shortage occurred.

\subsection{Resources}

\subsubsection{Data}

http://www.pjm.com/markets-and-operations/ancillary-services.aspx

\subsubsection{Ancillary Services Definition and Market Process \\ http://www.pjm.com/ /media/documents/manuals/m11.ashx}

http://www.monitoringanalytics.com/reports/PJM State of the Market/2015.shtml

\section{SPP}

\subsection{Overview}

In March 2014, the Southwest Power Pool (SPP) combined their 16 balancing authorities into a single consolidated balancing authority and began operating an Integrated Marketplace that conducts a market-based procurement of three types of ancillary services: Regulation (Regulation-up and Regulation-down), Spinning Contingency Reserves, and Non-spinning Contingency Reserves. These services are supplied by generators and are purchased by SPP on the basis of pre-determined requirements both system-wide and for four individual reserve zones, numbered one through four. Regulation is a power supply product that is used to continuously supply the SPP balancing authority area in order to maintain Area Control Error in accordance with NERC control performance criteria. Regulation-up and Regulation-down services are provided by generators that are specially equipped with AGC, which allows near-continuous adjustment to meet the regulation set points. Contingency Reserves are supplied by resources that are able to supply energy to the system within ten-minutes of a contingency event (unexpected generator or transmission equipment outages). Contingency Reserves are comprised of Synchronized (Spinning) Reserves, from online resources that are synchronized with the system, and Non-spinning (Supplemental) Reserves, from offline resources. SPP operates both a DAM and RTM for ancillary services.

\subsection{Regions}

The SPP region covers Kansas, Oklahoma, and parts of New Mexico, Texas, Louisiana, Missouri, Mississippi, and Arkansas. Figure 8-1 shows the different Electric Regions within the SPP service territory. 


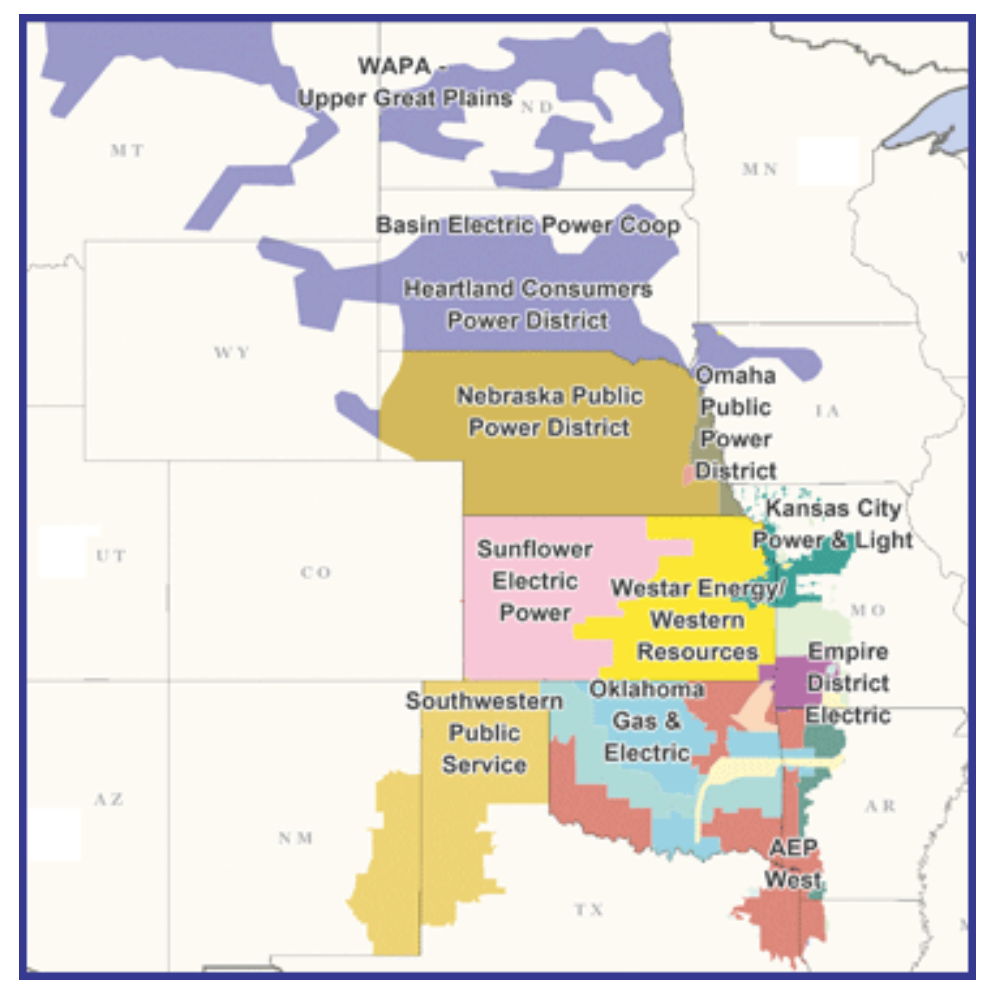

Figure 8-1 Map of the SPP territory

\subsection{Ancillary Services}

SPP currently has markets for Regulation-up and Regulation-down Reserves, Spinning Reserves, and Non-spinning Reserves. Table 8-1 summarizes the requirements and regions for each of the products. Regulation Reserves must be able to respond to AGC on a four-second basis, including telemetering that can be scanned and updated on a two-second basis. They must also be capable of deploying 100 percent of their cleared Regulation-up or Regulation-down capacity within the Regulation Response Time for a continuous duration of 60 minutes.

SPP establishes a minimum Regulation Reserve requirement for its consolidated balancing authority , which is sufficient to maintain compliance with control performance standards.

The Spinning Reserve allocated to any generating unit shall not exceed the amount of capacity increase that will be realized by prime-mover governor action because of a drop in frequency to $59.5 \mathrm{Hertz}$ (less than or equal to $16.7 \%$ of unit capability at a $5 \%$ droop setting). At least half of the total Contingency Reserves must be Spinning Reserves.

\begin{tabular}{|c|l|}
\hline Product & \multicolumn{1}{c}{ Description } \\
\hline Regulation & - \\
\hline Spinnt immediately increase or decrease output in response \\
to automated signals.
\end{tabular}




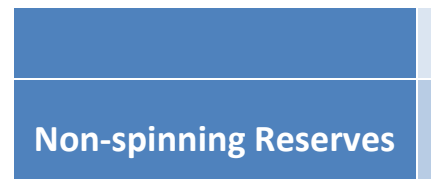

- Must respond within 10 minutes.

- Not necessarily synchronized to the grid.

- Must respond within 10 minutes.

Table 8-1 Summary of ancillary services offered by SPP

\subsection{Market Process}

The market-based mechanisms for ancillary service procurement are part of the SPP Integrated Marketplace, whereby ancillary services are introduced in conjunction with the SPP's day-ahead energy and the real-time balancing markets. The DAM provides market participants with the ability to submit bids and offers for energy and ancillary services. Market participants submit offers and bids from 0000 to 1100 hours Central time, and SPP posts operating reserve requirements at 0700 hours Central time. SPP performs the DAM process from 1100 to 1600 hours Central time, and posts the DAM results at 1600 hours Central time. SPP determines prices for ancillary services in both the DAM and the RTM through co-optimization of energy and operating reserves to minimize system costs subject to reliability constraints. In the event of capacity shortages either for an individual reserve zone or system-wide, prices are set according to pre-established demand curves for each reserves product. The process for assessing these scarcity prices is outlined in the SPP Integrated Market Protocols.

\subsection{Resources}

\subsubsection{Data}

https://marketplace.spp.org/

\subsubsection{Ancillary Services Definition and Market Process}

https://www.spp.org/spp-documents-filings/?id=20867 


\section{Comparative Analysis}

This section presents ancillary service market data for the various ISO/RTO markets over the entire period for which such data were obtained. It also provides direct annual comparisons of the prices and market sizes for each product in each market in terms volume. Sections 9.1, 9.2, and 9.3 present annual market size data for the Regulation, Spinning, and Non-spinning Reserves products. More detailed annual summary data are presented in tabular form in Section 9.4. The price data presented in these tables are referenced throughout sections 9.1, 9.2, and 9.3. The following analyses present price data from the DAM in CAISO, ERCOT, MISO, NYISO, and SPP. Data from the RTM are utilized for ISO-NE and PJM as these ISO/RTOs do not operate a traditional DAM for ancillary services.

\subsection{Regullation Reserves Market Data}

The Regulation Reserves market data that are analyzed in this section are summarized in Table 9-1.

\begin{tabular}{|c|c|c|c|c|}
\hline Market & $\begin{array}{l}\text { First Date } \\
\text { Available }\end{array}$ & $\begin{array}{l}\text { DAM/ } \\
\text { RTM }\end{array}$ & $\begin{array}{l}\text { Availability } \\
\text { of Market } \\
\text { Volume Data }\end{array}$ & Additional Information \\
\hline CAISO & $4 / 1 / 2009$ & DAM & Y & $\begin{array}{l}\text { Price and market volume data are reported for the } \\
\text { CAISO Expanded Region. }\end{array}$ \\
\hline ERCOT & $7 / 31 / 2001$ & DAM & $\mathrm{N}$ & \\
\hline ISO-NE & - & - & $\mathrm{N}$ & Regulation data were not obtained \\
\hline MISO & $1 / 1 / 2010$ & DAM & $\mathrm{Y}$ & $\begin{array}{l}\text { MISO has a single Regulation Reserves product for } \\
\text { its entire footprint }\end{array}$ \\
\hline NYISO & $2 / 1 / 2005$ & DAM & $\mathrm{N}$ & $\begin{array}{l}\text { NYISO has a single Regulation Reserves product for } \\
\text { its entire footprint }\end{array}$ \\
\hline PJM & $10 / 1 / 2012$ & RTM & Y & $\begin{array}{l}\text { Price and market volume data are reported for the } \\
\text { whole PJM Region. PJM does not operate a separate } \\
\text { Regulation market for its MAD sub-region. }\end{array}$ \\
\hline SPP & $3 / 1 / 2014$ & DAM & Y & \\
\hline
\end{tabular}

Table 9-1 Summary of the Regulation Reserves market data that are analyzed in this section

The summary tables in section 9.4 indicate that NYISO, which has only a single Regulation Reserves product for the whole ISO, consistently experienced higher prices for Regulation Reserves than ERCOT between 2006 and 2011. However, ERCOT experienced large price spikes in 2011. PJM has only operated its current market for Regulation Reserves since October 2012. In that time, prices at PJM have been consistently higher and more volatile than those found in other markets. PJM experienced particularly large price spikes for Regulation Reserves as a consequence of extreme weather conditions during the "Polar Vortex" of early 2014. PJM also has less Regulation Reserves provided by relatively inexpensive hydroelectric resources than most other markets do. Additional factors that might also play a role in the price differentiation across markets are payment structure, generation mix, network topology, etc. CAISO, ERCOT, and SPP have separate Regulation-up and Regulation-down prices, while ISO-NE, NYISO, MISO, and PJM have the same prices for Regulation-up and Regulation-down (a single ancillary service called Regulation). In SPP, Regulation-down prices are the same across all four reserve zones, but Regulation-up prices differ across zones. Price data for Regulation Reserves were not 
obtained for ISO-NE. In general, Regulation-up prices are higher and more volatile than Regulation-down prices because the lost opportunity costs from its deployment are greater.

Figure 9-1 shows the annual average market volume for Regulation Reserves across all ISO/RTOs for which data were obtained. The three markets for which market volume data were not obtained, ERCOT, ISO-NE, and NYISO, are not depicted in this figure. Therefore, even though ERCOT and NYISO have operated markets for Regulation Reserves since 2001 and 2005, respectively, no data are presented for the period before CAISO began operating its market in 2009. Most market volumes remain relatively constant year-to-year as these are largely dictated by system requirements.

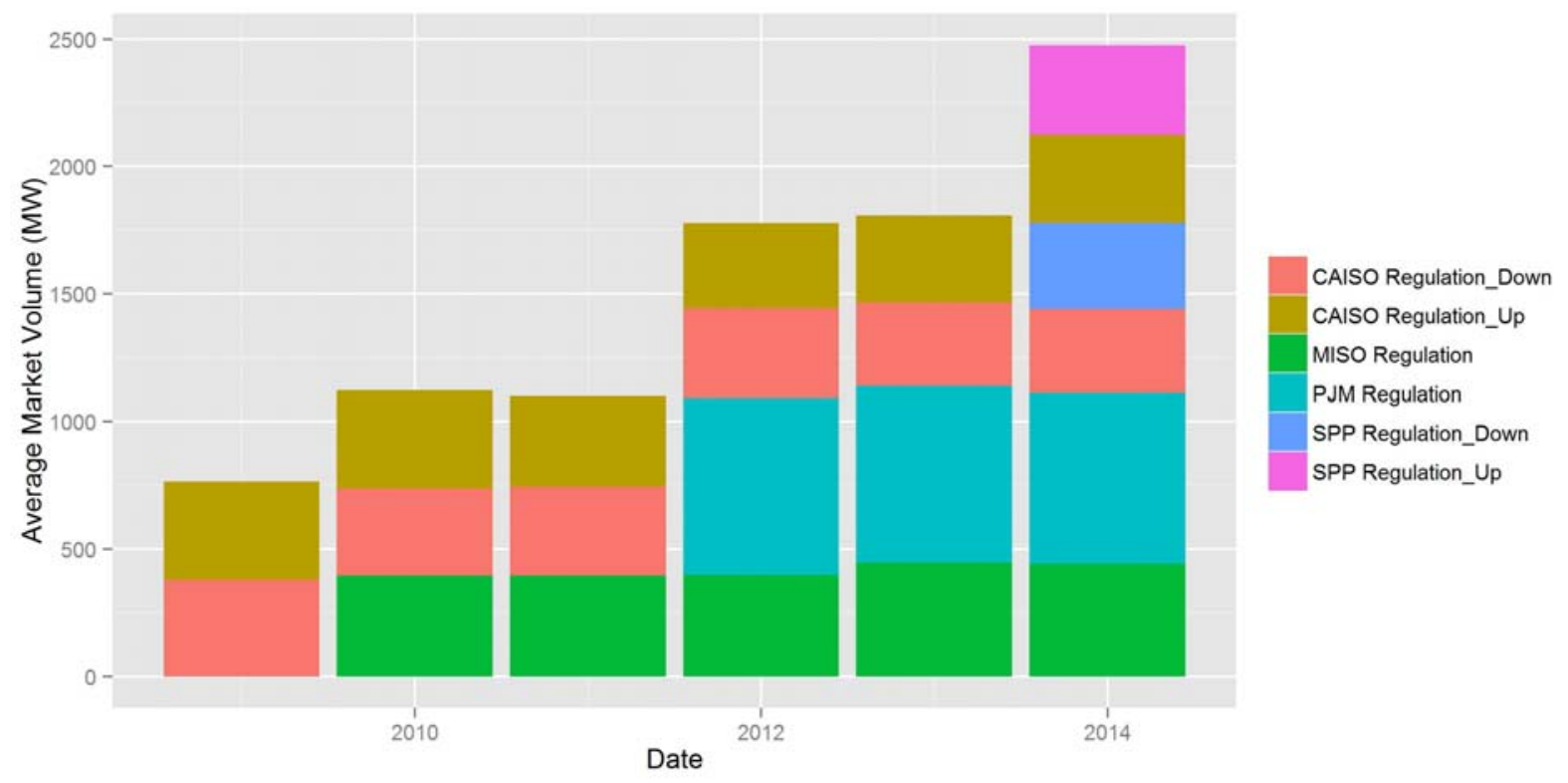

Figure 9-1 Average market volume in each Regulation Reserves market for which data were obtained

\subsection{Spinning Reserves Market Data}

The Spinning Reserves market data that are analyzed in this section are summarized in Table 9-2.

\begin{tabular}{|c|c|c|c|c|}
\hline Market & $\begin{array}{l}\text { First Date } \\
\text { Available }\end{array}$ & $\begin{array}{l}\text { DAM/ } \\
\text { RTM }\end{array}$ & $\begin{array}{l}\text { Availability } \\
\text { of Market } \\
\text { Volume Data }\end{array}$ & Additional Information \\
\hline CAISO & $4 / 1 / 2009$ & DAM & $Y$ & $\begin{array}{l}\text { Price and market volume data are reported for the } \\
\text { CAISO Expanded Region. }\end{array}$ \\
\hline ERCOT & $7 / 31 / 2001$ & DAM & $\mathrm{N}$ & \\
\hline ISO-NE & $1 / 1 / 2007$ & RTM & $Y$ & \\
\hline MISO & $1 / 1 / 2010$ & DAM & $Y$ & $\begin{array}{l}\text { Reported prices are the average across all zones, } \\
\text { volumes are the total across all zones. }\end{array}$ \\
\hline NYISO & $2 / 1 / 2005$ & DAM & $\mathrm{N}$ & \\
\hline PJM & $10 / 1 / 2012$ & RTM & $Y$ & $\begin{array}{l}\text { Price and market volume data are reported for the } \\
\text { whole PJM Region. }\end{array}$ \\
\hline SPP & $3 / 1 / 2014$ & DAM & $Y$ & \\
\hline
\end{tabular}


Table 9-2 Summary of the Spinning Reserves market data that are analyzed in this section

The summary tables in section 9.4 indicate that in recent years average Spinning Reserves prices have generally been the highest and most volatile in ERCOT. ERCOT has higher and more volatile Spinning Reserves prices for two reasons: (1) ERCOT has a relatively higher Spinning Reserves requirement compared to its peak load, and (2) ERCOT has a higher fraction of its energy provided by renewable resources, which requires more reserves to be deployed. In 2014, prices for NYISO East were also consistently greater than those for NYSIO West.

Figure 9-1 shows the annual average market volume for Spinning Reserves across all ISO/RTOs for which data were obtained. Of the markets with available data, PJM currently has the largest market for its Synchronized Reserves product, with an average of 2,081 MW in 2014, although this represents a decrease from an average of 3,613 MW in 2012. In 2014 CAISO, MISO, and ISO-NE all maintained comparable average market volumes, $849 \mathrm{MW}, 923 \mathrm{MW}$, and $921 \mathrm{MW}$ respective. Market volumes in SPP, which began operating its current Integrated Marketplace in 2014, were slightly smaller at an average of $645 \mathrm{MW}$.

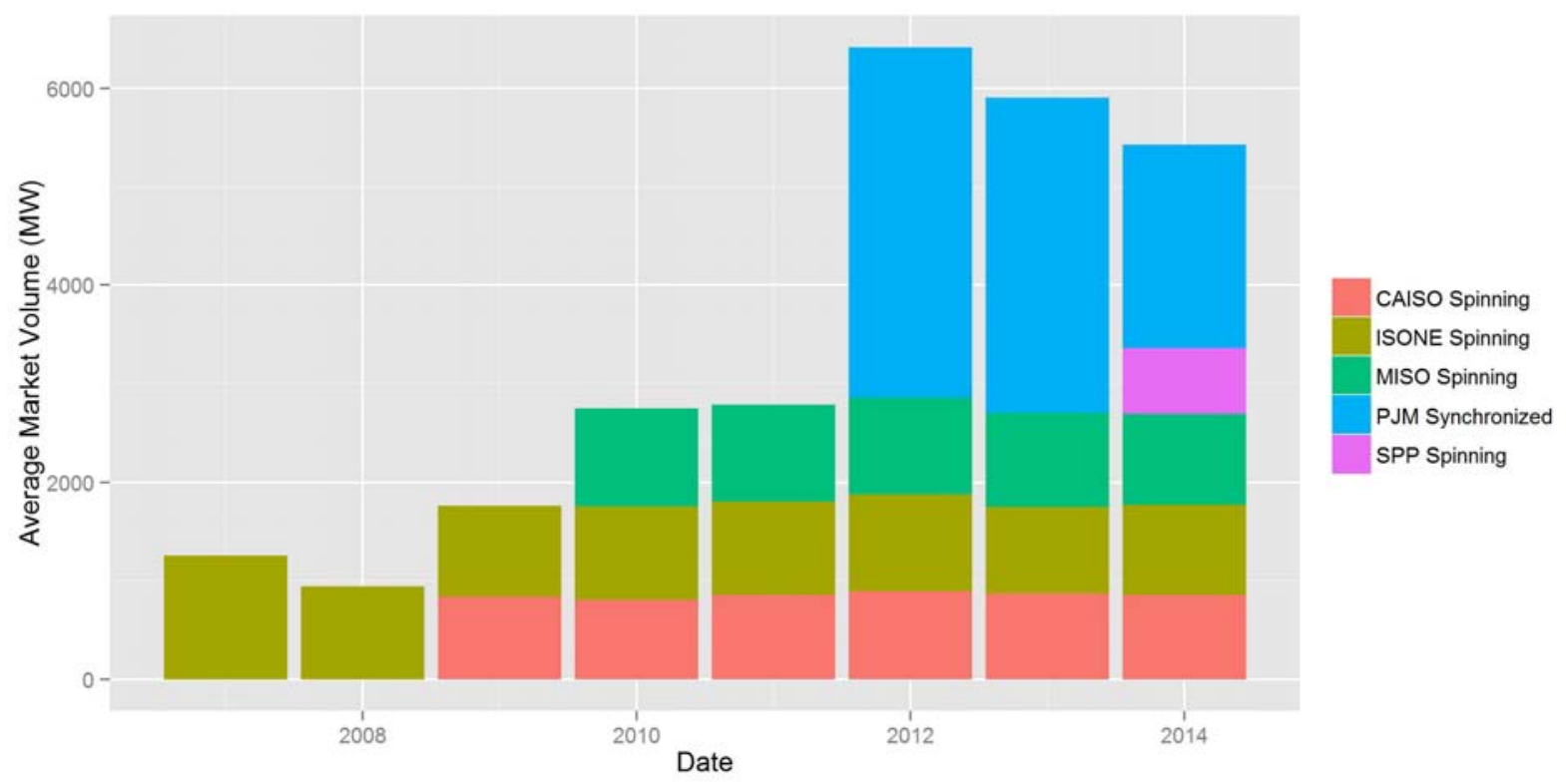

Figure 9-2 Average market volume in each Spinning Reserves market for which data were obtained

\subsection{Non-Spinning Reserves Market Data}

The Non-spinning Reserves market data that are analyzed in this section are summarized in Table 9-3.

\begin{tabular}{|c|c|c|c|c|}
\hline Market & $\begin{array}{l}\text { First Date } \\
\text { Available }\end{array}$ & $\begin{array}{l}\text { DAM/ } \\
\text { RTM }\end{array}$ & $\begin{array}{l}\text { Availability } \\
\text { of Market } \\
\text { Volume Data }\end{array}$ & Additional Information \\
\hline CAISO & $4 / 1 / 2009$ & DAM & $\mathrm{Y}$ & $\begin{array}{l}\text { Price and market volume data are reported for the } \\
\text { CAISO Expanded Region. }\end{array}$ \\
\hline ERCOT & $7 / 31 / 2001$ & DAM & $\mathrm{N}$ & \\
\hline ISO-NE & $1 / 1 / 2007$ & RTM & Y & \\
\hline
\end{tabular}




\begin{tabular}{|l|l|l|l|l|}
\hline MISO & $1 / 1 / 2010$ & DAM & Y & $\begin{array}{l}\text { Reported prices are the average across all zones, } \\
\text { volumes are the total across all zones. }\end{array}$ \\
\hline NYISO & $2 / 1 / 2005$ & RTM & N & $\begin{array}{l}\text { Price and market volume data are reported for the } \\
\text { whole PJM Region. }\end{array}$ \\
\hline PJM & $10 / 1 / 2012$ & RTM & Y & \\
\hline SPP & $3 / 1 / 2014$ & DAM & Y &
\end{tabular}

Table 9-3 Summary of the Non-spinning Reserves market data that are analyzed in this section

The summary tables in section 9.4 indicate that in general, Non-spinning Reserve prices are lower than Spinning Reserve prices. The average Non-spinning Reserve prices are generally highest in ERCOT, and lowest in the CAISO Expanded region. The prolonged periods of price spikes are not as large as they are for Spinning Reserves; however, a number of periods of prolonged moderate prices have occurred across many markets, particularly ERCOT, NYISO, and PJM.

Figure 9-1 shows the annual average market volume for Non-spinning Reserves across all ISO/RTOs for which data were obtained. PJM currently has the largest market for a single Non-spinning Reserves product, its Primary Reserves, maintaining an average capacity of 2,816 MW in 2014. However, it should be noted that in PJM Synchronized Reserves are also considered to simultaneously provide Primary Reserves and are thus, in a sense, doubled counted here. Alternatively, ISO-NE maintains two nonspinning products, which together comprised a larger market than Primary Reserves in PJM. In 2014, ISO-NE's Ten-minute Synchronized Reserve product had an average market volume of 2,520 MW and its 30-minute Operating Reserve had an average market volume of $825 \mathrm{MW}$.

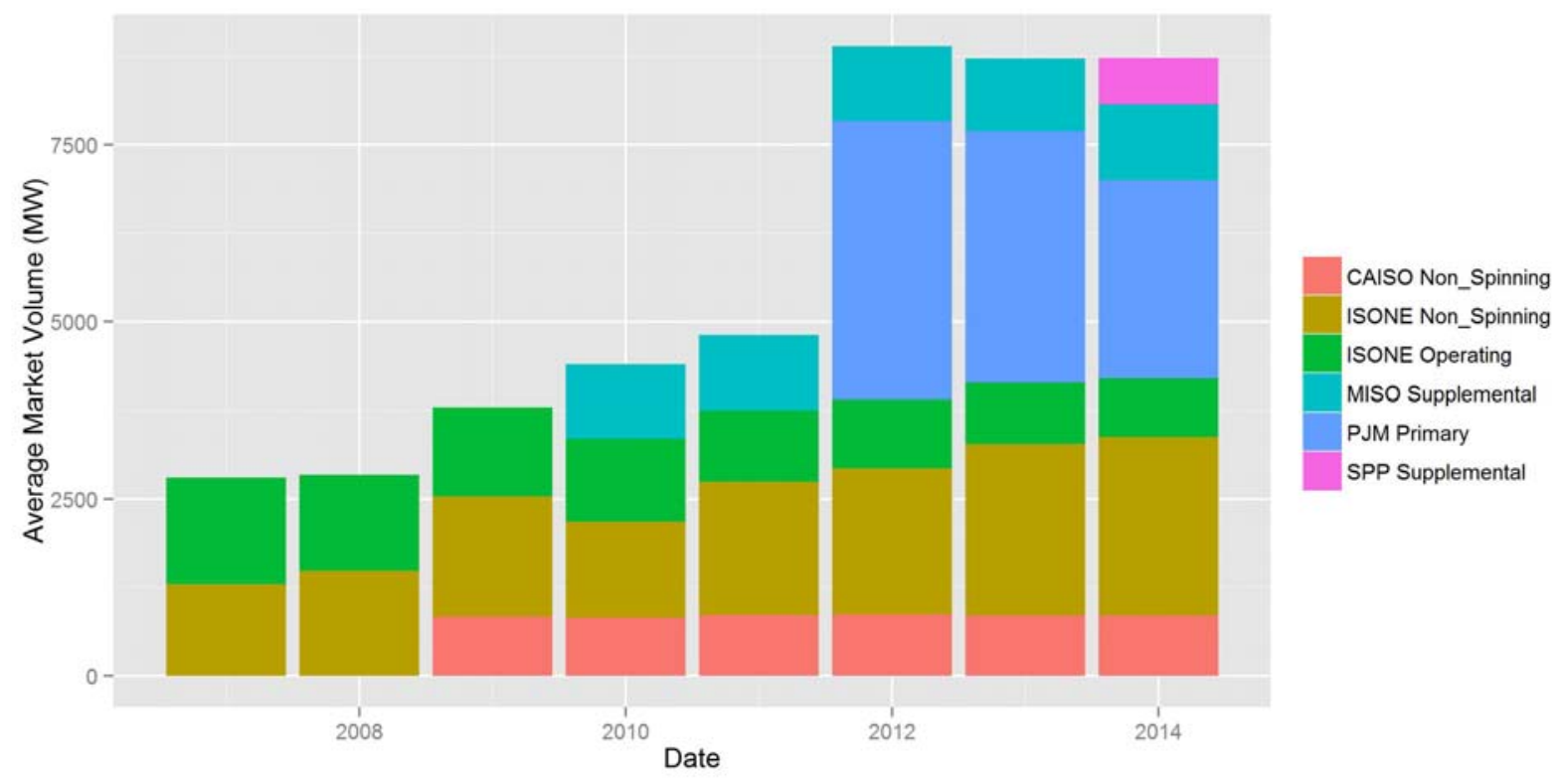

Figure 9-3 Average market volume in each Non-spinning Reserves market for which data were obtained 


\subsection{Annual Data Summaries}

Each of the tables in this section presents summary data on the prices and market volume of each ancillary service in each ISO/RTO over a single calendar year. Prices for ancillary services are almost always consistent across all zones in MISO; the data below represents a system-wide average. Data for are presented for the CAISO Extended region and for the entire PJM footprint, data for the CAISO and PJM MAD sub-zones are omitted. 


\begin{tabular}{|c|c|c|c|c|c|c|c|c|c|}
\hline \multicolumn{10}{|c|}{2014 Summary Data } \\
\hline ISO/RTO & Zone & \multirow[t]{2}{*}{ Product } & \multirow[t]{2}{*}{$\begin{array}{c}\text { Mean Price } \\
\text { (\$/MW-h) }\end{array}$} & \multirow[t]{2}{*}{$\begin{array}{l}\text { Min Price } \\
\text { (\$/MW-h) }\end{array}$} & \multirow[t]{2}{*}{$\begin{array}{l}\text { Max Price } \\
\text { (\$/MW-h) }\end{array}$} & \multirow[t]{2}{*}{$\begin{array}{c}\text { St. Dev } \\
\text { (\$/MW-h) }\end{array}$} & \multirow[t]{2}{*}{$\begin{array}{c}\text { Median } \\
\text { Price } \\
\text { (\$/MW-h) }\end{array}$} & \multirow[t]{2}{*}{$\begin{array}{c}\text { \% Hours } \\
\text { With \$0 } \\
\text { Price }\end{array}$} & \multirow[t]{2}{*}{$\begin{array}{c}\text { Average } \\
\text { Market } \\
\text { Volume (MW) }\end{array}$} \\
\hline Regulation & & & & & & & & & \\
\hline CAISO & Expanded & Regulation-Up & 5.42 & 0.09 & 50.01 & 5.50 & 3.26 & $0.0 \%$ & 343.56 \\
\hline CAISO & Expanded & Regulation-Down & 3.90 & - & 59.55 & 2.62 & 3.52 & $4.4 \%$ & 328.09 \\
\hline ERCOT & ERCOT & Regulation-Up & 12.48 & 1.00 & 4,999.00 & 61.94 & 6.39 & $0.0 \%$ & \#N/A \\
\hline ERCOT & ERCOT & Regulation-Down & 9.77 & 0.50 & 310.08 & 13.23 & 7.00 & $0.0 \%$ & $\# N / A$ \\
\hline MISO & MISO & Regulation & 11.24 & 2.50 & 202.39 & 6.43 & 10.26 & $0.0 \%$ & 443.80 \\
\hline NYSIO & NYISO & Regulation & 12.87 & 2.76 & 316.14 & 19.12 & 9.00 & $0.0 \%$ & $\# \mathrm{~N} / \mathrm{A}$ \\
\hline PJM & PJM & Regulation & 43.70 & 0.01 & $3,303.87$ & 104.07 & 22.27 & $0.0 \%$ & 662.95 \\
\hline SPP & $\mathrm{RZ} 1$ & Regulation-Up & 14.60 & 1.36 & 125.95 & 8.37 & 13.09 & $0.0 \%$ & 18.96 \\
\hline SPP & $\mathrm{RZ} 2$ & Regulation-Up & 13.20 & 0.00 & 125.95 & 8.22 & 11.34 & $0.0 \%$ & 37.60 \\
\hline SPP & $\mathrm{RZ} 3$ & Regulation-Up & 13.67 & 0.07 & 125.57 & 8.07 & 12.35 & $0.0 \%$ & 69.04 \\
\hline SPP & $\mathrm{RZ} 4$ & Regulation-Up & 14.60 & 1.36 & 125.95 & 8.37 & 13.09 & $0.0 \%$ & 213.09 \\
\hline SPP & RZ 1 & Regulation-Down & 7.85 & 0.07 & 294.09 & 6.04 & 8.00 & $0.0 \%$ & 25.55 \\
\hline SPP & $\mathrm{RZ} 2$ & Regulation-Down & 7.85 & 0.07 & 294.09 & 6.04 & 8.00 & $0.0 \%$ & 33.11 \\
\hline SPP & $\mathrm{RZ} 3$ & Regulation-Down & 7.85 & 0.07 & 294.09 & 6.04 & 8.00 & $0.0 \%$ & 79.14 \\
\hline SPP & $\mathrm{RZ} 4$ & Regulation-Down & 7.85 & 0.07 & 294.09 & 6.04 & 8.00 & $0.0 \%$ & 190.42 \\
\hline \multicolumn{10}{|l|}{ Spinning } \\
\hline CAISO & Expanded & Spinning & 3.34 & 0.09 & 46.29 & 5.12 & 0.26 & $0.0 \%$ & 849.30 \\
\hline ERCOT & ERCOT & Spinning & 14.15 & 2.00 & $1,285.73$ & 31.82 & 8.61 & $0.0 \%$ & $\# N / A$ \\
\hline MISO & MISO & Spinning & 2.58 & 0.45 & 88.62 & 3.31 & 2.00 & $0.0 \%$ & 923.38 \\
\hline ISONE & $\mathrm{CT}$ & Spinning & 2.49 & - & $2,500.00$ & 28.80 & - & $93.9 \%$ & 27.05 \\
\hline ISONE & NEMABSTN & Spinning & 2.73 & - & $2,500.00$ & 29.35 & - & $93.7 \%$ & 42.04 \\
\hline ISONE & SWCT & Spinning & 2.49 & - & $2,500.00$ & 28.80 & - & $93.9 \%$ & 36.18 \\
\hline ISONE & ROS & Spinning & 2.49 & - & $2,500.00$ & 28.80 & - & $93.9 \%$ & 816.05 \\
\hline NYISO & East & Spinning & 8.32 & 0.20 & 199.72 & 10.45 & 5.00 & $0.0 \%$ & $\# N / A$ \\
\hline NYISO & West & Spinning & 4.49 & 0.03 & 142.56 & 7.09 & 3.00 & $0.0 \%$ & $\# N / A$ \\
\hline PJM & PJM & Synchronized & 4.21 & - & $1,142.35$ & 32.55 & - & $62.5 \%$ & $2,080.57$ \\
\hline SPP & $\mathrm{RZ} 1$ & Spinning & 7.26 & 0.01 & 103.72 & 6.62 & 5.06 & $0.0 \%$ & 35.30 \\
\hline SPP & $\mathrm{RZ} 2$ & Spinning & 5.85 & - & 103.72 & 6.52 & 3.04 & $6.0 \%$ & 51.15 \\
\hline SPP & $\mathrm{RZ} 3$ & Spinning & 6.32 & - & 103.72 & 6.29 & 4.36 & $2.0 \%$ & 85.92 \\
\hline SPP & $\mathrm{RZ} 4$ & Spinning & 7.26 & 0.01 & 103.72 & 6.62 & 5.06 & $0.0 \%$ & 472.78 \\
\hline \multicolumn{10}{|l|}{ Non-spinning } \\
\hline CAISO & Expanded & Non-Spinning & 0.14 & 0.08 & 23.06 & 0.61 & 0.09 & $0.0 \%$ & 849.91 \\
\hline ERCOT & ERCOT & Non-Spinning & 5.47 & 0.77 & 435.70 & 14.02 & 1.98 & $0.0 \%$ & $\# N / A$ \\
\hline MISO & MISO & Supplemental & 1.35 & 0.45 & 87.95 & 2.96 & 0.70 & $0.0 \%$ & $1,073.22$ \\
\hline ISONE & $\mathrm{CT}$ & Non-Spinning & 1.61 & - & $2,500.00$ & 28.04 & - & $99.1 \%$ & 453.22 \\
\hline ISONE & NEMABSTN & Non-Spinning & 1.85 & - & $2,500.00$ & 28.61 & - & $98.9 \%$ & 38.16 \\
\hline ISONE & SWCT & Non-Spinning & 1.61 & - & $2,500.00$ & 28.04 & - & $99.1 \%$ & 468.10 \\
\hline ISONE & ROS & Non-Spinning & 1.61 & - & $2,500.00$ & 28.04 & - & $99.1 \%$ & $1,560.48$ \\
\hline ISONE & $\mathrm{CT}$ & Operating & 1.55 & - & $1,000.00$ & 25.00 & - & $99.1 \%$ & 64.00 \\
\hline ISONE & NEMABSTN & Operating & 1.79 & - & $1,000.00$ & 25.64 & - & $98.9 \%$ & 88.05 \\
\hline ISONE & SWCT & Operating & 1.55 & - & $1,000.00$ & 25.00 & - & $99.1 \%$ & 377.16 \\
\hline ISONE & ROS & Operating & 1.55 & - & $1,000.00$ & 25.00 & - & $99.1 \%$ & 295.64 \\
\hline NYISO & East & Non-Spinning & 4.14 & 0.20 & 192.72 & 5.60 & 3.34 & $0.0 \%$ & $\# N / A$ \\
\hline NYISO & West & Non-Spinning & 0.90 & - & 50.00 & 1.41 & 0.60 & $0.3 \%$ & $\# \mathrm{~N} / \mathrm{A}$ \\
\hline NYISO & East & Reserve_30 & 0.43 & - & 50.00 & 1.26 & 0.17 & $0.5 \%$ & $\# N / A$ \\
\hline NYISO & West & Reserve_30 & 0.43 & - & 50.00 & 1.26 & 0.17 & $0.5 \%$ & $\# N / A$ \\
\hline PJM & PJM & Primary & 0.95 & - & 400.00 & 13.32 & - & $95.5 \%$ & $2,816.24$ \\
\hline SPP & $\mathrm{RZ} 1$ & Supplemental & 1.80 & 0.01 & 98.00 & 2.16 & 1.50 & $0.0 \%$ & 146.72 \\
\hline SPP & $\mathrm{RZ} 2$ & Supplemental & 1.24 & - & 98.00 & 2.22 & 1.00 & $26.3 \%$ & 7.25 \\
\hline SPP & $\mathrm{RZ} 3$ & Supplemental & 0.89 & - & 98.00 & 2.06 & 1.00 & $30.1 \%$ & 176.08 \\
\hline SPP & $\mathrm{RZ} 4$ & Supplemental & 1.80 & 0.01 & 98.00 & 2.16 & 1.50 & $0.0 \%$ & 300.58 \\
\hline
\end{tabular}




\begin{tabular}{|c|c|c|c|c|c|c|c|c|c|}
\hline \multicolumn{10}{|c|}{2013 Summary Data } \\
\hline \multicolumn{2}{|l|}{ ISO/RTO } & Product & $\begin{array}{l}\text { Mean Price } \\
\text { (\$/MW-h) }\end{array}$ & $\begin{array}{l}\text { Min Price } \\
\text { (\$/MW-h) }\end{array}$ & $\begin{array}{l}\text { Max Price } \\
\text { (\$/MW-h) }\end{array}$ & $\begin{array}{c}\text { St. Dev } \\
\text { (\$/MW-h) }\end{array}$ & $\begin{array}{c}\text { Median } \\
\text { Price } \\
\text { (\$/MW-h) } \\
\end{array}$ & $\begin{array}{c}\% \text { Hours } \\
\text { With \$0 } \\
\text { Price } \\
\end{array}$ & $\begin{array}{c}\text { Average } \\
\text { Market } \\
\text { Volume (MW) } \\
\end{array}$ \\
\hline \multicolumn{10}{|l|}{ Regulation } \\
\hline CAISO & Expanded & Regulation-Up & 4.56 & 0.08 & 119.97 & 5.11 & 2.88 & $0.0 \%$ & 341.42 \\
\hline CAISO & Expanded & Regulation-Down & 3.25 & - & 23.30 & 1.82 & 3.03 & $2.7 \%$ & 326.19 \\
\hline ERCOT & ERCOT & Regulation-Up & 8.57 & 0.01 & $3,000.50$ & 34.53 & 5.60 & $0.0 \%$ & $\# N / A$ \\
\hline ERCOT & ERCOT & Regulation-Down & 4.89 & 0.01 & 150.00 & 5.17 & 3.25 & $0.0 \%$ & $\# \mathrm{~N} / \mathrm{A}$ \\
\hline MISO & MISO & Regulation & 9.10 & 1.51 & 49.11 & 5.11 & 8.02 & $0.0 \%$ & 448.15 \\
\hline NYSIO & NYISO & Regulation & 10.11 & 3.00 & 149.67 & 7.88 & 10.00 & $0.0 \%$ & $\# \mathrm{~N} / \mathrm{A}$ \\
\hline PJM & PJM & Regulation & 28.14 & - & 764.59 & 32.68 & 21.31 & $0.1 \%$ & 682.62 \\
\hline SPP & RZ 1 & Regulation-Up & $\# N / A$ & $\# N / A$ & $\# \mathrm{~N} / \mathrm{A}$ & $\# N / A$ & $\# \mathrm{~N} / \mathrm{A}$ & $\# \mathrm{~N} / \mathrm{A}$ & $\# N / A$ \\
\hline SPP & $\mathrm{RZ} 2$ & Regulation-Up & $\# N / A$ & $\# N / A$ & $\# N / A$ & $\# N / A$ & $\# \mathrm{~N} / \mathrm{A}$ & $\# N / A$ & $\# N / A$ \\
\hline SPP & RZ 3 & Regulation-Up & $\# N / A$ & $\# N / A$ & $\# \mathrm{~N} / \mathrm{A}$ & $\# N / A$ & $\# \mathrm{~N} / \mathrm{A}$ & $\# \mathrm{~N} / \mathrm{A}$ & $\# N / A$ \\
\hline SPP & RZ 4 & Regulation-Up & $\# N / A$ & $\# N / A$ & $\# \mathrm{~N} / \mathrm{A}$ & $\# N / A$ & $\# N / A$ & $\# \mathrm{~N} / \mathrm{A}$ & $\# \mathrm{~N} / \mathrm{A}$ \\
\hline SPP & RZ 1 & Regulation-Down & $\# N / A$ & $\# \mathrm{~N} / \mathrm{A}$ & $\# \mathrm{~N} / \mathrm{A}$ & $\# N / A$ & $\# \mathrm{~N} / \mathrm{A}$ & $\# \mathrm{~N} / \mathrm{A}$ & $\# \mathrm{~N} / \mathrm{A}$ \\
\hline SPP & $\mathrm{RZ} 2$ & Regulation-Down & $\# N / A$ & $\# N / A$ & $\# N / A$ & $\# N / A$ & $\# N / A$ & $\# \mathrm{~N} / \mathrm{A}$ & $\# N / A$ \\
\hline SPP & RZ 3 & Regulation-Down & $\# N / A$ & $\# \mathrm{~N} / \mathrm{A}$ & $\# \mathrm{~N} / \mathrm{A}$ & $\# N / A$ & $\# \mathrm{~N} / \mathrm{A}$ & $\# N / A$ & $\# N / A$ \\
\hline SPP & RZ 4 & Regulation-Down & $\# N / A$ & $\# N / A$ & $\# \mathrm{~N} / \mathrm{A}$ & $\# N / A$ & $\# N / A$ & $\# \mathrm{~N} / \mathrm{A}$ & $\# N / A$ \\
\hline \multicolumn{10}{|l|}{ Spinning } \\
\hline CAISO & Expanded & Spinning & 2.74 & 0.08 & 119.87 & 4.84 & 0.41 & $0.0 \%$ & 867.55 \\
\hline ERCOT & ERCOT & Spinning & 9.77 & 0.84 & $3,000.00$ & 34.82 & 7.00 & $0.0 \%$ & $\# N / A$ \\
\hline MISO & MISO & Spinning & 3.24 & 0.25 & 42.90 & 3.57 & 1.57 & $0.0 \%$ & 963.06 \\
\hline ISONE & CT & Spinning & 2.97 & - & $1,350.00$ & 33.51 & - & $96.8 \%$ & 27.95 \\
\hline ISONE & NEMABSTN & Spinning & 3.00 & - & $1,350.00$ & 33.56 & - & $96.8 \%$ & 107.54 \\
\hline ISONE & SWCT & Spinning & 2.97 & - & $1,350.00$ & 33.51 & - & $96.8 \%$ & 33.11 \\
\hline ISONE & ROS & Spinning & 2.97 & - & $1,350.00$ & 33.51 & - & $96.8 \%$ & 714.10 \\
\hline NYISO & East & Spinning & $\# N / A$ & $\# \mathrm{~N} / \mathrm{A}$ & $\# N / A$ & $\# N / A$ & $\# \mathrm{~N} / \mathrm{A}$ & $\# N / A$ & $\# N / A$ \\
\hline NYISO & West & Spinning & 4.79 & 0.20 & 113.44 & 4.56 & 5.00 & $0.0 \%$ & $\# \mathrm{~N} / \mathrm{A}$ \\
\hline PJM & PJM & Synchronized & 0.75 & - & 105.66 & 2.94 & - & $85.4 \%$ & $3,230.81$ \\
\hline SPP & RZ 1 & Spinning & $\# N / A$ & $\# N / A$ & $\# N / A$ & $\# N / A$ & $\# N / A$ & $\# \mathrm{~N} / \mathrm{A}$ & $\# N / A$ \\
\hline SPP & $\mathrm{RZ} 2$ & Spinning & $\# N / A$ & $\# \mathrm{~N} / \mathrm{A}$ & $\# \mathrm{~N} / \mathrm{A}$ & $\# N / A$ & $\# N / A$ & $\# \mathrm{~N} / \mathrm{A}$ & $\# \mathrm{~N} / \mathrm{A}$ \\
\hline SPP & RZ3 & Spinning & $\# N / A$ & $\# \mathrm{~N} / \mathrm{A}$ & $\# \mathrm{~N} / \mathrm{A}$ & $\# N / A$ & $\# N / A$ & $\# \mathrm{~N} / \mathrm{A}$ & $\# \mathrm{~N} / \mathrm{A}$ \\
\hline SPP & RZ 4 & Spinning & $\# N / A$ & $\# N / A$ & $\# N / A$ & $\# N / A$ & $\# N / A$ & $\# \mathrm{~N} / \mathrm{A}$ & $\# N / A$ \\
\hline \multicolumn{10}{|l|}{ Non-spinning } \\
\hline CAISO & Expanded & Non-Spinning & 0.20 & 0.05 & 115.39 & 2.29 & 0.10 & $0.0 \%$ & 846.77 \\
\hline ERCOT & ERCOT & Non-Spinning & 3.47 & 0.90 & $3,000.00$ & 32.99 & 1.00 & $0.0 \%$ & $\# \mathrm{~N} / \mathrm{A}$ \\
\hline MISO & MISO & Supplemental & 1.75 & 0.25 & 42.90 & 2.86 & 0.70 & $0.0 \%$ & $1,029.19$ \\
\hline ISONE & CT & Non-Spinning & 2.45 & - & $1,350.00$ & 32.85 & - & $98.8 \%$ & 426.62 \\
\hline ISONE & NEMABSTN & Non-Spinning & 2.48 & - & $1,350.00$ & 32.90 & - & $98.8 \%$ & 19.39 \\
\hline ISONE & SWCT & Non-Spinning & 2.45 & - & $1,350.00$ & 32.85 & - & $98.8 \%$ & 412.56 \\
\hline ISONE & ROS & Non-Spinning & 2.45 & - & $1,350.00$ & 32.85 & - & $98.8 \%$ & $1,575.07$ \\
\hline ISONE & $\mathrm{CT}$ & Operating & 2.28 & - & 500.00 & 28.57 & - & $98.9 \%$ & 55.56 \\
\hline ISONE & NEMABSTN & Operating & 2.31 & - & 500.00 & 28.63 & - & $98.8 \%$ & 84.82 \\
\hline ISONE & SWCT & Operating & 2.28 & - & 500.00 & 28.57 & - & $98.9 \%$ & 452.87 \\
\hline ISONE & ROS & Operating & 2.28 & - & 500.00 & 28.57 & - & $98.9 \%$ & 260.39 \\
\hline NYISO & East & Non-Spinning & 4.22 & 0.20 & 196.17 & 6.89 & 3.38 & $0.0 \%$ & $\# \mathrm{~N} / \mathrm{A}$ \\
\hline NYISO & West & Non-Spinning & 1.04 & - & 26.64 & 1.45 & 0.50 & $1.5 \%$ & $\# \mathrm{~N} / \mathrm{A}$ \\
\hline NYISO & East & Reserve_30 & 0.48 & - & 19.64 & 0.51 & 0.40 & $1.8 \%$ & $\# N / A$ \\
\hline NYISO & West & Reserve_30 & 0.48 & - & 19.64 & 0.51 & 0.40 & $1.8 \%$ & $\# \mathrm{~N} / \mathrm{A}$ \\
\hline PJM & PJM & Primary & 0.02 & - & 9.40 & 0.25 & - & $99.2 \%$ & $3,593.18$ \\
\hline SPP & RZ 1 & Supplemental & $\# N / A$ & $\# N / A$ & $\# N / A$ & $\# N / A$ & $\# N / A$ & $\# N / A$ & $\# \mathrm{~N} / \mathrm{A}$ \\
\hline SPP & $\mathrm{RZ} 2$ & Supplemental & $\# N / A$ & $\# N / A$ & $\# N / A$ & $\# N / A$ & $\# N / A$ & $\# \mathrm{~N} / \mathrm{A}$ & $\# \mathrm{~N} / \mathrm{A}$ \\
\hline SPP & RZ 3 & Supplemental & $\# N / A$ & $\# N / A$ & $\# N / A$ & $\# N / A$ & $\# N / A$ & $\# \mathrm{~N} / \mathrm{A}$ & $\# \mathrm{~N} / \mathrm{A}$ \\
\hline SPP & RZ 4 & Supplemental & $\# N / A$ & $\# N / A$ & $\# N / A$ & $\# N / A$ & $\# N / A$ & $\# N / A$ & $\# N / A$ \\
\hline
\end{tabular}




\begin{tabular}{|c|c|c|c|c|c|c|c|c|c|}
\hline \multicolumn{10}{|c|}{2012 Summary Data } \\
\hline \multicolumn{2}{|l|}{ ISO/RTO } & Product & $\begin{array}{l}\text { Mean Price } \\
\text { (\$/MW-h) }\end{array}$ & $\begin{array}{l}\text { Min Price } \\
\text { (\$/MW-h) }\end{array}$ & $\begin{array}{l}\text { Max Price } \\
\text { (\$/MW-h) }\end{array}$ & $\begin{array}{c}\text { St. Dev } \\
\text { (\$/MW-h) }\end{array}$ & $\begin{array}{c}\text { Median } \\
\text { Price } \\
\text { (\$/MW-h) } \\
\end{array}$ & $\begin{array}{c}\% \text { Hours } \\
\text { With \$0 } \\
\text { Price } \\
\end{array}$ & $\begin{array}{c}\text { Average } \\
\text { Market } \\
\text { Volume (MW) } \\
\end{array}$ \\
\hline \multicolumn{10}{|l|}{ Regulation } \\
\hline CAISO & Expanded & Regulation-Up & 5.65 & - & 129.74 & 6.35 & 3.66 & $0.0 \%$ & 333.52 \\
\hline CAISO & Expanded & Regulation-Down & 4.39 & - & 25.61 & 2.13 & 3.87 & $0.1 \%$ & 351.35 \\
\hline ERCOT & ERCOT & Regulation-Up & 8.94 & 0.01 & $1,456.49$ & 37.44 & 4.96 & $0.0 \%$ & $\# N / A$ \\
\hline ERCOT & ERCOT & Regulation-Down & 4.23 & 0.01 & 150.00 & 3.23 & 4.00 & $0.0 \%$ & $\# N / A$ \\
\hline MISO & MISO & Regulation & 7.79 & 1.27 & 145.02 & 4.97 & 6.65 & $0.0 \%$ & 397.93 \\
\hline NYSIO & NYISO & Regulation & 10.41 & 4.00 & 96.19 & 6.75 & 9.00 & $0.0 \%$ & $\# \mathrm{~N} / \mathrm{A}$ \\
\hline PJM & PJM & Regulation & 35.58 & 0.83 & 386.91 & 31.34 & 26.62 & $0.0 \%$ & 686.30 \\
\hline SPP & RZ 1 & Regulation-Up & $\# N / A$ & \#N/A & $\# \mathrm{~N} / \mathrm{A}$ & $\# N / A$ & $\# \mathrm{~N} / \mathrm{A}$ & $\# \mathrm{~N} / \mathrm{A}$ & $\# N / A$ \\
\hline SPP & $\mathrm{RZ} 2$ & Regulation-Up & $\# N / A$ & $\# N / A$ & $\# N / A$ & $\# N / A$ & $\# \mathrm{~N} / \mathrm{A}$ & $\# N / A$ & $\# N / A$ \\
\hline SPP & RZ 3 & Regulation-Up & $\# N / A$ & $\# N / A$ & $\# \mathrm{~N} / \mathrm{A}$ & $\# N / A$ & $\# \mathrm{~N} / \mathrm{A}$ & $\# \mathrm{~N} / \mathrm{A}$ & $\# N / A$ \\
\hline SPP & RZ 4 & Regulation-Up & $\# N / A$ & $\# N / A$ & $\# \mathrm{~N} / \mathrm{A}$ & $\# N / A$ & $\# N / A$ & $\# \mathrm{~N} / \mathrm{A}$ & $\# \mathrm{~N} / \mathrm{A}$ \\
\hline SPP & RZ 1 & Regulation-Down & $\# \mathrm{~N} / \mathrm{A}$ & \#N/A & $\# \mathrm{~N} / \mathrm{A}$ & $\# N / A$ & $\# N / A$ & $\# \mathrm{~N} / \mathrm{A}$ & $\# \mathrm{~N} / \mathrm{A}$ \\
\hline SPP & $\mathrm{RZ} 2$ & Regulation-Down & $\# N / A$ & \#N/A & $\# N / A$ & $\# N / A$ & $\# N / A$ & $\# \mathrm{~N} / \mathrm{A}$ & $\# N / A$ \\
\hline SPP & RZ 3 & Regulation-Down & $\# N / A$ & $\# N / A$ & $\# \mathrm{~N} / \mathrm{A}$ & $\# N / A$ & $\# \mathrm{~N} / \mathrm{A}$ & $\# N / A$ & $\# N / A$ \\
\hline SPP & RZ 4 & Regulation-Down & $\# N / A$ & $\# N / A$ & $\# \mathrm{~N} / \mathrm{A}$ & $\# N / A$ & $\# N / A$ & $\# \mathrm{~N} / \mathrm{A}$ & $\# N / A$ \\
\hline \multicolumn{10}{|l|}{ Spinning } \\
\hline CAISO & Expanded & Spinning & 3.27 & - & 129.73 & 6.14 & 1.00 & $0.0 \%$ & 893.30 \\
\hline ERCOT & ERCOT & Spinning & 9.76 & 0.45 & $1,461.06$ & 37.81 & 5.24 & $0.0 \%$ & $\# N / A$ \\
\hline MISO & MISO & Spinning & 2.26 & 0.32 & 131.87 & 3.70 & 1.05 & $0.0 \%$ & 982.84 \\
\hline ISONE & CT & Spinning & 1.74 & - & 608.06 & 15.86 & - & $96.0 \%$ & 31.10 \\
\hline ISONE & NEMABSTN & Spinning & 1.71 & - & 608.06 & 15.72 & - & $96.0 \%$ & 132.53 \\
\hline ISONE & SWCT & Spinning & 1.76 & - & 608.06 & 15.99 & - & $96.0 \%$ & 31.38 \\
\hline ISONE & ROS & Spinning & 1.66 & - & 608.06 & 15.46 & - & $96.0 \%$ & 790.00 \\
\hline NYISO & East & Spinning & $\# N / A$ & $\# N / A$ & $\# \mathrm{~N} / \mathrm{A}$ & $\# N / A$ & $\# \mathrm{~N} / \mathrm{A}$ & $\# N / A$ & $\# N / A$ \\
\hline NYISO & West & Spinning & 3.07 & - & 50.00 & 3.40 & 1.84 & $0.0 \%$ & $\# \mathrm{~N} / \mathrm{A}$ \\
\hline PJM & PJM & Synchronized & 0.09 & - & 29.16 & 1.16 & - & $97.9 \%$ & $3,613.26$ \\
\hline SPP & RZ 1 & Spinning & $\# N / A$ & \#N/A & $\# N / A$ & $\# N / A$ & $\# N / A$ & $\# \mathrm{~N} / \mathrm{A}$ & $\# N / A$ \\
\hline SPP & $\mathrm{RZ} 2$ & Spinning & $\# N / A$ & $\# N / A$ & $\# \mathrm{~N} / \mathrm{A}$ & $\# N / A$ & $\# N / A$ & $\# \mathrm{~N} / \mathrm{A}$ & $\# \mathrm{~N} / \mathrm{A}$ \\
\hline SPP & RZ3 & Spinning & $\# N / A$ & $\# N / A$ & $\# \mathrm{~N} / \mathrm{A}$ & $\# N / A$ & $\# N / A$ & $\# \mathrm{~N} / \mathrm{A}$ & $\# \mathrm{~N} / \mathrm{A}$ \\
\hline SPP & RZ 4 & Spinning & $\# N / A$ & \#N/A & $\# N / A$ & $\# N / A$ & $\# N / A$ & $\# \mathrm{~N} / \mathrm{A}$ & $\# N / A$ \\
\hline \multicolumn{10}{|l|}{ Non-spinning } \\
\hline CAISO & Expanded & Non-Spinning & 0.94 & - & 129.73 & 5.26 & 0.10 & $0.0 \%$ & 863.22 \\
\hline ERCOT & ERCOT & Non-Spinning & 3.67 & 0.01 & $1,310.54$ & 20.73 & 1.00 & $0.0 \%$ & $\# \mathrm{~N} / \mathrm{A}$ \\
\hline MISO & MISO & Supplemental & 1.39 & 0.32 & 131.87 & 3.49 & 0.70 & $0.0 \%$ & $1,059.58$ \\
\hline ISONE & CT & Non-Spinning & 1.06 & - & 558.06 & 14.41 & - & $99.1 \%$ & 349.36 \\
\hline ISONE & NEMABSTN & Non-Spinning & 1.03 & - & 558.06 & 14.24 & - & $99.1 \%$ & 17.44 \\
\hline ISONE & SWCT & Non-Spinning & 1.08 & - & 558.06 & 14.56 & - & $99.1 \%$ & 342.68 \\
\hline ISONE & ROS & Non-Spinning & 0.98 & - & 558.06 & 13.96 & - & $99.2 \%$ & $1,353.94$ \\
\hline ISONE & $\mathrm{CT}$ & Operating & 1.06 & - & 500.00 & 14.37 & - & $99.1 \%$ & 80.45 \\
\hline ISONE & NEMABSTN & Operating & 1.03 & - & 500.00 & 14.20 & - & $99.2 \%$ & 86.62 \\
\hline ISONE & SWCT & Operating & 1.08 & - & 500.00 & 14.51 & - & $99.1 \%$ & 580.13 \\
\hline ISONE & ROS & Operating & 0.98 & - & 500.00 & 13.92 & - & $99.2 \%$ & 221.57 \\
\hline NYISO & East & Non-Spinning & 3.81 & 0.01 & 212.91 & 7.01 & 3.33 & $0.0 \%$ & $\# \mathrm{~N} / \mathrm{A}$ \\
\hline NYISO & West & Non-Spinning & 1.05 & - & 50.00 & 1.95 & 0.26 & $0.1 \%$ & $\# \mathrm{~N} / \mathrm{A}$ \\
\hline NYISO & East & Reserve_30 & 0.31 & - & 50.00 & 0.88 & 0.20 & $0.4 \%$ & $\# N / A$ \\
\hline NYISO & West & Reserve_30 & 0.31 & - & 50.00 & 0.88 & 0.20 & $0.4 \%$ & $\# \mathrm{~N} / \mathrm{A}$ \\
\hline PJM & PJM & Primary & 0.02 & - & 19.85 & 0.58 & - & $99.9 \%$ & $3,985.42$ \\
\hline SPP & RZ 1 & Supplemental & $\# N / A$ & \#N/A & $\# \mathrm{~N} / \mathrm{A}$ & $\# N / A$ & $\# N / A$ & $\# N / A$ & $\# \mathrm{~N} / \mathrm{A}$ \\
\hline SPP & $\mathrm{RZ} 2$ & Supplemental & $\# N / A$ & \#N/A & $\# N / A$ & $\# N / A$ & $\# N / A$ & $\# \mathrm{~N} / \mathrm{A}$ & $\# \mathrm{~N} / \mathrm{A}$ \\
\hline SPP & RZ 3 & Supplemental & $\# N / A$ & \#N/A & $\# N / A$ & $\# N / A$ & $\# N / A$ & $\# \mathrm{~N} / \mathrm{A}$ & $\# \mathrm{~N} / \mathrm{A}$ \\
\hline SPP & RZ 4 & Supplemental & $\# N / A$ & $\# N / A$ & $\# N / A$ & $\# N / A$ & $\# N / A$ & $\# N / A$ & $\# N / A$ \\
\hline
\end{tabular}




\begin{tabular}{|c|c|c|c|c|c|c|c|c|c|}
\hline \multicolumn{10}{|c|}{2011 Summary Data } \\
\hline \multicolumn{2}{|l|}{ ISO/RTO } & Product & $\begin{array}{l}\text { Mean Price } \\
(\$ / M W-h)\end{array}$ & $\begin{array}{l}\text { Min Price } \\
\text { (\$/MW-h) }\end{array}$ & $\begin{array}{l}\text { Max Price } \\
\text { (\$/MW-h) }\end{array}$ & $\begin{array}{c}\text { St. Dev } \\
\text { (\$/MW-h) }\end{array}$ & $\begin{array}{c}\text { Median } \\
\text { Price } \\
\text { (\$/MW-h) } \\
\end{array}$ & $\begin{array}{c}\text { \% Hours } \\
\text { With \$0 } \\
\text { Price } \\
\end{array}$ & $\begin{array}{c}\text { Average } \\
\text { Market } \\
\text { Volume (MW) } \\
\end{array}$ \\
\hline \multicolumn{10}{|l|}{ Regulation } \\
\hline CAISO & Expanded & Regulation-Up & 9.21 & - & 90.81 & 8.48 & 6.86 & $0.0 \%$ & 355.04 \\
\hline CAISO & Expanded & Regulation-Down & 6.93 & - & 79.55 & 5.68 & 5.29 & $0.1 \%$ & 346.50 \\
\hline ERCOT & ERCOT & Regulation-Up & 22.67 & 0.47 & $2,584.94$ & 125.62 & 8.02 & $0.0 \%$ & $\# \mathrm{~N} / \mathrm{A}$ \\
\hline ERCOT & ERCOT & Regulation-Down & 8.58 & 0.14 & 593.00 & 12.26 & 7.00 & $0.0 \%$ & $\# N / A$ \\
\hline MISO & MISO & Regulation & 11.16 & 3.24 & 101.64 & 5.85 & 9.47 & $0.0 \%$ & 395.97 \\
\hline NYSIO & NYISO & Regulation & 11.80 & 4.47 & 95.09 & 7.66 & 9.13 & $0.0 \%$ & $\# \mathrm{~N} / \mathrm{A}$ \\
\hline PJM & PJM & Regulation & $\# N / A$ & $\# N / A$ & $\# \mathrm{~N} / \mathrm{A}$ & $\# N / A$ & $\# \mathrm{~N} / \mathrm{A}$ & $\# N / A$ & $\# \mathrm{~N} / \mathrm{A}$ \\
\hline SPP & RZ 1 & Regulation-Up & $\# N / A$ & $\# N / A$ & $\# \mathrm{~N} / \mathrm{A}$ & $\# N / A$ & $\# \mathrm{~N} / \mathrm{A}$ & $\# N / A$ & $\# N / A$ \\
\hline SPP & RZ 2 & Regulation-Up & $\# N / A$ & $\# N / A$ & $\# N / A$ & $\# N / A$ & $\# N / A$ & $\# N / A$ & $\# \mathrm{~N} / \mathrm{A}$ \\
\hline SPP & RZ 3 & Regulation-Up & $\# N / A$ & $\# N / A$ & $\# \mathrm{~N} / \mathrm{A}$ & $\# N / A$ & $\# \mathrm{~N} / \mathrm{A}$ & $\# N / A$ & $\# N / A$ \\
\hline SPP & RZ 4 & Regulation-Up & $\# N / A$ & $\# N / A$ & $\# N / A$ & $\# N / A$ & $\# \mathrm{~N} / \mathrm{A}$ & $\# N / A$ & $\# \mathrm{~N} / \mathrm{A}$ \\
\hline SPP & RZ 1 & Regulation-Down & $\# N / A$ & $\# N / A$ & $\# \mathrm{~N} / \mathrm{A}$ & $\# N / A$ & $\# N / A$ & $\# N / A$ & $\# \mathrm{~N} / \mathrm{A}$ \\
\hline SPP & RZ 2 & Regulation-Down & $\# N / A$ & $\# N / A$ & $\# N / A$ & $\# N / A$ & $\# \mathrm{~N} / \mathrm{A}$ & $\# N / A$ & $\# N / A$ \\
\hline SPP & RZ3 & Regulation-Down & $\# N / A$ & $\# \mathrm{~N} / \mathrm{A}$ & $\# N / A$ & $\# N / A$ & $\# \mathrm{~N} / \mathrm{A}$ & $\# N / A$ & $\# N / A$ \\
\hline SPP & RZ 4 & Regulation-Down & $\# N / A$ & $\# N / A$ & $\# \mathrm{~N} / \mathrm{A}$ & $\# N / A$ & $\# N / A$ & $\# N / A$ & $\# \mathrm{~N} / \mathrm{A}$ \\
\hline \multicolumn{10}{|l|}{ Spinning } \\
\hline CAISO & Expanded & Spinning & 7.22 & - & 47.96 & 7.20 & 5.00 & $0.0 \%$ & 849.90 \\
\hline ERCOT & ERCOT & Spinning & 22.92 & 0.67 & $2,605.75$ & 127.27 & 8.05 & $0.0 \%$ & $\# N / A$ \\
\hline MISO & MISO & Spinning & 2.84 & 0.50 & 28.85 & 2.89 & 1.46 & $0.0 \%$ & 986.33 \\
\hline ISONE & CT & Spinning & 1.10 & - & 578.00 & 10.93 & - & $95.7 \%$ & 9.32 \\
\hline ISONE & NEMABSTN & Spinning & 1.08 & - & 578.00 & 10.87 & - & $95.7 \%$ & 96.44 \\
\hline ISONE & SWCT & Spinning & 1.10 & - & 578.00 & 10.93 & - & $95.7 \%$ & 34.43 \\
\hline ISONE & ROS & Spinning & 1.04 & - & 578.00 & 10.57 & - & $95.8 \%$ & 816.26 \\
\hline NYISO & East & Spinning & $\# N / A$ & $\# N / A$ & $\# \mathrm{~N} / \mathrm{A}$ & $\# N / A$ & $\# N / A$ & $\# N / A$ & $\# \mathrm{~N} / \mathrm{A}$ \\
\hline NYISO & West & Spinning & 3.37 & - & 44.72 & 3.48 & 2.00 & $0.2 \%$ & $\# \mathrm{~N} / \mathrm{A}$ \\
\hline PJM & PJM & Synchronized & $\# N / A$ & $\# N / A$ & $\# \mathrm{~N} / \mathrm{A}$ & $\# N / A$ & $\# N / A$ & $\# N / A$ & $\# \mathrm{~N} / \mathrm{A}$ \\
\hline SPP & RZ 1 & Spinning & $\# N / A$ & $\# N / A$ & $\# N / A$ & $\# N / A$ & $\# \mathrm{~N} / \mathrm{A}$ & $\# N / A$ & $\# N / A$ \\
\hline SPP & RZ 2 & Spinning & $\# N / A$ & $\# \mathrm{~N} / \mathrm{A}$ & $\# N / A$ & $\# N / A$ & $\# \mathrm{~N} / \mathrm{A}$ & $\# N / A$ & $\# \mathrm{~N} / \mathrm{A}$ \\
\hline SPP & RZ3 3 & Spinning & $\# N / A$ & $\# N / A$ & $\# \mathrm{~N} / \mathrm{A}$ & $\# N / A$ & $\# N / A$ & $\# N / A$ & $\# \mathrm{~N} / \mathrm{A}$ \\
\hline SPP & RZ 4 & Spinning & $\# N / A$ & $\# N / A$ & $\# \mathrm{~N} / \mathrm{A}$ & $\# N / A$ & $\# N / A$ & $\# N / A$ & $\# N / A$ \\
\hline \multicolumn{10}{|l|}{ Non-spinning } \\
\hline CAISO & Expanded & Non-Spinning & 0.98 & - & 35.01 & 2.48 & 0.46 & $0.0 \%$ & 852.63 \\
\hline ERCOT & ERCOT & Non-Spinning & 11.77 & 0.01 & $1,500.00$ & 62.22 & 3.08 & $0.0 \%$ & $\# \mathrm{~N} / \mathrm{A}$ \\
\hline MISO & MISO & Supplemental & 1.22 & 0.45 & 27.27 & 1.24 & 0.90 & $0.0 \%$ & $1,055.98$ \\
\hline ISONE & CT & Non-Spinning & 0.45 & - & 578.00 & 9.69 & - & $99.6 \%$ & 246.05 \\
\hline ISONE & NEMABSTN & Non-Spinning & 0.42 & - & 578.00 & 9.61 & - & $99.6 \%$ & 27.00 \\
\hline ISONE & SWCT & Non-Spinning & 0.45 & - & 578.00 & 9.69 & - & $99.6 \%$ & 305.30 \\
\hline ISONE & ROS & Non-Spinning & 0.39 & - & 578.00 & 9.28 & - & $99.6 \%$ & $1,304.09$ \\
\hline ISONE & $\mathrm{CT}$ & Operating & 0.31 & - & 274.93 & 5.63 & - & $99.6 \%$ & 110.84 \\
\hline ISONE & NEMABSTN & Operating & 0.28 & - & 274.93 & 5.49 & - & $99.6 \%$ & 71.78 \\
\hline ISONE & SWCT & Operating & 0.31 & - & 274.93 & 5.63 & - & $99.6 \%$ & 569.94 \\
\hline ISONE & ROS & Operating & 0.25 & - & 274.93 & 4.89 & - & $99.7 \%$ & 261.17 \\
\hline NYISO & East & Non-Spinning & 3.89 & 0.07 & 74.81 & 2.95 & 3.38 & $0.0 \%$ & $\# \mathrm{~N} / \mathrm{A}$ \\
\hline NYISO & West & Non-Spinning & 0.10 & - & 6.00 & 0.23 & 0.03 & $0.9 \%$ & $\# N / A$ \\
\hline NYISO & East & Reserve_30 & 0.10 & - & 6.00 & 0.23 & 0.03 & $0.9 \%$ & $\# N / A$ \\
\hline NYISO & West & Reserve_30 & 0.10 & - & 6.00 & 0.23 & 0.03 & $0.9 \%$ & $\# \mathrm{~N} / \mathrm{A}$ \\
\hline PJM & PJM & Primary & $\# N / A$ & $\# N / A$ & $\# N / A$ & $\# N / A$ & $\# N / A$ & $\# N / A$ & $\# N / A$ \\
\hline SPP & RZ 1 & Supplemental & $\# N / A$ & $\# N / A$ & $\# N / A$ & $\# N / A$ & $\# N / A$ & $\# N / A$ & $\# N / A$ \\
\hline SPP & $\mathrm{RZ} 2$ & Supplemental & $\# N / A$ & $\# N / A$ & $\# \mathrm{~N} / \mathrm{A}$ & $\# N / A$ & $\# \mathrm{~N} / \mathrm{A}$ & $\# N / A$ & $\# \mathrm{~N} / \mathrm{A}$ \\
\hline SPP & RZ3 & Supplemental & $\# N / A$ & $\# N / A$ & $\# \mathrm{~N} / \mathrm{A}$ & $\# N / A$ & $\# N / A$ & $\# N / A$ & $\# \mathrm{~N} / \mathrm{A}$ \\
\hline SPP & RZ 4 & Supplemental & $\# N / A$ & $\# N / A$ & $\# N / A$ & $\# N / A$ & $\# N / A$ & $\# N / A$ & $\# N / A$ \\
\hline
\end{tabular}




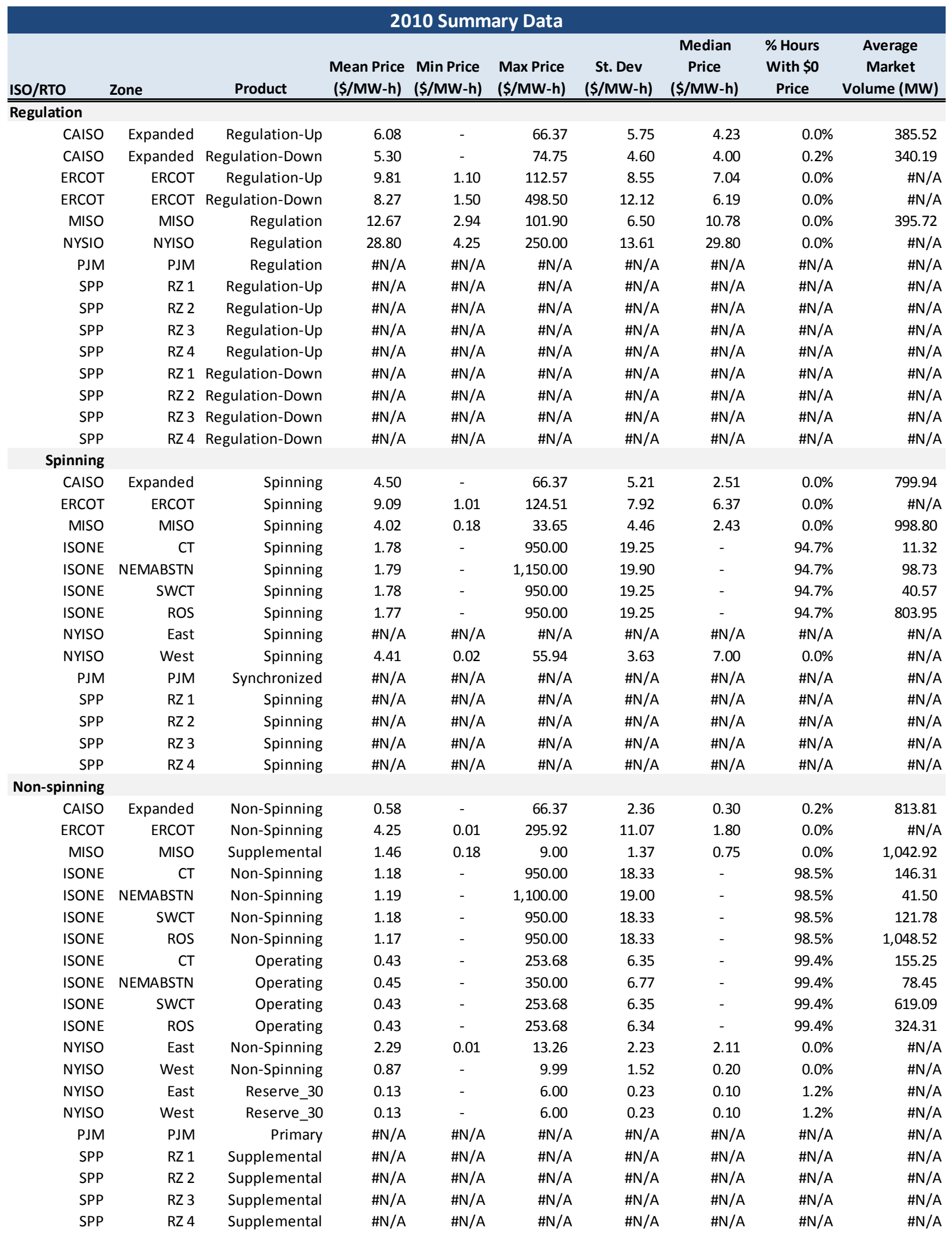




\begin{tabular}{|c|c|c|c|c|c|c|c|c|c|}
\hline \multicolumn{10}{|c|}{2009 Summary Data } \\
\hline \multicolumn{2}{|l|}{ ISO/RTO } & Product & $\begin{array}{l}\text { Mean Price } \\
\text { (\$/MW-h) }\end{array}$ & $\begin{array}{l}\text { Min Price } \\
\text { (\$/MW-h) }\end{array}$ & $\begin{array}{l}\text { Max Price } \\
\text { (\$/MW-h) }\end{array}$ & $\begin{array}{c}\text { St. Dev } \\
\text { (\$/MW-h) }\end{array}$ & $\begin{array}{c}\text { Median } \\
\text { Price } \\
\text { (\$/MW-h) } \\
\end{array}$ & $\begin{array}{c}\% \text { Hours } \\
\text { With \$0 } \\
\text { Price } \\
\end{array}$ & $\begin{array}{c}\text { Average } \\
\text { Market } \\
\text { Volume (MW) }\end{array}$ \\
\hline \multicolumn{10}{|l|}{ Regulation } \\
\hline CAISO & Expanded & Regulation-Up & 5.32 & 0.60 & 416.94 & 7.81 & 4.23 & $0.0 \%$ & 385.81 \\
\hline CAISO & Expanded & Regulation-Down & 5.02 & - & 64.80 & 4.44 & 3.81 & $0.7 \%$ & 378.17 \\
\hline ERCOT & ERCOT & Regulation-Up & 9.70 & 1.14 & 300.01 & 12.34 & 6.03 & $0.0 \%$ & $\# N / A$ \\
\hline ERCOT & ERCOT & Regulation-Down & 7.25 & 1.21 & 500.00 & 10.26 & 5.01 & $0.0 \%$ & $\# N / A$ \\
\hline MISO & MISO & Regulation & $\# N / A$ & $\# \mathrm{~N} / \mathrm{A}$ & $\# \mathrm{~N} / \mathrm{A}$ & $\# N / A$ & $\# \mathrm{~N} / \mathrm{A}$ & $\# \mathrm{~N} / \mathrm{A}$ & $\# N / A$ \\
\hline NYSIO & NYISO & Regulation & 37.20 & 9.29 & 250.00 & 16.14 & 32.00 & $0.0 \%$ & $\# N / A$ \\
\hline PJM & PJM & Regulation & $\# N / A$ & $\# N / A$ & $\# \mathrm{~N} / \mathrm{A}$ & $\# N / A$ & $\# \mathrm{~N} / \mathrm{A}$ & $\# \mathrm{~N} / \mathrm{A}$ & $\# N / A$ \\
\hline SPP & RZ 1 & Regulation-Up & $\# N / A$ & $\# N / A$ & $\# \mathrm{~N} / \mathrm{A}$ & $\# N / A$ & $\# \mathrm{~N} / \mathrm{A}$ & $\# \mathrm{~N} / \mathrm{A}$ & $\# N / A$ \\
\hline SPP & $\mathrm{RZ} 2$ & Regulation-Up & $\# N / A$ & $\# N / A$ & $\# N / A$ & $\# N / A$ & $\# \mathrm{~N} / \mathrm{A}$ & $\# N / A$ & $\# N / A$ \\
\hline SPP & RZ 3 & Regulation-Up & $\# N / A$ & $\# N / A$ & $\# \mathrm{~N} / \mathrm{A}$ & $\# N / A$ & $\# \mathrm{~N} / \mathrm{A}$ & $\# \mathrm{~N} / \mathrm{A}$ & $\# \mathrm{~N} / \mathrm{A}$ \\
\hline SPP & RZ 4 & Regulation-Up & $\# N / A$ & $\# N / A$ & $\# \mathrm{~N} / \mathrm{A}$ & $\# N / A$ & $\# N / A$ & $\# \mathrm{~N} / \mathrm{A}$ & $\# N / A$ \\
\hline SPP & RZ 1 & Regulation-Down & $\# \mathrm{~N} / \mathrm{A}$ & $\# N / A$ & $\# \mathrm{~N} / \mathrm{A}$ & $\# N / A$ & $\# N / A$ & $\# \mathrm{~N} / \mathrm{A}$ & $\# N / A$ \\
\hline SPP & $\mathrm{RZ} 2$ & Regulation-Down & $\# N / A$ & $\# N / A$ & $\# N / A$ & $\# N / A$ & $\# N / A$ & $\# \mathrm{~N} / \mathrm{A}$ & $\# N / A$ \\
\hline SPP & RZ 3 & Regulation-Down & $\# N / A$ & $\# N / A$ & $\# \mathrm{~N} / \mathrm{A}$ & $\# \mathrm{~N} / \mathrm{A}$ & $\# \mathrm{~N} / \mathrm{A}$ & $\# N / A$ & $\# \mathrm{~N} / \mathrm{A}$ \\
\hline SPP & RZ 4 & Regulation-Down & $\# N / A$ & $\# N / A$ & $\# \mathrm{~N} / \mathrm{A}$ & $\# N / A$ & $\# N / A$ & $\# \mathrm{~N} / \mathrm{A}$ & $\# \mathrm{~N} / \mathrm{A}$ \\
\hline \multicolumn{10}{|l|}{ Spinning } \\
\hline CAISO & Expanded & Spinning & 3.73 & 0.59 & 416.37 & 7.72 & 1.79 & $0.0 \%$ & 834.76 \\
\hline ERCOT & ERCOT & Spinning & 9.96 & 0.01 & 185.11 & 10.77 & 6.40 & $0.0 \%$ & $\# N / A$ \\
\hline MISO & MISO & Spinning & $\# N / A$ & $\# \mathrm{~N} / \mathrm{A}$ & $\# \mathrm{~N} / \mathrm{A}$ & $\# \mathrm{~N} / \mathrm{A}$ & $\# \mathrm{~N} / \mathrm{A}$ & $\# \mathrm{~N} / \mathrm{A}$ & $\# \mathrm{~N} / \mathrm{A}$ \\
\hline ISONE & CT & Spinning & 0.72 & - & 279.70 & 8.46 & - & $97.5 \%$ & 3.48 \\
\hline ISONE & NEMABSTN & Spinning & 0.76 & - & 279.70 & 8.51 & - & $97.4 \%$ & 94.34 \\
\hline ISONE & SWCT & Spinning & 0.72 & - & 279.70 & 8.46 & - & $97.5 \%$ & 63.08 \\
\hline ISONE & ROS & Spinning & 0.72 & - & 279.70 & 8.45 & - & $97.5 \%$ & 763.73 \\
\hline NYISO & East & Spinning & $\# N / A$ & $\# N / A$ & $\# \mathrm{~N} / \mathrm{A}$ & $\# N / A$ & $\# N / A$ & $\# N / A$ & \#N/A \\
\hline NYISO & West & Spinning & 4.15 & 0.07 & 24.77 & 3.23 & 5.00 & $0.0 \%$ & $\# N / A$ \\
\hline PJM & PJM & Synchronized & $\# N / A$ & $\# N / A$ & $\# N / A$ & $\# N / A$ & $\# N / A$ & $\# \mathrm{~N} / \mathrm{A}$ & $\# N / A$ \\
\hline SPP & RZ 1 & Spinning & $\# N / A$ & $\# N / A$ & $\# N / A$ & $\# N / A$ & $\# N / A$ & $\# \mathrm{~N} / \mathrm{A}$ & \#N/A \\
\hline SPP & $\mathrm{RZ} 2$ & Spinning & $\# N / A$ & $\# \mathrm{~N} / \mathrm{A}$ & $\# \mathrm{~N} / \mathrm{A}$ & $\# N / A$ & $\# N / A$ & $\# \mathrm{~N} / \mathrm{A}$ & $\# N / A$ \\
\hline SPP & RZ3 & Spinning & $\# N / A$ & $\# \mathrm{~N} / \mathrm{A}$ & $\# \mathrm{~N} / \mathrm{A}$ & $\# N / A$ & $\# N / A$ & $\# \mathrm{~N} / \mathrm{A}$ & $\# \mathrm{~N} / \mathrm{A}$ \\
\hline SPP & RZ 4 & Spinning & $\# N / A$ & $\# N / A$ & $\# N / A$ & $\# N / A$ & $\# N / A$ & $\# \mathrm{~N} / \mathrm{A}$ & \#N/A \\
\hline \multicolumn{10}{|l|}{ Non-spinning } \\
\hline CAISO & Expanded & Non-Spinning & 1.44 & - & 416.33 & 7.20 & 0.75 & $0.2 \%$ & 832.61 \\
\hline ERCOT & ERCOT & Non-Spinning & 2.31 & - & 175.00 & 6.99 & 0.83 & $7.0 \%$ & $\# \mathrm{~N} / \mathrm{A}$ \\
\hline MISO & MISO & Supplemental & $\# N / A$ & $\# N / A$ & $\# \mathrm{~N} / \mathrm{A}$ & $\# N / A$ & $\# N / A$ & $\# N / A$ & $\# N / A$ \\
\hline ISONE & CT & Non-Spinning & 0.48 & - & 279.70 & 7.83 & - & $99.2 \%$ & 133.55 \\
\hline ISONE & NEMABSTN & Non-Spinning & 0.51 & - & 279.70 & 7.88 & - & $99.0 \%$ & 94.66 \\
\hline ISONE & SWCT & Non-Spinning & 0.48 & - & 279.70 & 7.83 & - & $99.2 \%$ & 19.55 \\
\hline ISONE & ROS & Non-Spinning & 0.48 & - & 279.70 & 7.82 & - & $99.2 \%$ & $1,453.14$ \\
\hline ISONE & $\mathrm{CT}$ & Operating & 0.09 & - & 100.00 & 2.66 & - & $99.9 \%$ & 144.97 \\
\hline ISONE & NEMABSTN & Operating & 0.12 & - & 100.00 & 2.83 & - & $99.7 \%$ & 145.73 \\
\hline ISONE & SWCT & Operating & 0.09 & - & 100.00 & 2.66 & - & $99.9 \%$ & 671.39 \\
\hline ISONE & ROS & Operating & 0.08 & - & 100.00 & 2.65 & - & $99.9 \%$ & 296.21 \\
\hline NYISO & East & Non-Spinning & 2.46 & - & 9.95 & 1.51 & 3.33 & $0.4 \%$ & $\# \mathrm{~N} / \mathrm{A}$ \\
\hline NYISO & West & Non-Spinning & 1.66 & - & 9.32 & 1.50 & 0.82 & $0.4 \%$ & $\# N / A$ \\
\hline NYISO & East & Reserve_30 & 0.54 & - & 5.00 & 0.63 & 0.50 & $3.2 \%$ & $\# N / A$ \\
\hline NYISO & West & Reserve_30 & 0.54 & - & 5.00 & 0.63 & 0.50 & $3.2 \%$ & $\# \mathrm{~N} / \mathrm{A}$ \\
\hline PJM & PJM & Primary & $\# N / A$ & $\# N / A$ & $\# N / A$ & $\# N / A$ & $\# N / A$ & $\# N / A$ & $\# N / A$ \\
\hline SPP & RZ 1 & Supplemental & $\# N / A$ & $\# N / A$ & $\# N / A$ & $\# N / A$ & $\# N / A$ & $\# N / A$ & $\# N / A$ \\
\hline SPP & $\mathrm{RZ} 2$ & Supplemental & $\# N / A$ & $\# N / A$ & $\# N / A$ & $\# N / A$ & $\# N / A$ & $\# \mathrm{~N} / \mathrm{A}$ & $\# N / A$ \\
\hline SPP & RZ 3 & Supplemental & $\# N / A$ & $\# N / A$ & $\# N / A$ & $\# N / A$ & $\# N / A$ & $\# \mathrm{~N} / \mathrm{A}$ & $\# \mathrm{~N} / \mathrm{A}$ \\
\hline SPP & RZ 4 & Supplemental & $\# N / A$ & $\# N / A$ & $\# N / A$ & $\# N / A$ & $\# N / A$ & $\# N / A$ & $\# N / A$ \\
\hline
\end{tabular}




\begin{tabular}{|c|c|c|c|c|c|c|c|c|c|}
\hline \multicolumn{10}{|c|}{2008 Summary Data } \\
\hline \multicolumn{2}{|l|}{ ISO/RTO } & Product & $\begin{array}{l}\text { Mean Price } \\
\text { (\$/MW-h) }\end{array}$ & $\begin{array}{l}\text { Min Price } \\
\text { (\$/MW-h) }\end{array}$ & $\begin{array}{l}\text { Max Price } \\
\text { (\$/MW-h) }\end{array}$ & $\begin{array}{c}\text { St. Dev } \\
\text { (\$/MW-h) }\end{array}$ & $\begin{array}{c}\text { Median } \\
\text { Price } \\
\text { (\$/MW-h) } \\
\end{array}$ & $\begin{array}{c}\% \text { Hours } \\
\text { With \$0 } \\
\text { Price } \\
\end{array}$ & $\begin{array}{c}\text { Average } \\
\text { Market } \\
\text { Volume (MW) } \\
\end{array}$ \\
\hline \multicolumn{10}{|l|}{ Regulation } \\
\hline CAISO & Expanded & Regulation-Up & $\# N / A$ & $\# N / A$ & $\# \mathrm{~N} / \mathrm{A}$ & $\# N / A$ & $\# \mathrm{~N} / \mathrm{A}$ & $\# \mathrm{~N} / \mathrm{A}$ & $\# N / A$ \\
\hline CAISO & Expanded & Regulation-Down & $\# N / A$ & $\# N / A$ & $\# \mathrm{~N} / \mathrm{A}$ & $\# N / A$ & $\# N / A$ & $\# \mathrm{~N} / \mathrm{A}$ & \#N/A \\
\hline ERCOT & ERCOT & Regulation-Up & 22.71 & 1.66 & 500.03 & 24.64 & 15.30 & $0.0 \%$ & $\# N / A$ \\
\hline ERCOT & ERCOT & Regulation-Down & 19.52 & 0.78 & 500.00 & 15.05 & 16.80 & $0.0 \%$ & \#N/A \\
\hline MISO & MISO & Regulation & $\# N / A$ & $\# N / A$ & $\# \mathrm{~N} / \mathrm{A}$ & $\# N / A$ & $\# \mathrm{~N} / \mathrm{A}$ & $\# \mathrm{~N} / \mathrm{A}$ & $\# \mathrm{~N} / \mathrm{A}$ \\
\hline NYSIO & NYISO & Regulation & 59.45 & 24.11 & 300.00 & 25.66 & 50.00 & $0.0 \%$ & $\# N / A$ \\
\hline PJM & PJM & Regulation & $\# N / A$ & $\# N / A$ & $\# \mathrm{~N} / \mathrm{A}$ & $\# N / A$ & $\# \mathrm{~N} / \mathrm{A}$ & $\# \mathrm{~N} / \mathrm{A}$ & $\# N / A$ \\
\hline SPP & RZ 1 & Regulation-Up & $\# N / A$ & $\# N / A$ & $\# \mathrm{~N} / \mathrm{A}$ & $\# N / A$ & $\# \mathrm{~N} / \mathrm{A}$ & $\# \mathrm{~N} / \mathrm{A}$ & \#N/A \\
\hline SPP & $\mathrm{RZ} 2$ & Regulation-Up & $\# N / A$ & $\# N / A$ & $\# N / A$ & $\# N / A$ & $\# N / A$ & $\# N / A$ & $\# N / A$ \\
\hline SPP & RZ 3 & Regulation-Up & $\# N / A$ & $\# N / A$ & $\# \mathrm{~N} / \mathrm{A}$ & $\# N / A$ & $\# \mathrm{~N} / \mathrm{A}$ & $\# \mathrm{~N} / \mathrm{A}$ & $\# N / A$ \\
\hline SPP & RZ 4 & Regulation-Up & $\# N / A$ & $\# N / A$ & $\# \mathrm{~N} / \mathrm{A}$ & $\# N / A$ & $\# N / A$ & $\# \mathrm{~N} / \mathrm{A}$ & $\# \mathrm{~N} / \mathrm{A}$ \\
\hline SPP & RZ 1 & Regulation-Down & $\# N / A$ & $\# N / A$ & $\# \mathrm{~N} / \mathrm{A}$ & $\# N / A$ & $\# N / A$ & $\# \mathrm{~N} / \mathrm{A}$ & $\# \mathrm{~N} / \mathrm{A}$ \\
\hline SPP & $\mathrm{RZ} 2$ & Regulation-Down & $\# N / A$ & $\# N / A$ & $\# N / A$ & $\# N / A$ & $\# N / A$ & $\# \mathrm{~N} / \mathrm{A}$ & $\# N / A$ \\
\hline SPP & RZ 3 & Regulation-Down & $\# N / A$ & $\# N / A$ & $\# \mathrm{~N} / \mathrm{A}$ & $\# N / A$ & $\# \mathrm{~N} / \mathrm{A}$ & $\# N / A$ & $\# N / A$ \\
\hline SPP & RZ 4 & Regulation-Down & $\# N / A$ & $\# N / A$ & $\# \mathrm{~N} / \mathrm{A}$ & $\# N / A$ & $\# N / A$ & $\# \mathrm{~N} / \mathrm{A}$ & $\# N / A$ \\
\hline \multicolumn{10}{|l|}{ Spinning } \\
\hline CAISO & Expanded & Spinning & $\# N / A$ & $\# \mathrm{~N} / \mathrm{A}$ & $\# \mathrm{~N} / \mathrm{A}$ & $\# N / A$ & $\# N / A$ & $\# N / A$ & $\# N / A$ \\
\hline ERCOT & ERCOT & Spinning & 27.05 & 2.50 & $2,000.02$ & 38.88 & 20.00 & $0.0 \%$ & $\# \mathrm{~N} / \mathrm{A}$ \\
\hline MISO & MISO & Spinning & $\# N / A$ & $\# N / A$ & $\# N / A$ & $\# N / A$ & $\# N / A$ & $\# \mathrm{~N} / \mathrm{A}$ & $\# \mathrm{~N} / \mathrm{A}$ \\
\hline ISONE & CT & Spinning & 1.71 & - & 900.00 & 22.01 & - & $96.6 \%$ & 4.51 \\
\hline ISONE & NEMABSTN & Spinning & 1.69 & - & 900.00 & 21.96 & - & $96.6 \%$ & 113.24 \\
\hline ISONE & SWCT & Spinning & 1.73 & - & 900.00 & 22.03 & - & $96.5 \%$ & 61.69 \\
\hline ISONE & ROS & Spinning & 1.68 & - & 900.00 & 21.95 & - & $96.7 \%$ & 765.09 \\
\hline NYISO & East & Spinning & $\# N / A$ & $\# N / A$ & $\# \mathrm{~N} / \mathrm{A}$ & $\# N / A$ & $\# N / A$ & $\# N / A$ & $\# \mathrm{~N} / \mathrm{A}$ \\
\hline NYISO & West & Spinning & 6.19 & 0.20 & 60.00 & 6.16 & 7.00 & $0.0 \%$ & $\# N / A$ \\
\hline PJM & PJM & Synchronized & $\# N / A$ & $\# N / A$ & $\# N / A$ & $\# N / A$ & $\# \mathrm{~N} / \mathrm{A}$ & $\# \mathrm{~N} / \mathrm{A}$ & $\# N / A$ \\
\hline SPP & RZ 1 & Spinning & $\# N / A$ & $\# N / A$ & $\# N / A$ & $\# N / A$ & $\# N / A$ & $\# \mathrm{~N} / \mathrm{A}$ & $\# N / A$ \\
\hline SPP & $\mathrm{RZ} 2$ & Spinning & $\# N / A$ & $\# N / A$ & $\# \mathrm{~N} / \mathrm{A}$ & $\# N / A$ & $\# N / A$ & $\# \mathrm{~N} / \mathrm{A}$ & $\# N / A$ \\
\hline SPP & RZ3 & Spinning & $\# N / A$ & $\# N / A$ & $\# \mathrm{~N} / \mathrm{A}$ & $\# N / A$ & $\# N / A$ & $\# \mathrm{~N} / \mathrm{A}$ & $\# \mathrm{~N} / \mathrm{A}$ \\
\hline SPP & RZ 4 & Spinning & $\# N / A$ & $\# N / A$ & $\# N / A$ & $\# N / A$ & $\# \mathrm{~N} / \mathrm{A}$ & $\# N / A$ & $\# N / A$ \\
\hline \multicolumn{10}{|l|}{ Non-spinning } \\
\hline CAISO & Expanded & Non-Spinning & $\# N / A$ & $\# N / A$ & $\# \mathrm{~N} / \mathrm{A}$ & $\# N / A$ & $\# N / A$ & $\# \mathrm{~N} / \mathrm{A}$ & $\# N / A$ \\
\hline ERCOT & ERCOT & Non-Spinning & 4.11 & - & $2,000.00$ & 37.90 & 0.05 & $48.4 \%$ & $\# \mathrm{~N} / \mathrm{A}$ \\
\hline MISO & MISO & Supplemental & $\# N / A$ & $\# N / A$ & $\# N / A$ & $\# N / A$ & $\# N / A$ & $\# N / A$ & $\# N / A$ \\
\hline ISONE & CT & Non-Spinning & 1.25 & - & 850.00 & 21.39 & - & $98.3 \%$ & 150.00 \\
\hline ISONE & NEMABSTN & Non-Spinning & 1.22 & - & 850.00 & 21.34 & - & $98.4 \%$ & 84.01 \\
\hline ISONE & SWCT & Non-Spinning & 1.27 & - & 850.00 & 21.41 & - & $98.3 \%$ & 19.78 \\
\hline ISONE & ROS & Non-Spinning & 1.21 & - & 850.00 & 21.33 & - & $98.4 \%$ & $1,226.68$ \\
\hline ISONE & $\mathrm{CT}$ & Operating & 0.10 & - & 150.00 & 2.87 & - & $99.8 \%$ & 128.70 \\
\hline ISONE & NEMABSTN & Operating & 0.08 & - & 100.00 & 2.45 & - & $99.8 \%$ & 230.87 \\
\hline ISONE & SWCT & Operating & 0.12 & - & 150.00 & 3.03 & - & $99.8 \%$ & 570.17 \\
\hline ISONE & ROS & Operating & 0.06 & - & 100.00 & 2.36 & - & $99.9 \%$ & 426.49 \\
\hline NYISO & East & Non-Spinning & 3.07 & 0.19 & 58.80 & 1.95 & 3.34 & $0.0 \%$ & $\# \mathrm{~N} / \mathrm{A}$ \\
\hline NYISO & West & Non-Spinning & 1.72 & 0.10 & 10.00 & 1.61 & 0.50 & $0.0 \%$ & $\# N / A$ \\
\hline NYISO & East & Reserve_30 & 1.06 & - & 4.02 & 1.22 & 0.50 & $1.8 \%$ & $\# N / A$ \\
\hline NYISO & West & Reserve_30 & 1.06 & - & 4.02 & 1.22 & 0.50 & $1.8 \%$ & $\# \mathrm{~N} / \mathrm{A}$ \\
\hline PJM & PJM & Primary & $\# N / A$ & $\# N / A$ & $\# N / A$ & $\# N / A$ & $\# N / A$ & $\# N / A$ & $\# N / A$ \\
\hline SPP & RZ 1 & Supplemental & $\# N / A$ & $\# N / A$ & $\# N / A$ & $\# N / A$ & $\# N / A$ & $\# N / A$ & $\# \mathrm{~N} / \mathrm{A}$ \\
\hline SPP & $\mathrm{RZ} 2$ & Supplemental & $\# N / A$ & $\# N / A$ & $\# N / A$ & $\# N / A$ & $\# N / A$ & $\# \mathrm{~N} / \mathrm{A}$ & $\# \mathrm{~N} / \mathrm{A}$ \\
\hline SPP & RZ 3 & Supplemental & $\# N / A$ & $\# N / A$ & $\# N / A$ & $\# N / A$ & $\# N / A$ & $\# \mathrm{~N} / \mathrm{A}$ & $\# \mathrm{~N} / \mathrm{A}$ \\
\hline SPP & RZ 4 & Supplemental & $\# N / A$ & $\# N / A$ & $\# N / A$ & $\# N / A$ & $\# N / A$ & $\# N / A$ & $\# N / A$ \\
\hline
\end{tabular}




\begin{tabular}{|c|c|c|c|c|c|c|c|c|c|}
\hline \multicolumn{10}{|c|}{2007 Summary Data } \\
\hline \multicolumn{2}{|l|}{ ISO/RTO } & Product & $\begin{array}{l}\text { Mean Price } \\
\text { (\$/MW-h) }\end{array}$ & $\begin{array}{l}\text { Min Price } \\
\text { (\$/MW-h) }\end{array}$ & $\begin{array}{l}\text { Max Price } \\
\text { (\$/MW-h) }\end{array}$ & $\begin{array}{c}\text { St. Dev } \\
\text { (\$/MW-h) }\end{array}$ & $\begin{array}{c}\text { Median } \\
\text { Price } \\
\text { (\$/MW-h) } \\
\end{array}$ & $\begin{array}{c}\% \text { Hours } \\
\text { With \$0 } \\
\text { Price } \\
\end{array}$ & $\begin{array}{c}\text { Average } \\
\text { Market } \\
\text { Volume (MW) } \\
\end{array}$ \\
\hline \multicolumn{10}{|l|}{ Regulation } \\
\hline CAISO & Expanded & Regulation-Up & $\# N / A$ & $\# N / A$ & $\# \mathrm{~N} / \mathrm{A}$ & $\# N / A$ & $\# \mathrm{~N} / \mathrm{A}$ & $\# \mathrm{~N} / \mathrm{A}$ & $\# N / A$ \\
\hline CAISO & Expanded & Regulation-Down & $\# N / A$ & $\# N / A$ & $\# N / A$ & $\# N / A$ & $\# N / A$ & $\# \mathrm{~N} / \mathrm{A}$ & $\# N / A$ \\
\hline ERCOT & ERCOT & Regulation-Up & 13.14 & 0.01 & 298.00 & 12.04 & 9.89 & $0.0 \%$ & $\# \mathrm{~N} / \mathrm{A}$ \\
\hline ERCOT & ERCOT & Regulation-Down & 8.30 & 0.27 & 70.00 & 5.09 & 7.26 & $0.0 \%$ & \#N/A \\
\hline MISO & MISO & Regulation & $\# N / A$ & $\# N / A$ & $\# \mathrm{~N} / \mathrm{A}$ & $\# N / A$ & $\# N / A$ & $\# \mathrm{~N} / \mathrm{A}$ & $\# \mathrm{~N} / \mathrm{A}$ \\
\hline NYSIO & NYISO & Regulation & 56.32 & 22.29 & 300.00 & 20.51 & 50.00 & $0.0 \%$ & $\# N / A$ \\
\hline PJM & PJM & Regulation & $\# N / A$ & $\# N / A$ & $\# \mathrm{~N} / \mathrm{A}$ & $\# N / A$ & $\# \mathrm{~N} / \mathrm{A}$ & $\# \mathrm{~N} / \mathrm{A}$ & $\# N / A$ \\
\hline SPP & RZ 1 & Regulation-Up & $\# N / A$ & $\# N / A$ & $\# \mathrm{~N} / \mathrm{A}$ & $\# N / A$ & $\# \mathrm{~N} / \mathrm{A}$ & $\# \mathrm{~N} / \mathrm{A}$ & \#N/A \\
\hline SPP & $\mathrm{RZ} 2$ & Regulation-Up & $\# N / A$ & $\# N / A$ & $\# N / A$ & $\# N / A$ & $\# \mathrm{~N} / \mathrm{A}$ & $\# N / A$ & $\# N / A$ \\
\hline SPP & RZ 3 & Regulation-Up & $\# N / A$ & $\# N / A$ & $\# \mathrm{~N} / \mathrm{A}$ & $\# N / A$ & $\# \mathrm{~N} / \mathrm{A}$ & $\# \mathrm{~N} / \mathrm{A}$ & $\# N / A$ \\
\hline SPP & RZ 4 & Regulation-Up & $\# N / A$ & $\# N / A$ & $\# \mathrm{~N} / \mathrm{A}$ & $\# N / A$ & $\# N / A$ & $\# \mathrm{~N} / \mathrm{A}$ & $\# \mathrm{~N} / \mathrm{A}$ \\
\hline SPP & RZ 1 & Regulation-Down & $\# N / A$ & $\# N / A$ & $\# \mathrm{~N} / \mathrm{A}$ & $\# N / A$ & $\# N / A$ & $\# \mathrm{~N} / \mathrm{A}$ & $\# \mathrm{~N} / \mathrm{A}$ \\
\hline SPP & $\mathrm{RZ} 2$ & Regulation-Down & $\# N / A$ & $\# N / A$ & $\# N / A$ & $\# N / A$ & $\# N / A$ & $\# \mathrm{~N} / \mathrm{A}$ & $\# N / A$ \\
\hline SPP & RZ 3 & Regulation-Down & $\# N / A$ & $\# N / A$ & $\# \mathrm{~N} / \mathrm{A}$ & $\# N / A$ & $\# \mathrm{~N} / \mathrm{A}$ & $\# N / A$ & $\# N / A$ \\
\hline SPP & RZ 4 & Regulation-Down & $\# N / A$ & $\# N / A$ & $\# \mathrm{~N} / \mathrm{A}$ & $\# N / A$ & $\# N / A$ & $\# \mathrm{~N} / \mathrm{A}$ & $\# \mathrm{~N} / \mathrm{A}$ \\
\hline \multicolumn{10}{|l|}{ Spinning } \\
\hline CAISO & Expanded & Spinning & $\# N / A$ & $\# N / A$ & $\# \mathrm{~N} / \mathrm{A}$ & $\# N / A$ & $\# \mathrm{~N} / \mathrm{A}$ & $\# N / A$ & $\# N / A$ \\
\hline ERCOT & ERCOT & Spinning & 12.61 & 0.86 & 100.00 & 9.91 & 9.90 & $0.0 \%$ & $\# \mathrm{~N} / \mathrm{A}$ \\
\hline MISO & MISO & Spinning & $\# N / A$ & $\# N / A$ & $\# N / A$ & $\# N / A$ & $\# N / A$ & $\# \mathrm{~N} / \mathrm{A}$ & $\# \mathrm{~N} / \mathrm{A}$ \\
\hline ISONE & CT & Spinning & 0.58 & - & 306.35 & 6.88 & - & $98.2 \%$ & 16.66 \\
\hline ISONE & NEMABSTN & Spinning & 0.47 & - & 343.19 & 6.88 & - & $98.7 \%$ & 187.63 \\
\hline ISONE & SWCT & Spinning & 0.75 & - & 343.19 & 7.68 & - & $97.7 \%$ & 58.03 \\
\hline ISONE & ROS & Spinning & 0.41 & - & 306.35 & 6.38 & - & $98.8 \%$ & 996.60 \\
\hline NYISO & East & Spinning & $\# N / A$ & $\# N / A$ & $\# \mathrm{~N} / \mathrm{A}$ & $\# N / A$ & $\# N / A$ & $\# N / A$ & $\# \mathrm{~N} / \mathrm{A}$ \\
\hline NYISO & West & Spinning & 5.38 & - & 52.95 & 5.01 & 7.00 & $0.0 \%$ & $\# N / A$ \\
\hline PJM & PJM & Synchronized & $\# N / A$ & $\# N / A$ & $\# N / A$ & $\# N / A$ & $\# \mathrm{~N} / \mathrm{A}$ & $\# \mathrm{~N} / \mathrm{A}$ & $\# N / A$ \\
\hline SPP & RZ 1 & Spinning & $\# N / A$ & $\# N / A$ & $\# N / A$ & $\# N / A$ & $\# N / A$ & $\# \mathrm{~N} / \mathrm{A}$ & $\# N / A$ \\
\hline SPP & $\mathrm{RZ} 2$ & Spinning & $\# N / A$ & $\# N / A$ & $\# \mathrm{~N} / \mathrm{A}$ & $\# N / A$ & $\# N / A$ & $\# \mathrm{~N} / \mathrm{A}$ & $\# N / A$ \\
\hline SPP & RZ3 & Spinning & $\# N / A$ & $\# N / A$ & $\# \mathrm{~N} / \mathrm{A}$ & $\# N / A$ & $\# N / A$ & $\# \mathrm{~N} / \mathrm{A}$ & $\# \mathrm{~N} / \mathrm{A}$ \\
\hline SPP & RZ 4 & Spinning & $\# N / A$ & $\# N / A$ & $\# N / A$ & $\# N / A$ & $\# \mathrm{~N} / \mathrm{A}$ & $\# N / A$ & $\# N / A$ \\
\hline \multicolumn{10}{|l|}{ Non-spinning } \\
\hline CAISO & Expanded & Non-Spinning & $\# N / A$ & $\# N / A$ & $\# \mathrm{~N} / \mathrm{A}$ & $\# N / A$ & $\# N / A$ & $\# \mathrm{~N} / \mathrm{A}$ & $\# N / A$ \\
\hline ERCOT & ERCOT & Non-Spinning & 3.01 & - & 180.00 & 6.59 & - & $50.7 \%$ & $\# \mathrm{~N} / \mathrm{A}$ \\
\hline MISO & MISO & Supplemental & $\# N / A$ & $\# N / A$ & $\# \mathrm{~N} / \mathrm{A}$ & $\# N / A$ & $\# N / A$ & $\# N / A$ & $\# N / A$ \\
\hline ISONE & CT & Non-Spinning & 0.51 & - & 306.35 & 6.61 & - & $98.7 \%$ & 170.50 \\
\hline ISONE & NEMABSTN & Non-Spinning & 0.39 & - & 306.35 & 6.59 & - & $99.2 \%$ & 123.28 \\
\hline ISONE & SWCT & Non-Spinning & 0.68 & - & 306.35 & 7.42 & - & $98.2 \%$ & 66.93 \\
\hline ISONE & ROS & Non-Spinning & 0.34 & - & 306.35 & 6.09 & - & $99.3 \%$ & 933.90 \\
\hline ISONE & $\mathrm{CT}$ & Operating & 0.26 & - & 150.00 & 3.98 & - & $99.2 \%$ & 126.14 \\
\hline ISONE & NEMABSTN & Operating & 0.15 & - & 150.00 & 3.72 & - & $99.8 \%$ & 258.74 \\
\hline ISONE & SWCT & Operating & 0.43 & - & 150.00 & 5.03 & - & $98.8 \%$ & 445.42 \\
\hline ISONE & ROS & Operating & 0.09 & - & 150.00 & 3.03 & - & $99.9 \%$ & 679.63 \\
\hline NYISO & East & Non-Spinning & 2.66 & - & 12.45 & 2.23 & 3.04 & $0.0 \%$ & $\# \mathrm{~N} / \mathrm{A}$ \\
\hline NYISO & West & Non-Spinning & 1.65 & - & 12.45 & 1.61 & 0.50 & $0.1 \%$ & $\# \mathrm{~N} / \mathrm{A}$ \\
\hline NYISO & East & Reserve_30 & 0.87 & - & 8.91 & 1.08 & 0.50 & $2.8 \%$ & $\# N / A$ \\
\hline NYISO & West & Reserve_30 & 0.87 & - & 8.91 & 1.08 & 0.50 & $2.8 \%$ & $\# \mathrm{~N} / \mathrm{A}$ \\
\hline PJM & PJM & Primary & $\# N / A$ & $\# N / A$ & $\# N / A$ & $\# N / A$ & $\# N / A$ & $\# N / A$ & $\# N / A$ \\
\hline SPP & RZ 1 & Supplemental & $\# N / A$ & $\# N / A$ & $\# N / A$ & $\# N / A$ & $\# N / A$ & $\# N / A$ & $\# \mathrm{~N} / \mathrm{A}$ \\
\hline SPP & RZ 2 & Supplemental & $\# N / A$ & $\# N / A$ & $\# \mathrm{~N} / \mathrm{A}$ & $\# N / A$ & $\# \mathrm{~N} / \mathrm{A}$ & $\# \mathrm{~N} / \mathrm{A}$ & $\# \mathrm{~N} / \mathrm{A}$ \\
\hline SPP & RZ 3 & Supplemental & $\# N / A$ & $\# N / A$ & $\# N / A$ & $\# N / A$ & $\# N / A$ & $\# \mathrm{~N} / \mathrm{A}$ & $\# \mathrm{~N} / \mathrm{A}$ \\
\hline SPP & RZ 4 & Supplemental & $\# N / A$ & $\# N / A$ & $\# N / A$ & $\# N / A$ & $\# N / A$ & $\# N / A$ & $\# N / A$ \\
\hline
\end{tabular}




\begin{tabular}{|c|c|c|c|c|c|c|c|c|c|}
\hline \multicolumn{10}{|c|}{2006 Summary Data } \\
\hline \multicolumn{2}{|l|}{ ISO/RTO } & Product & $\begin{array}{l}\text { Mean Price } \\
\text { (\$/MW-h) }\end{array}$ & $\begin{array}{l}\text { Min Price } \\
(\$ / M W-h)\end{array}$ & $\begin{array}{l}\text { Max Price } \\
\text { (\$/MW-h) }\end{array}$ & $\begin{array}{c}\text { St. Dev } \\
\text { (\$\$/MW-h) }\end{array}$ & $\begin{array}{l}\text { Median } \\
\text { Price } \\
\text { (\$/MW-h) }\end{array}$ & $\begin{array}{c}\text { \% Hours } \\
\text { With \$0 } \\
\text { Price }\end{array}$ & $\begin{array}{c}\text { Average } \\
\text { Market } \\
\text { Volume (MW) }\end{array}$ \\
\hline \multicolumn{10}{|l|}{ Regulation } \\
\hline CAISO & Expanded & Regulation-Up & $\# N / A$ & $\# N / A$ & $\# \mathrm{~N} / \mathrm{A}$ & $\# N / A$ & $\# \mathrm{~N} / \mathrm{A}$ & $\# \mathrm{~N} / \mathrm{A}$ & $\# N / A$ \\
\hline CAISO & Expanded & Regulation-Down & $\# N / A$ & $\# \mathrm{~N} / \mathrm{A}$ & $\# \mathrm{~N} / \mathrm{A}$ & $\# N / A$ & $\# \mathrm{~N} / \mathrm{A}$ & $\# \mathrm{~N} / \mathrm{A}$ & $\# \mathrm{~N} / \mathrm{A}$ \\
\hline ERCOT & ERCOT & Regulation-Up & 15.24 & 1.00 & 219.41 & 14.71 & 11.55 & $0.0 \%$ & $\# N / A$ \\
\hline ERCOT & ERCOT & Regulation-Down & 7.95 & 0.01 & 331.16 & 8.79 & 6.19 & $0.0 \%$ & \#N/A \\
\hline MISO & MISO & Regulation & $\# N / A$ & $\# N / A$ & $\# \mathrm{~N} / \mathrm{A}$ & $\# N / A$ & $\# \mathrm{~N} / \mathrm{A}$ & $\# \mathrm{~N} / \mathrm{A}$ & $\# \mathrm{~N} / \mathrm{A}$ \\
\hline NYSIO & NYISO & Regulation & 51.18 & 28.00 & 300.00 & 20.16 & 43.00 & $0.0 \%$ & $\# N / A$ \\
\hline PJM & PJM & Regulation & $\# N / A$ & $\# N / A$ & $\# \mathrm{~N} / \mathrm{A}$ & $\# N / A$ & $\# \mathrm{~N} / \mathrm{A}$ & $\# \mathrm{~N} / \mathrm{A}$ & $\# N / A$ \\
\hline SPP & RZ 1 & Regulation-Up & $\# N / A$ & $\# N / A$ & $\# \mathrm{~N} / \mathrm{A}$ & $\# N / A$ & $\# \mathrm{~N} / \mathrm{A}$ & $\# \mathrm{~N} / \mathrm{A}$ & \#N/A \\
\hline SPP & $\mathrm{RZ} 2$ & Regulation-Up & $\# N / A$ & $\# N / A$ & $\# N / A$ & $\# N / A$ & $\# \mathrm{~N} / \mathrm{A}$ & $\# N / A$ & $\# N / A$ \\
\hline SPP & RZ 3 & Regulation-Up & $\# N / A$ & $\# N / A$ & $\# \mathrm{~N} / \mathrm{A}$ & $\# N / A$ & $\# \mathrm{~N} / \mathrm{A}$ & $\# \mathrm{~N} / \mathrm{A}$ & $\# N / A$ \\
\hline SPP & RZ 4 & Regulation-Up & $\# N / A$ & $\# N / A$ & $\# \mathrm{~N} / \mathrm{A}$ & $\# N / A$ & $\# N / A$ & $\# \mathrm{~N} / \mathrm{A}$ & $\# \mathrm{~N} / \mathrm{A}$ \\
\hline SPP & RZ 1 & Regulation-Down & $\# N / A$ & $\# N / A$ & $\# \mathrm{~N} / \mathrm{A}$ & $\# N / A$ & $\# N / A$ & $\# \mathrm{~N} / \mathrm{A}$ & $\# \mathrm{~N} / \mathrm{A}$ \\
\hline SPP & $\mathrm{RZ} 2$ & Regulation-Down & $\# N / A$ & $\# N / A$ & $\# N / A$ & $\# N / A$ & $\# N / A$ & $\# \mathrm{~N} / \mathrm{A}$ & $\# N / A$ \\
\hline SPP & RZ 3 & Regulation-Down & $\# N / A$ & $\# N / A$ & $\# \mathrm{~N} / \mathrm{A}$ & $\# N / A$ & $\# \mathrm{~N} / \mathrm{A}$ & $\# N / A$ & $\# N / A$ \\
\hline SPP & RZ 4 & Regulation-Down & $\# N / A$ & $\# N / A$ & $\# \mathrm{~N} / \mathrm{A}$ & $\# N / A$ & $\# N / A$ & $\# \mathrm{~N} / \mathrm{A}$ & $\# N / A$ \\
\hline \multicolumn{10}{|l|}{ Spinning } \\
\hline CAISO & Expanded & Spinning & $\# N / A$ & $\# N / A$ & $\# \mathrm{~N} / \mathrm{A}$ & $\# N / A$ & $\# \mathrm{~N} / \mathrm{A}$ & $\# N / A$ & $\# N / A$ \\
\hline ERCOT & ERCOT & Spinning & 12.93 & 1.02 & 168.78 & 13.33 & 9.00 & $0.0 \%$ & $\# \mathrm{~N} / \mathrm{A}$ \\
\hline MISO & MISO & Spinning & $\# N / A$ & $\# N / A$ & $\# N / A$ & $\# N / A$ & $\# N / A$ & $\# \mathrm{~N} / \mathrm{A}$ & $\# \mathrm{~N} / \mathrm{A}$ \\
\hline ISONE & CT & Spinning & $\# N / A$ & $\# N / A$ & $\# \mathrm{~N} / \mathrm{A}$ & $\# N / A$ & $\# N / A$ & $\# \mathrm{~N} / \mathrm{A}$ & $\# N / A$ \\
\hline ISONE & NEMABSTN & Spinning & $\# N / A$ & $\# N / A$ & $\# \mathrm{~N} / \mathrm{A}$ & $\# N / A$ & $\# \mathrm{~N} / \mathrm{A}$ & $\# \mathrm{~N} / \mathrm{A}$ & $\# N / A$ \\
\hline ISONE & SWCT & Spinning & $\# N / A$ & $\# N / A$ & $\# N / A$ & $\# N / A$ & $\# N / A$ & $\# \mathrm{~N} / \mathrm{A}$ & $\# \mathrm{~N} / \mathrm{A}$ \\
\hline ISONE & ROS & Spinning & $\# N / A$ & $\# N / A$ & $\# N / A$ & $\# N / A$ & $\# \mathrm{~N} / \mathrm{A}$ & $\# N / A$ & $\# N / A$ \\
\hline NYISO & East & Spinning & $\# N / A$ & $\# N / A$ & $\# \mathrm{~N} / \mathrm{A}$ & $\# N / A$ & $\# N / A$ & $\# N / A$ & $\# N / A$ \\
\hline NYISO & West & Spinning & 6.26 & - & 53.93 & 6.41 & 7.00 & $0.1 \%$ & $\# N / A$ \\
\hline PJM & PJM & Synchronized & $\# N / A$ & $\# N / A$ & $\# N / A$ & $\# N / A$ & $\# \mathrm{~N} / \mathrm{A}$ & $\# \mathrm{~N} / \mathrm{A}$ & $\# \mathrm{~N} / \mathrm{A}$ \\
\hline SPP & RZ 1 & Spinning & $\# N / A$ & $\# N / A$ & $\# N / A$ & $\# N / A$ & $\# N / A$ & $\# \mathrm{~N} / \mathrm{A}$ & $\# N / A$ \\
\hline SPP & $\mathrm{RZ} 2$ & Spinning & $\# N / A$ & $\# N / A$ & $\# \mathrm{~N} / \mathrm{A}$ & $\# N / A$ & $\# N / A$ & $\# \mathrm{~N} / \mathrm{A}$ & $\# N / A$ \\
\hline SPP & RZ3 & Spinning & $\# N / A$ & $\# N / A$ & $\# \mathrm{~N} / \mathrm{A}$ & $\# N / A$ & $\# N / A$ & $\# \mathrm{~N} / \mathrm{A}$ & $\# \mathrm{~N} / \mathrm{A}$ \\
\hline SPP & RZ 4 & Spinning & $\# N / A$ & $\# N / A$ & $\# N / A$ & $\# N / A$ & $\# N / A$ & $\# \mathrm{~N} / \mathrm{A}$ & $\# N / A$ \\
\hline \multicolumn{10}{|l|}{ Non-spinning } \\
\hline CAISO & Expanded & Non-Spinning & $\# N / A$ & $\# N / A$ & $\# \mathrm{~N} / \mathrm{A}$ & $\# N / A$ & $\# N / A$ & $\# \mathrm{~N} / \mathrm{A}$ & $\# \mathrm{~N} / \mathrm{A}$ \\
\hline ERCOT & ERCOT & Non-Spinning & 8.98 & - & 314.55 & 20.42 & - & $59.5 \%$ & $\# \mathrm{~N} / \mathrm{A}$ \\
\hline MISO & MISO & Supplemental & $\# N / A$ & $\# N / A$ & $\# N / A$ & $\# N / A$ & $\# N / A$ & $\# N / A$ & $\# N / A$ \\
\hline ISONE & CT & Non-Spinning & $\# N / A$ & $\# N / A$ & $\# \mathrm{~N} / \mathrm{A}$ & $\# N / A$ & $\# \mathrm{~N} / \mathrm{A}$ & $\# \mathrm{~N} / \mathrm{A}$ & $\# \mathrm{~N} / \mathrm{A}$ \\
\hline ISONE & NEMABSTN & Non-Spinning & $\# N / A$ & $\# N / A$ & $\# N / A$ & $\# N / A$ & $\# N / A$ & $\# \mathrm{~N} / \mathrm{A}$ & $\# \mathrm{~N} / \mathrm{A}$ \\
\hline ISONE & SWCT & Non-Spinning & $\# N / A$ & $\# N / A$ & $\# N / A$ & $\# N / A$ & $\# N / A$ & $\# N / A$ & $\# N / A$ \\
\hline ISONE & ROS & Non-Spinning & $\# N / A$ & $\# N / A$ & $\# N / A$ & $\# N / A$ & $\# \mathrm{~N} / \mathrm{A}$ & $\# \mathrm{~N} / \mathrm{A}$ & $\# N / A$ \\
\hline ISONE & $\mathrm{CT}$ & Operating & $\# N / A$ & $\# N / A$ & $\# N / A$ & $\# N / A$ & $\# N / A$ & $\# \mathrm{~N} / \mathrm{A}$ & $\# \mathrm{~N} / \mathrm{A}$ \\
\hline ISONE & NEMABSTN & Operating & $\# N / A$ & $\# N / A$ & $\# N / A$ & $\# N / A$ & $\# N / A$ & $\# N / A$ & $\# N / A$ \\
\hline ISONE & SWCT & Operating & $\# N / A$ & $\# N / A$ & $\# N / A$ & $\# N / A$ & $\# N / A$ & $\# \mathrm{~N} / \mathrm{A}$ & $\# \mathrm{~N} / \mathrm{A}$ \\
\hline ISONE & ROS & Operating & $\# N / A$ & $\# N / A$ & $\# N / A$ & $\# N / A$ & $\# \mathrm{~N} / \mathrm{A}$ & $\# N / A$ & $\# N / A$ \\
\hline NYISO & East & Non-Spinning & 2.69 & - & 171.27 & 4.75 & 2.49 & $0.1 \%$ & $\# \mathrm{~N} / \mathrm{A}$ \\
\hline NYISO & West & Non-Spinning & 1.44 & - & 43.24 & 2.07 & 0.50 & $0.1 \%$ & $\# \mathrm{~N} / \mathrm{A}$ \\
\hline NYISO & East & Reserve_30 & 0.81 & - & 36.74 & 1.34 & 0.50 & $4.4 \%$ & $\# \mathrm{~N} / \mathrm{A}$ \\
\hline NYISO & West & Reserve_30 & 0.81 & - & 36.74 & 1.34 & 0.50 & $4.4 \%$ & $\# \mathrm{~N} / \mathrm{A}$ \\
\hline PJM & PJM & Primary & $\# N / A$ & $\# N / A$ & $\# N / A$ & $\# N / A$ & $\# N / A$ & $\# N / A$ & $\# N / A$ \\
\hline SPP & RZ 1 & Supplemental & $\# N / A$ & $\# N / A$ & $\# N / A$ & $\# N / A$ & $\# N / A$ & $\# N / A$ & $\# \mathrm{~N} / \mathrm{A}$ \\
\hline SPP & RZ 2 & Supplemental & $\# N / A$ & $\# N / A$ & $\# N / A$ & $\# N / A$ & $\# \mathrm{~N} / \mathrm{A}$ & $\# \mathrm{~N} / \mathrm{A}$ & $\# \mathrm{~N} / \mathrm{A}$ \\
\hline SPP & RZ 3 & Supplemental & $\# N / A$ & $\# N / A$ & $\# N / A$ & $\# N / A$ & $\# N / A$ & $\# \mathrm{~N} / \mathrm{A}$ & $\# \mathrm{~N} / \mathrm{A}$ \\
\hline SPP & RZ 4 & Supplemental & $\# N / A$ & $\# N / A$ & $\# N / A$ & $\# N / A$ & $\# N / A$ & $\# N / A$ & $\# N / A$ \\
\hline
\end{tabular}




\begin{tabular}{|c|c|c|c|c|c|c|c|c|c|}
\hline \multicolumn{10}{|c|}{2005 Summary Data } \\
\hline \multicolumn{2}{|l|}{ ISO/RTO } & Product & $\begin{array}{l}\text { Mean Price } \\
\text { (\$/MW-h) }\end{array}$ & $\begin{array}{l}\text { Min Price } \\
\text { (\$/MW-h) }\end{array}$ & $\begin{array}{l}\text { Max Price } \\
\text { (\$/MW-h) }\end{array}$ & $\begin{array}{c}\text { St. Dev } \\
\text { (\$/MW-h) }\end{array}$ & $\begin{array}{c}\text { Median } \\
\text { Price } \\
\text { (\$/MW-h) } \\
\end{array}$ & $\begin{array}{c}\% \text { Hours } \\
\text { With \$0 } \\
\text { Price } \\
\end{array}$ & $\begin{array}{c}\text { Average } \\
\text { Market } \\
\text { Volume (MW) } \\
\end{array}$ \\
\hline \multicolumn{10}{|l|}{ Regulation } \\
\hline CAISO & Expanded & Regulation-Up & $\# N / A$ & $\# N / A$ & $\# \mathrm{~N} / \mathrm{A}$ & $\# N / A$ & $\# \mathrm{~N} / \mathrm{A}$ & $\# \mathrm{~N} / \mathrm{A}$ & $\# N / A$ \\
\hline CAISO & Expanded & Regulation-Down & $\# N / A$ & $\# N / A$ & $\# \mathrm{~N} / \mathrm{A}$ & $\# N / A$ & $\# N / A$ & $\# \mathrm{~N} / \mathrm{A}$ & \#N/A \\
\hline ERCOT & ERCOT & Regulation-Up & 18.53 & 1.67 & 322.45 & 17.37 & 14.43 & $0.0 \%$ & $\# \mathrm{~N} / \mathrm{A}$ \\
\hline ERCOT & ERCOT & Regulation-Down & 19.54 & 1.98 & 700.00 & 27.50 & 13.50 & $0.0 \%$ & \#N/A \\
\hline MISO & MISO & Regulation & $\# N / A$ & $\# N / A$ & $\# \mathrm{~N} / \mathrm{A}$ & $\# N / A$ & $\# \mathrm{~N} / \mathrm{A}$ & $\# \mathrm{~N} / \mathrm{A}$ & $\# \mathrm{~N} / \mathrm{A}$ \\
\hline NYSIO & NYISO & Regulation & 39.17 & 14.00 & 250.00 & 28.66 & 28.00 & $0.0 \%$ & $\# N / A$ \\
\hline PJM & PJM & Regulation & $\# N / A$ & $\# N / A$ & $\# \mathrm{~N} / \mathrm{A}$ & $\# N / A$ & $\# \mathrm{~N} / \mathrm{A}$ & $\# \mathrm{~N} / \mathrm{A}$ & $\# N / A$ \\
\hline SPP & RZ 1 & Regulation-Up & $\# N / A$ & $\# N / A$ & $\# \mathrm{~N} / \mathrm{A}$ & $\# N / A$ & $\# \mathrm{~N} / \mathrm{A}$ & $\# \mathrm{~N} / \mathrm{A}$ & \#N/A \\
\hline SPP & $\mathrm{RZ} 2$ & Regulation-Up & $\# N / A$ & $\# N / A$ & $\# N / A$ & $\# N / A$ & $\# \mathrm{~N} / \mathrm{A}$ & $\# N / A$ & $\# N / A$ \\
\hline SPP & RZ 3 & Regulation-Up & $\# N / A$ & $\# N / A$ & $\# \mathrm{~N} / \mathrm{A}$ & $\# N / A$ & $\# \mathrm{~N} / \mathrm{A}$ & $\# \mathrm{~N} / \mathrm{A}$ & $\# N / A$ \\
\hline SPP & RZ 4 & Regulation-Up & $\# N / A$ & $\# N / A$ & $\# \mathrm{~N} / \mathrm{A}$ & $\# N / A$ & $\# N / A$ & $\# \mathrm{~N} / \mathrm{A}$ & $\# \mathrm{~N} / \mathrm{A}$ \\
\hline SPP & RZ 1 & Regulation-Down & $\# N / A$ & $\# N / A$ & $\# \mathrm{~N} / \mathrm{A}$ & $\# N / A$ & $\# N / A$ & $\# \mathrm{~N} / \mathrm{A}$ & $\# \mathrm{~N} / \mathrm{A}$ \\
\hline SPP & $\mathrm{RZ} 2$ & Regulation-Down & $\# N / A$ & $\# N / A$ & $\# N / A$ & $\# N / A$ & $\# N / A$ & $\# \mathrm{~N} / \mathrm{A}$ & $\# N / A$ \\
\hline SPP & RZ 3 & Regulation-Down & $\# N / A$ & $\# N / A$ & $\# \mathrm{~N} / \mathrm{A}$ & $\# N / A$ & $\# \mathrm{~N} / \mathrm{A}$ & $\# N / A$ & $\# N / A$ \\
\hline SPP & RZ 4 & Regulation-Down & $\# N / A$ & $\# N / A$ & $\# \mathrm{~N} / \mathrm{A}$ & $\# N / A$ & $\# N / A$ & $\# \mathrm{~N} / \mathrm{A}$ & $\# N / A$ \\
\hline \multicolumn{10}{|l|}{ Spinning } \\
\hline CAISO & Expanded & Spinning & $\# N / A$ & $\# \mathrm{~N} / \mathrm{A}$ & $\# \mathrm{~N} / \mathrm{A}$ & $\# N / A$ & $\# N / A$ & $\# N / A$ & $\# N / A$ \\
\hline ERCOT & ERCOT & Spinning & 16.61 & 0.01 & 731.32 & 22.13 & 11.91 & $0.0 \%$ & $\# \mathrm{~N} / \mathrm{A}$ \\
\hline MISO & MISO & Spinning & $\# N / A$ & $\# N / A$ & $\# \mathrm{~N} / \mathrm{A}$ & $\# N / A$ & $\# N / A$ & $\# \mathrm{~N} / \mathrm{A}$ & $\# \mathrm{~N} / \mathrm{A}$ \\
\hline ISONE & CT & Spinning & $\# N / A$ & $\# N / A$ & $\# \mathrm{~N} / \mathrm{A}$ & $\# N / A$ & $\# N / A$ & $\# \mathrm{~N} / \mathrm{A}$ & $\# N / A$ \\
\hline ISONE & NEMABSTN & Spinning & $\# N / A$ & $\# N / A$ & $\# \mathrm{~N} / \mathrm{A}$ & $\# N / A$ & $\# \mathrm{~N} / \mathrm{A}$ & $\# \mathrm{~N} / \mathrm{A}$ & $\# N / A$ \\
\hline ISONE & SWCT & Spinning & $\# N / A$ & $\# N / A$ & $\# \mathrm{~N} / \mathrm{A}$ & $\# N / A$ & $\# N / A$ & $\# \mathrm{~N} / \mathrm{A}$ & $\# \mathrm{~N} / \mathrm{A}$ \\
\hline ISONE & ROS & Spinning & $\# N / A$ & $\# N / A$ & $\# N / A$ & $\# N / A$ & $\# \mathrm{~N} / \mathrm{A}$ & $\# N / A$ & $\# N / A$ \\
\hline NYISO & East & Spinning & $\# N / A$ & $\# N / A$ & $\# \mathrm{~N} / \mathrm{A}$ & $\# N / A$ & $\# \mathrm{~N} / \mathrm{A}$ & $\# N / A$ & $\# N / A$ \\
\hline NYISO & West & Spinning & 4.92 & 0.05 & 50.00 & 5.40 & 7.00 & $0.0 \%$ & $\# N / A$ \\
\hline PJM & PJM & Synchronized & $\# N / A$ & $\# N / A$ & $\# N / A$ & $\# N / A$ & $\# \mathrm{~N} / \mathrm{A}$ & $\# \mathrm{~N} / \mathrm{A}$ & $\# \mathrm{~N} / \mathrm{A}$ \\
\hline SPP & RZ 1 & Spinning & $\# N / A$ & $\# N / A$ & $\# N / A$ & $\# N / A$ & $\# N / A$ & $\# \mathrm{~N} / \mathrm{A}$ & $\# N / A$ \\
\hline SPP & $\mathrm{RZ} 2$ & Spinning & $\# N / A$ & $\# N / A$ & $\# \mathrm{~N} / \mathrm{A}$ & $\# N / A$ & $\# N / A$ & $\# \mathrm{~N} / \mathrm{A}$ & $\# N / A$ \\
\hline SPP & RZ3 & Spinning & $\# N / A$ & $\# N / A$ & $\# \mathrm{~N} / \mathrm{A}$ & $\# N / A$ & $\# N / A$ & $\# \mathrm{~N} / \mathrm{A}$ & $\# \mathrm{~N} / \mathrm{A}$ \\
\hline SPP & RZ 4 & Spinning & $\# N / A$ & $\# N / A$ & $\# N / A$ & $\# N / A$ & $\# N / A$ & $\# \mathrm{~N} / \mathrm{A}$ & $\# N / A$ \\
\hline \multicolumn{10}{|l|}{ Non-spinning } \\
\hline CAISO & Expanded & Non-Spinning & $\# N / A$ & $\# N / A$ & $\# \mathrm{~N} / \mathrm{A}$ & $\# N / A$ & $\# N / A$ & $\# \mathrm{~N} / \mathrm{A}$ & $\# \mathrm{~N} / \mathrm{A}$ \\
\hline ERCOT & ERCOT & Non-Spinning & 5.97 & - & 510.00 & 17.19 & - & $76.7 \%$ & $\# \mathrm{~N} / \mathrm{A}$ \\
\hline MISO & MISO & Supplemental & $\# N / A$ & $\# N / A$ & $\# N / A$ & $\# N / A$ & $\# N / A$ & $\# N / A$ & $\# N / A$ \\
\hline ISONE & CT & Non-Spinning & $\# N / A$ & $\# N / A$ & $\# \mathrm{~N} / \mathrm{A}$ & $\# N / A$ & $\# \mathrm{~N} / \mathrm{A}$ & $\# \mathrm{~N} / \mathrm{A}$ & $\# \mathrm{~N} / \mathrm{A}$ \\
\hline ISONE & NEMABSTN & Non-Spinning & $\# N / A$ & $\# N / A$ & $\# N / A$ & $\# N / A$ & $\# N / A$ & $\# \mathrm{~N} / \mathrm{A}$ & $\# \mathrm{~N} / \mathrm{A}$ \\
\hline ISONE & SWCT & Non-Spinning & $\# N / A$ & $\# N / A$ & $\# N / A$ & $\# N / A$ & $\# N / A$ & $\# N / A$ & $\# N / A$ \\
\hline ISONE & ROS & Non-Spinning & $\# N / A$ & $\# N / A$ & $\# N / A$ & $\# N / A$ & $\# \mathrm{~N} / \mathrm{A}$ & $\# \mathrm{~N} / \mathrm{A}$ & $\# N / A$ \\
\hline ISONE & $\mathrm{CT}$ & Operating & $\# N / A$ & $\# N / A$ & $\# N / A$ & $\# N / A$ & $\# N / A$ & $\# \mathrm{~N} / \mathrm{A}$ & $\# \mathrm{~N} / \mathrm{A}$ \\
\hline ISONE & NEMABSTN & Operating & $\# N / A$ & $\# N / A$ & $\# N / A$ & $\# N / A$ & $\# N / A$ & $\# \mathrm{~N} / \mathrm{A}$ & $\# \mathrm{~N} / \mathrm{A}$ \\
\hline ISONE & SWCT & Operating & $\# N / A$ & $\# N / A$ & $\# N / A$ & $\# N / A$ & $\# N / A$ & $\# \mathrm{~N} / \mathrm{A}$ & $\# N / A$ \\
\hline ISONE & ROS & Operating & $\# N / A$ & $\# N / A$ & $\# N / A$ & $\# N / A$ & $\# \mathrm{~N} / \mathrm{A}$ & $\# N / A$ & $\# N / A$ \\
\hline NYISO & East & Non-Spinning & 1.51 & 0.10 & 64.11 & 2.50 & 0.34 & $0.0 \%$ & $\# \mathrm{~N} / \mathrm{A}$ \\
\hline NYISO & West & Non-Spinning & 0.59 & - & 13.28 & 1.13 & 0.25 & $0.6 \%$ & $\# \mathrm{~N} / \mathrm{A}$ \\
\hline NYISO & East & Reserve_30 & 0.35 & - & 3.55 & 0.28 & 0.25 & $3.4 \%$ & $\# \mathrm{~N} / \mathrm{A}$ \\
\hline NYISO & West & Reserve_30 & 0.35 & - & 3.55 & 0.28 & 0.25 & $3.4 \%$ & $\# \mathrm{~N} / \mathrm{A}$ \\
\hline PJM & PJM & Primary & $\# N / A$ & $\# N / A$ & $\# N / A$ & $\# N / A$ & $\# N / A$ & $\# N / A$ & $\# N / A$ \\
\hline SPP & RZ 1 & Supplemental & $\# N / A$ & $\# N / A$ & $\# N / A$ & $\# N / A$ & $\# N / A$ & $\# N / A$ & $\# \mathrm{~N} / \mathrm{A}$ \\
\hline SPP & RZ 2 & Supplemental & $\# N / A$ & $\# N / A$ & $\# N / A$ & $\# N / A$ & $\# \mathrm{~N} / \mathrm{A}$ & $\# \mathrm{~N} / \mathrm{A}$ & $\# \mathrm{~N} / \mathrm{A}$ \\
\hline SPP & RZ 3 & Supplemental & $\# N / A$ & $\# N / A$ & $\# N / A$ & $\# N / A$ & $\# N / A$ & $\# \mathrm{~N} / \mathrm{A}$ & $\# \mathrm{~N} / \mathrm{A}$ \\
\hline SPP & RZ 4 & Supplemental & $\# N / A$ & $\# N / A$ & $\# N / A$ & $\# N / A$ & $\# N / A$ & $\# N / A$ & $\# N / A$ \\
\hline
\end{tabular}


Argonne

Energy Systems Division

Argonne National Laboratory

9700 South Cass Avenue, Bldg. \#362

Argonne, IL 60439

unw.anl.gov 